\title{
Medidas de Ajuste de Modelos de Equações Estruturais
}

Tatiana Terabayashi Melhado

DISSERTAÇÃO .APRESENTADA

$\mathrm{AO}$

INSTITUTO DE MATEMÁTICA E ESTATÍSTICA

DA

UNIVERSIDADE DE SÃO PAULO

PARA

OBTENÇÃO DO GRAU

$\mathrm{DE}$

MESTRE EM ESTATÍSTICA

Área de Concentração: Estatística

Orientadora: Profa. Dra. Lúcia Pereira Barroso

São Paulo, março de 2004. 


\title{
Medidas de Ajuste de Modelos de Equações Estruturais
}

\author{
Este exemplar corresponde à redação final \\ da dissertação devidamente corrigida e \\ defendida por Tatiana Terabayashi Melhado \\ e aprovada pela comissão julgadora.
}

São Paulo, 05 de março de 2004.

Banca Examinadora:

- Prof. Dr. Rinaldo Artes (presidente) - IME/USP

- Prof. Dr. Dalton Francisco de Andrade - UFSC

- Prof. Dr. Wilton de Oliveira Bussab - FGV/SP 
À minha mãe, aos meus avós $e$ ao meu namorado. 


\section{Agradecimentos}

Agradeço a todos que contribuíram para a elaboração deste trabalho, em especial:

À professora Lúcia Pereira Barroso, pela orientação, confiança, apoio e amizade.

Ao professor Rinaldo Artes, pela atenção especial concedida principalmente na fase final do meu trabalho.

À minha mãe Marina, pela atenção e pelo estímulo para que eu vencesse mais esta etapa, mesmo estando distante.

Aos meus avós Sumako e Yoshio pela confiança e pelo incentivo.

Ao meu namorado Daniel, pela compreensão, companheirismo e pelo apoio nos momentos mais difíceis.

Aos meus queridos amigos Cléber, Émerson, Gisela, Lívia, Marcel, Marcelo e Paula e, aos meus primos Juliana e Márcio, pela amizade, carinho e incentivo.

Ao CNPQ, pela bolsa de mestrado concedida, com a qual pude me dedicar em tempo integral ao trabalho. 


\section{Resumo}

A modelagem de equações estruturais permite especificar como variáveis não observáveis (conhecidas como variáveis latentes) podem ser mensuradas através de variáveis observáveis utilizando equações de mensuração. Ela também permite analisar várias relações de dependência entre as variáveis que são intercorrelacionadas utilizando equações estruturais.

Esta modelagem é uma extensão das técnicas de Análise de Regressão Multivariada e Análise Fatorial e está sendo muito utilizada em diversas áreas, tais como: Educação, Marketing, Psicologia, Saúde, entre outras. Na estatística, pode ser utilizada na estimação de modelos multivariados como Regressão, Análise Fatorial Confirmatória, Análise de Caminho, entre outros.

Neste trabalho, apresentamos os principais tipos de modelos existentes nessa modelagem, os métodos de estimação para alguns casos típicos de modelos e as medidas de ajuste mais usuais para verificação da qualidade de ajuste dos modelos. Também apresentamos uma aplicação a um exemplo real sobre agricultores familiares modernos de Salto, através do qual tentamos explicitar melhor o uso das medidas de ajuste para esta modelagem. 


\section{Abstract}

The structural equation modelling allows specifying how unobserved variables (known as latent variables) can be measured by observed variables using measurement equations. It also allows analyzing several dependency relations among inter-correlated observed variables using structural equations.

This modelling is an extension of Multivariate Regression Analysis and Factorial Analysis techniques and it has being used in several areas, like: Education, Marketing, Psychology, Medicine, and others. In statistics, it can be used in the estimation of multivariate models like Regression, Confirmatory Factor Analysis, Path Analysis, and others.

In this text, we present the principal kinds of existing models for this modelling, the estimation methods for some of those models and the usual fit indices to verify their goodness-of-fit. By an application to a real example about Salto's modern farmers, we try to explain the usage of the fit indices for this modelling. 


\section{Sumário}

1 Introdução 9

2 Modelagem 13

2.1 Diagramas de Caminho . . . . . . . . . . . . . . . . . . . . 13

2.2 Modelos . . . . . . . . . . . . . . . . . . . . 38

2.2 .1 Modelo Completo . . . . . . . . . . . . . . . . . 38

2.2 .2 Análise Fatorial . . . . . . . . . . . . . . . . . 40

2.2.3 Modelo para análise de várias amostras independentes . . . . . . 44

2.2.4 Modelo completo com estrutura de médias . . . . . . . . . . . . . 45

2.3 Identificabilidade . . . . . . . . . . . . . . . . . . . 45

2.3 .1 Regrat ...................... 47

2.3.2 Regra Dois-Passos . . . . . . . . . . . . . . . . . . 47

3 Estimação $\quad 52$

3.1 Estimação do modelo completo . . . . . . . . . . . . . . . . . 54

3.1.1 Função de ajustamento para o método de máxima verossimilhança . 56

3.1.2 Função de ajustamento para o método de mínimos quadrados generalizados . . . . . . . . . . . . . . . . . . 57

3.1.3 Função de ajustamento para o método de mínimos quadrados nãoponderados ........................... 58

3.1 .4 Função de ajustamento global . . . . . . . . . . . . . . . . . 58 
4 Medidas de Ajuste $\quad 61$

4.1 Resíduos . . . . . . . . . . . . . . . . . . . 62

4.2 Teste Qui-quadrado . . . . . . . . . . . . . . . . . 63

4.3 Medidas de Ajuste Alternativas . . . . . . . . . . . . . . . . 65

4.3.1 Discrepância Mínima da Amostra (CMIN) . . . . . . . . . . . . 65

4.3 .2 Índice de Ajuste Normalizado (NFI) . . . . . . . . . . . . . . 66

4.3 .3 Índice de Ajuste Corrigido (IFI) . . . . . . . . . . . . . . . . 67

4.3 .4 Índice de Ajuste Relativo (RFI) . . . . . . . . . . . . . . . . 68

4.3 .5 Índice de Tucker-Lewis (TLI) . . . . . . . . . . . . . . . . 69

4.3.6 Índice de Qualidade do Ajuste (GFI) e Índice de Qualidade do Ajuste Corrigido (AGFI) . . . . . . . . . . . . . . . 71

4.3.7 Índice de Qualidade do Ajuste de Parsimônia (PGFI) . . . . . . . . 73

4.3.8 Índice de Ajuste Normalizado de Parsimônia (PNFI) . . . . . . . 73

4.3 .9 Índice de Ajuste Comparativo (CFI) . . . . . . . . . . . . . 74

4.3.10 Raiz do Erro Quadrático Médio de Aproximação (RMSEA) . . . . . 74

4.3.11 Qui-quadrado Relativo . . . . . . . . . . . . . . . 76

4.3 .12 Qui-quadrado Padronizado $\left(\chi_{P}^{2}\right) \ldots \ldots \ldots 77$

4.3.13 Critério da Informação de Akaike (AIC) . . . . . . . . . . . 77

4.3.14 Critério da Informação de Bayes (BIC) . . . . . . . . . . . 77

4.3.15 Critério de Browne-Cudeck (BCC) . . . . . . . . . . 78

4.3.16 Critério da Informação de Akaike Consistente (CAIC) . . . . . . . . 78

5 Aplicação $\quad 80$

6 Conclusão $\quad 91$

7 Trabalhos Futuros $\quad 93$

A Correlações $\quad 94$

A.1 Correlação "Polychoric" (para tabelas r x s) . . . . . . . . . . . . . . . 94 
A.2 Correlação "Tetrachoric" (para tabelas $2 \times 2$ ) . . . . . . . . . . . . . 97

A.3 Correlação "Polyserial" (para tabelas $\mathrm{r}$ x s) . . . . . . . . . . . . . . . . . 100

A.4 Correlação "Biserial" (para tabelas $2 \times 2$ ) . . . . . . . . . . . . . 103 


\section{Capítulo 1}

\section{Introdução}

A Modelagem de Equações Estruturais é uma evolução da modelagem de multiequações desenvolvida principalmente na área de Econometria e também dos princípios de mensuração da Psicologia e Sociologia. Essa técnica tem utilidade em diversas áreas do conhecimento e, além das já mencionadas, podemos incluir Educação, Demografia, Administração, Marketing, Biologia, Saúde e Genética.

Nestas áreas de ciências sociais e comportamentais, muitas teorias e modelos são formulados em termos de conceitos teóricos que não são diretamente observáveis ou mensuráveis, mas que podem ser avaliados de forma bastante razoável por indicadores. Com isto, geralmente surgem dois problemas básicos que a modelagem de equações estruturais procura responder:

- O que a medida observada (indicador) realmente está medindo?

- Como inferir relações causais complexas entre as variáveis que não são observáveis diretamente?

Para responder a estas perguntas, a Modelagem de Equações Estruturais é composta por duas partes:

- Modelo estrutural (análogo ao modelo de regressão);

- Modelo de mensuração (análogo ao modelo de análise fatorial). 
Essa técnica é mais geral que outras, como por exemplo, Análise de Regressão Múltipla, Análise Fatorial, Análise de Variância Multivariada e Análise Discriminante, pois permite o estudo simultâneo de várias relações de interdependência.

Um outro aspecto que diferencia esta modelagem das técnicas citadas anteriormente é que esta enfatiza as covariâncias ao invés das observações individuais. Ou seja, ao invés de minimizar funções de valores individuais observados e preditos, minimiza-se a diferença entre as covariâncias amostrais e as covariâncias preditas pelo modelo.

A modelagem de equações estruturais utiliza equações estruturais para analisar várias relações de dependência entre as variáveis que são intercorrelacionadas e, equações de mensuração, para especificar como variáveis não-observáveis são mensuradas por intermédio de variáveis observáveis.

A seguir, apresentamos alguns exemplos de aplicação da modelagem de equações estruturais:

Exemplo 1. O Estudo de Wheaton (Wheaton et al., 1977) que avalia a alienação social é um exemplo de aplicação dessa modelagem. Os dados desse estudo podem ser encontrados no pacote específico para modelagem de equações estruturais, AMOS (Arbuckle, 1997). O estudo contém três variáveis latentes, cada uma mensurada por dois indicadores. A Alienação, medida em 1967 e 1971, foi mensurada por dois escores, Anomia e Incapacidade. A terceira variável latente - Situação Sócio-Econômica (SES) - foi mensurada por Educação (anos de instrução a partir de 1967) e por SEI (Índice Sócio-Econômico de Duncan, a partir de 1967) (Garson, 2001).

Exemplo 2. O Estudo do Desempenho da Função Administrativa de Funcionários (Warren et al., 1974) que avalia o desempenho de administradores de fazendas também é um exemplo de aplicação dessa modelagem. Nele temos quatro variáveis não-observáveis (Desempenho, Conhecimento, Valor e Satisfação), onde cada uma foi mensurada por dois testes. 
Exemplo 3. O Estudo sobre Nacionalismo e Identificação na Espanha (Bollen e Medrano, 1998) também é um exemplo de aplicação da modelagem. Nele temos duas variáveis latentes: Sentimento de pertencer à Espanha e Sentimento de moral associado a esta identidade. A primeira variável foi mensurada por 3 indicadores $\left(P_{1}, P_{2}\right.$ e $\left.P_{3}\right)$ : "Espanha é minha nação", "Eu me sinto espanhol" e "Espanha é o país ao qual eu pertenço". $\mathrm{E}$, a segunda variável também foi mensurada por três indicadores $\left(M_{1}, M_{2}\right.$ e $\left.M_{3}\right)$ : "Espanha é fenomenal", "Eu amo a Espanha" e "Espanha é um ótimo país".

Exemplo 4. O Estudo da Relação entre a Democracia Política e a Industrialização no desenvolvimento de países (Bollen, 1989b) também é um exemplo de aplicação da modelagem. Nele temos três variáveis não-observáveis: Democracia Política em 1960 e em 1965 e, Industrialização em 1960. A Democracia Política em 1960 e em 1965 são mensuradas por quatro indicadores observados em 1960 e em 1965: Índice de Liberdade de Imprensa ( $y_{1}$ em 1960 e $y_{5}$ em 1965), Liberdade de Oposição Política ( $y_{2}$ e $\left.y_{6}\right)$, Clareza no Processo Eleitoral ( $y_{3}$ e $y_{7}$ ) e Atuação do Colegiado Recém-eleito $\left(y_{4}\right.$ e $\left.y_{8}\right)$. E, a Industrialização é mensurada por três indicadores: Produtó Interno Bruto (PIB) per capita $\left(x_{1}\right)$, Consumo de Energia per capita $\left(x_{2}\right)$ e Porcentagem da Força de Trabalho na Indústria $\left(x_{3}\right)$.

Exemplo 5. O estudo realizado com agricultores familiares de Salto ao norte de Uruguai (Barroso e Gabriel, 1996), cujo interesse era avaliar a "estrutura financeiro-tecnológica" (EFT) e a "estrutura social e familiar" (ESF) desses agricultores também é um exemplo de aplicação da modelagem. Nele temos duas variáveis não-observáveis (EFT e ESF), onde EFT é mensurada por três indicadores ("Tipo de Fertilização", "Veículo" e "Tipo de Dedetização) e ESF, também por três indicadores ("Número de Parentes", "Pai" e "Trabalhadores Permanentes"). 
O objetivo do trabalho é apresentar medidas de ajuste dos modelos de equações estruturais e aplicá-las aos dados do Exemplo 5.

Este trabalho é desenvolvido na seguinte seqüência: no Capítulo 2 são apresentados os principais tipos de modelos existentes na modelagem de equações estruturais; no Capítulo 3 discute-se os métodos de estimação plausíveis para alguns casos típicos de modelos; no Capítulo 4 apresentam-se algumas medidas de ajuste para verificação da qualidade do ajuste dos modelos; finalmente, no Capítulo 5 apresenta-se aplicação ao Exemplo 5. 


\section{Capítulo 2}

\section{Modelagem}

Ao modelar equações estruturais podemos fazer representações gráficas das relações existentes entre as variáveis observadas e as latentes e das correlações entre os parâmetros através de diagramas de caminho.

\subsection{Diagramas de Caminho}

A elaboração dos diagramas é realizada da seguinte maneira:

- as variáveis observadas são representadas por quadrados ou retângulos;

- as variáveis latentes, por círculos ou elipses;

- as variáveis de erro não são representadas dentro de figuras;

- flechas retas únicas indicam influência direta;

- flechas retas duplas, influência recíproca;

- flechas curvas, possíveis correlações entre as variáveis.

Na Figura 2.1, apresenta-se um exemplo teórico de diagrama de caminho para a representação da modelagem de equações estruturais. 
Figura 2.1. Exemplo de diagrama de caminho.

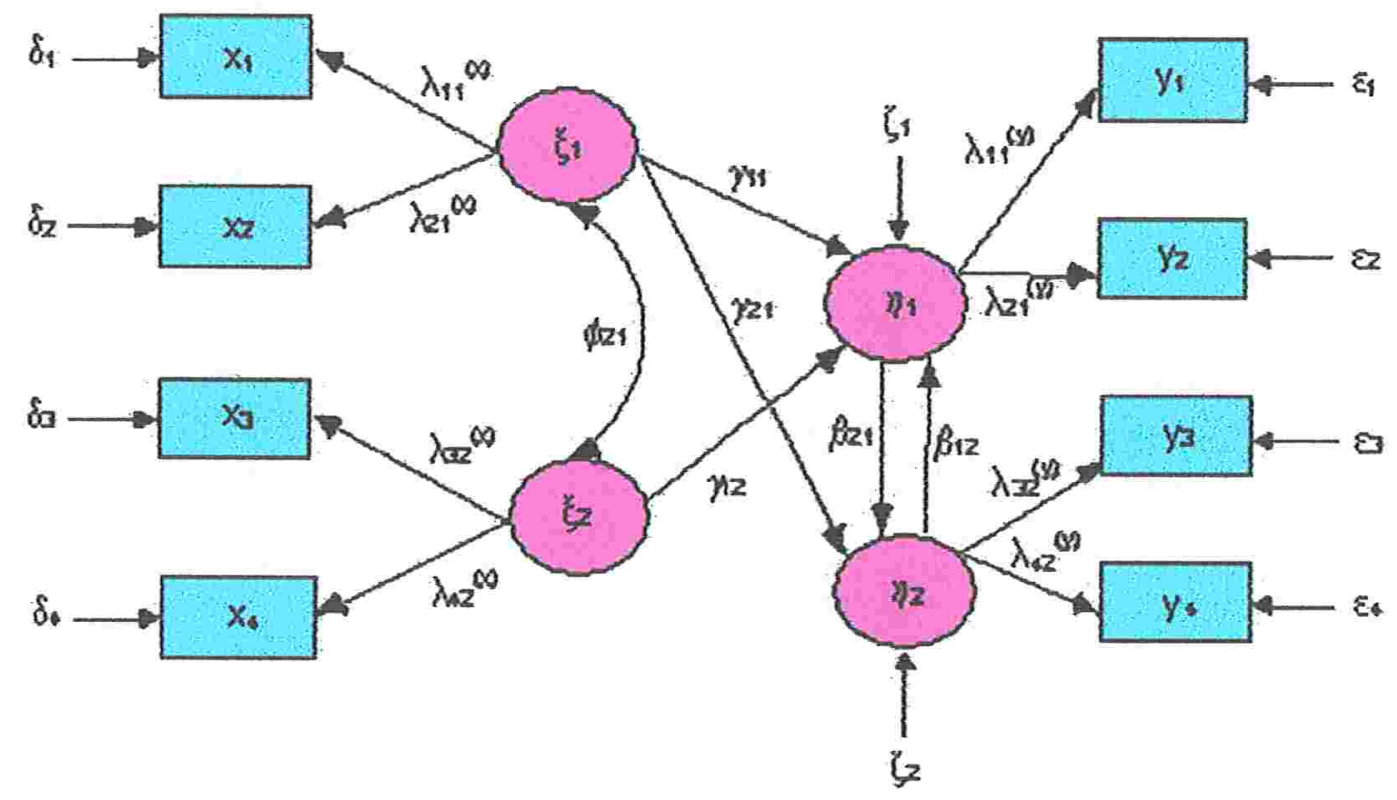

Portanto, observando as regras de elaboração dos diagramas de caminho apresentadas na página 13 temos para o diagrama da Figura 2.1 que:

- $\xi_{1}, \xi_{2}, \eta_{1}$ e $\eta_{2}$ são variáveis latentes;

- $x_{1}, \ldots, x_{4} @ y_{1}, \ldots, y_{4}$ são variáveis observadas;

- $\delta_{1}, \ldots, \delta_{4}, \varepsilon_{1}, \ldots, \varepsilon_{4}, \zeta_{1}$ e $\zeta_{2}$ são variáveis de erro;

- $\xi_{1}$ e $\xi_{2}$ têm influência direta sobre $\eta_{1}$

- $\xi_{1}$ tem influência direta sobre $\eta_{2}, x_{1}$ e $x_{2}$ 
- $\xi_{2}$ tem influência direta sobre $x_{3}$ e $x_{4}$;

- $\eta_{1}$ e $\eta_{2}$ têm influência recíproca;

- $\eta_{1}$ tem influência direta sobre $y_{1}$ e $y_{2}$;

- $\eta_{2}$ tem influência direta sobre $y_{3}$ e $y_{4}$;

- $\xi_{1}$ e $\xi_{2}$ podem ser correlacionadas.

Como as variáveis latentes $\eta_{1}$ e $\eta_{2}$ recebem influência direta de outras variáveis latentes, dizemos que elas são variáveis latentes endógenas (ou dependentes). E, como as variáveis latentes $\xi_{1}$ e $\xi_{2}$ não recebem influência direta de outras variáveis latentes, elas são denominadas variáveis latentes exógenas (ou independentes).

Note agora que, através da Figura 2.1, podemos escrever as equações do modelo com mais facilidade. Vimos anteriormente na página 10 que as equações estruturais são utilizadas para analisar várias relações de dependência entre as variáveis que são intercorrelacionadas. Portanto, as equações estruturais para o diagrama do exemplo teórico são dadas por:

$$
\begin{aligned}
& \eta_{1}=\beta_{12} \eta_{2}+\gamma_{11} \xi_{1}+\gamma_{12} \xi_{2}+\zeta_{1} \\
& \eta_{2}=\beta_{21} \eta_{1}+\gamma_{21} \xi_{1}+\zeta_{2}
\end{aligned}
$$

em que

$\beta_{12}$ : parâmetro estrutural que indica a mudança no valor esperado de $\eta_{1}$ com o acréscimo de uma unidade em $\eta_{2}$, mantendo $\xi_{1}$ e $\xi_{2}$ constantes; ou seja, representa o efeito direto da variável latente dependente $\eta_{2}$ sobre a variável latente dependente $\eta_{1}$;

$\beta_{21}$ : parâmetro estrutural que tem intepretação análoga ao $\beta_{12}$;

$\gamma_{11}$ : parâmetro de regressão que indica a mudança no valor esperado de $\eta_{1}$ com o acréscimo de uma unidade em $\xi_{1}$, mantendo $\eta_{2}$ e $\xi_{2}$ constantes; ou seja, representa o efeito direto da variável latente independente $\xi_{1}$ sobre a variável latente dependente $\eta_{1}$; 
$\gamma_{12}$ e $\gamma_{21}$ : parâmetros de regressão que têm interpretações análogas ao $\gamma_{11}$;

$\zeta_{1}$ e $\zeta_{2}$ : erros aleatórios do modelo.

Também vimos na página 10 que as equações de mensuração são utilizadas para especificar como variáveis não-observáveis são mensuradas por intermédio de variáveis observáveis. Portanto, as equações de mensuração para o diagrama do exemplo teórico são dadas por:

- Equações de mensuração para as variáveis latentes dependentes:

$$
\begin{aligned}
& y_{1}=\lambda_{11}^{(y)} \eta_{1}+\varepsilon_{1} \\
& y_{2}=\lambda_{21}^{(y)} \eta_{1}+\varepsilon_{2} \\
& y_{3}=\lambda_{32}^{(y)} \eta_{2}+\varepsilon_{3} \\
& y_{4}=\lambda_{42}^{(y)} \eta_{2}+\varepsilon_{4}
\end{aligned}
$$

- Equações de mensuração para as variáveis latentes independentes:

$$
\begin{aligned}
& x_{1}=\lambda_{11}^{(x)} \xi_{1}+\delta_{1} \\
& x_{2}=\lambda_{21}^{(x)} \xi_{1}+\delta_{2} \\
& x_{3}=\lambda_{32}^{(x)} \xi_{2}+\delta_{3} \\
& x_{4}=\lambda_{42}^{(x)} \xi_{2}+\delta_{4}
\end{aligned}
$$

em que

$\lambda_{21}^{(y)}$ : magnitude da mudança na variável observada $y_{2}$ com a mudança de uma unidade na variável latente dependente $\eta_{1}$, ou seja, representa o impacto da variável latente dependente $\eta_{1}$ na variável observada $y_{2}$

$\lambda_{11}^{(y)}, \lambda_{32}^{(y)}$ e $\lambda_{42}^{(y)}$ : têm interpretação análoga ao $\lambda_{21}^{(y)}$;

$\lambda_{21}^{(x)}$ : magnitude da mudança na variável observada $x_{2}$ com a mudança de uma unidade na variável latente independente $\xi_{1}$, ou seja, representa o impacto da variável latente independente $\xi_{1}$ na variável observada $x_{2}$; 
$\lambda_{11}^{(x)}, \lambda_{32}^{(x)}$ e $\lambda_{42}^{(x)}$ : têm interpretação análoga ao $\lambda_{21}^{(x)} ;$

$\varepsilon_{1}, \ldots, \varepsilon_{4}$ : erros de mensuração das variáveis $y_{1}, \ldots, y_{4}$, respectivamente;

$\delta_{1}, \ldots, \delta_{4}$ : erros de mensuração das variáveis $x_{1}, \ldots, x_{4}$, respectivamente.

Podemos também definir:

$$
\begin{aligned}
& \operatorname{var}\left(\xi_{1}\right)=\phi_{11} \\
& \operatorname{var}\left(\xi_{2}\right)=\phi_{22} \\
& \operatorname{cov}\left(\xi_{1}, \xi_{2}\right)=\phi_{12}=\phi_{21} \\
& \operatorname{var}\left(\zeta_{1}\right)=\psi_{11} \\
& \operatorname{var}\left(\zeta_{2}\right)=\psi_{22} \\
& \operatorname{cov}\left(\zeta_{1}, \zeta_{2}\right)=\psi_{12}=\psi_{21} \\
& \operatorname{corr}\left(\xi_{1}, \xi_{2}\right)=\theta_{12}
\end{aligned}
$$

Tanto as equações estruturais quanto as equações de mensuração também podem ser escritas matricialmente:

- Equações Estruturais:

$$
\left(\begin{array}{l}
\eta_{1} \\
\eta_{2}
\end{array}\right)=\left(\begin{array}{cc}
0 & \beta_{12} \\
\beta_{21} & 0
\end{array}\right)\left(\begin{array}{l}
\eta_{1} \\
\eta_{2}
\end{array}\right)+\left(\begin{array}{cc}
\gamma_{11} & \gamma_{12} \\
\gamma_{21} & 0
\end{array}\right)\left(\begin{array}{l}
\xi_{1} \\
\xi_{2}
\end{array}\right)+\left(\begin{array}{l}
\zeta_{1} \\
\zeta_{2}
\end{array}\right)
$$

com

$$
\begin{aligned}
& \Phi=\left(\begin{array}{ll}
\phi_{11} & \phi_{12} \\
\phi_{21} & \phi_{22}
\end{array}\right) \\
& \Psi=\left(\begin{array}{ll}
\psi_{11} & \psi_{12} \\
\psi_{21} & \psi_{22}
\end{array}\right)
\end{aligned}
$$


e

$$
\Theta=\left(\begin{array}{cc}
1 & \theta_{12} \\
& 1
\end{array}\right)
$$

ou seja,

$$
\eta=\mathrm{B} \eta+\Gamma \xi+\zeta
$$

A equação (2.1) é a representação matricial geral do modelo de variáveis latentes (equações estruturais), onde:

$\eta_{(m \times 1)}$ : vetor de variáveis latentes endógenas;

$\xi_{(n \times 1)}$ : vetor de variáveis latentes exógenas;

$\zeta_{(m \times 1)}$ : vetor de erros aleatórios;

$\mathrm{B}_{(m \times m)}$ : matriz de coeficientes das variáveis latentes endógenas, ou seja, seus elementos representam efeitos diretos das variáveis $\eta$ em outras variáveis $\eta$;

$\Gamma_{(m \times n)}$ : matriz de coeficientes das variáveis latentes exógenas, ou seja, seus elementos representam efeitos diretos de variáveis $\xi$ em variáveis $\eta$.

$\mathrm{E}$, adicionalmente:

$\Phi_{(n \times n)}$ : matriz de covariância das variáveis latentes exógenas (ou seja, dos $\xi^{\prime} s$ );

$\Theta_{(n \times n)}$ : matriz de correlação das variáveis latentes exógenas (ou seja, dos $\xi^{\prime} s$ );

$\Psi_{(m \times m)}$ : matriz de covariância dos erros nas equações (ou seja, dos $\zeta^{\prime} s$ ). 
- Equações de Mensuração para as variáveis latentes dependentes:

$$
\left(\begin{array}{l}
y_{1} \\
y_{2} \\
y_{3} \\
y_{4}
\end{array}\right)=\left(\begin{array}{cc}
\lambda_{11}^{(y)} & 0 \\
\lambda_{21}^{(y)} & 0 \\
0 & \lambda_{32}^{(x)} \\
0 & \lambda_{42}^{(x)}
\end{array}\right)\left(\begin{array}{l}
\eta_{1} \\
\eta_{2}
\end{array}\right)+\left(\begin{array}{c}
\varepsilon_{1} \\
\varepsilon_{2} \\
\varepsilon_{3} \\
\varepsilon_{4}
\end{array}\right)
$$

- Equações de Mensuração para as variáveis latentes independentes:

$$
\left(\begin{array}{l}
x_{1} \\
x_{2} \\
x_{3} \\
x_{4}
\end{array}\right)=\left(\begin{array}{cc}
\lambda_{11}^{(x)} & 0 \\
\lambda_{21}^{(x)} & 0 \\
0 & \lambda_{32}^{(x)} \\
0 & \lambda_{42}^{(x)}
\end{array}\right)\left(\begin{array}{l}
\xi_{1} \\
\xi_{2}
\end{array}\right)+\left(\begin{array}{c}
\delta_{1} \\
\delta_{2} \\
\delta_{3} \\
\delta_{4}
\end{array}\right)
$$

ou seja,

$$
\begin{aligned}
& \mathrm{y}=\Lambda_{y} \eta+\varepsilon \\
& \mathrm{x}=\Lambda_{x} \xi+\delta
\end{aligned}
$$

As equações (2.2) e (2.3) são as representações matriciais gerais do modelo de mensuração, onde:

$\mathrm{y}_{(p \times 1)}$ : vetor de indicadores observados de $\eta$;

$\mathrm{x}_{(q \times 1)}$ : vetor de indicadores observados de $\xi$;

$\varepsilon_{(p \times 1)}$ : vetor de erros de mensuração para $\mathrm{y}$;

$\delta_{(q \times 1)}$ : vetor de erros de mensuração para $\mathrm{x}$;

$\Lambda_{y(p \times m)}$ : matriz de coeficientes que relacionam y com $\eta$, ou seja, seus elementos representam o impacto das variáveis latentes endógenas $\left(\eta^{\prime} s\right)$ nas variáveis observáveis $y$; 
$\Lambda_{x(q \times n)}$ : matriz de coeficientes que relacionam $\mathrm{x} \operatorname{com} \xi$, ou seja, seus elementos representam o impacto das variáveis latentes exógenas $\left(\xi^{\prime} s\right)$ nas variáveis observáveis $x$.

E, ałicionalmente:

$\Theta_{\varepsilon(p \times p)}$ : matriz de covariância de $\varepsilon$;

$\Theta_{\delta(q \times q)}:$ matriz de covariância de $\delta$.

A seguir, na Figura 2.2 apresenta-se o diagrama de caminho do Estudo de Wheaton (Exemplo 1).

Figura 2.2. Diagrama de caminho para o Estudo de Wheston.

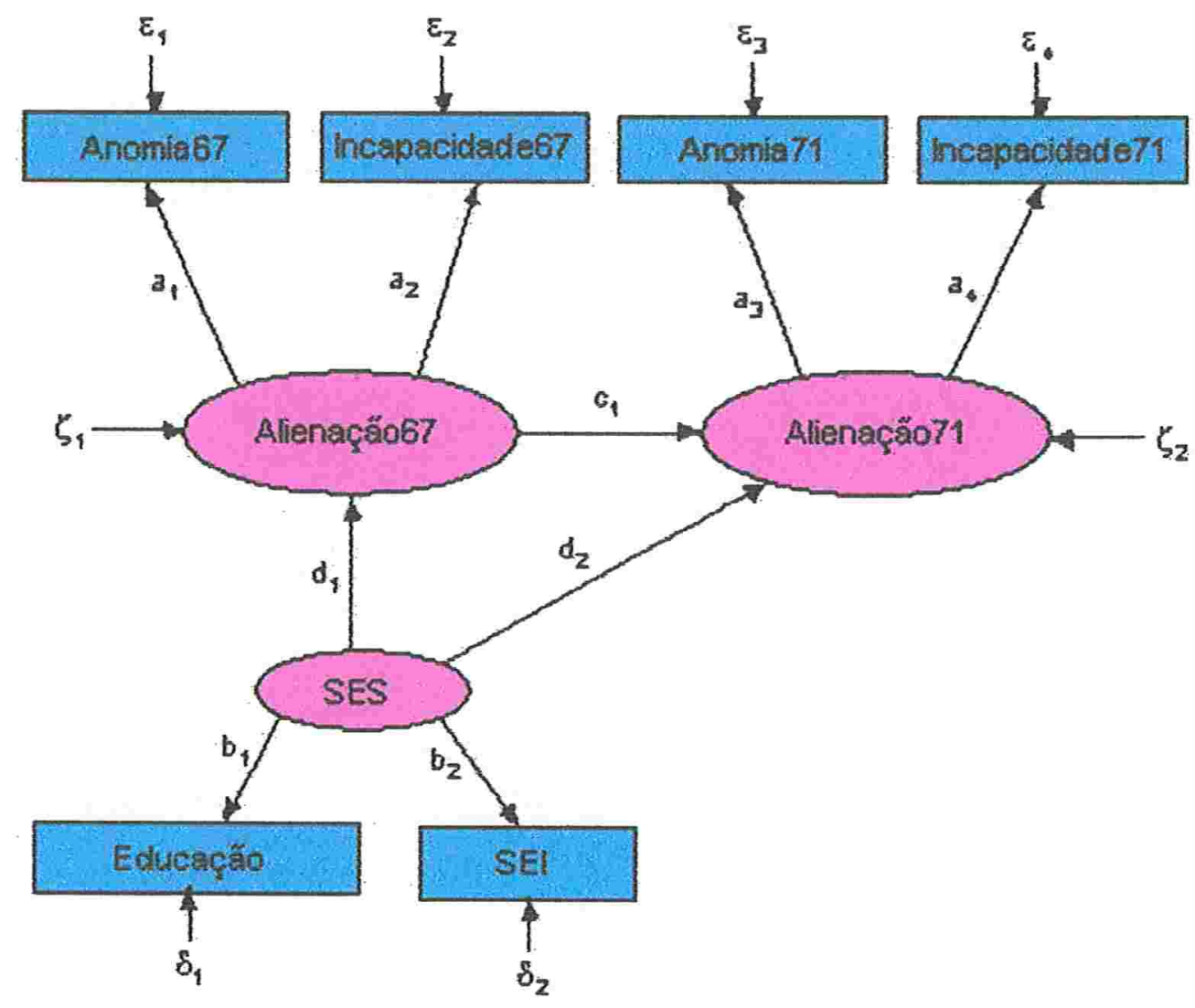


Observando a Figura 2.2 percebemos que as variáveis latentes Alienação67 e Alienação71 recebem influência direta da variável latente SES e, a variável Alienação71 também recebe influência direta da variável Alienação67, portanto, Alienação67 e Alienação71 são variáveis latentes endógenas (dependentes). Por sua vez, a variável latente SES não recebe influência direta de outras variáveis latentes e, assim, ela é uma variável latente exógena (independente).

Então, as equações estruturais para o Estudo de Wheaton são dadas por:

Alienação67 $=d_{1}$ SES $+\zeta_{1}$

Alienação71 $=c_{1}$ Alienação67 $+d_{2} \mathrm{SES}+\zeta_{2}$

E, as equações de mensuração são divididas em dois grupos:

- Equações para as variáveis latentes dependentes:

Anomia67 $=a_{1}$ Alienação67 $+\varepsilon_{1}$

Incapacidade67 $=a_{2}$ Alienação67 $+\varepsilon_{2}$

Anomia71 $=a_{3}$ Alienação71 $+\varepsilon_{3}$

Incapacidade71 $=a_{4}$ Alienação71 $+\varepsilon_{4}$

- Equações para as variáveis latentes independentes:

Educação $=b_{1} \mathrm{SES}+\delta_{1}$

$\mathrm{SEI}=b_{2} \mathrm{SES}+\delta_{2}$

Temos também que:

$\operatorname{var}(\mathrm{SES})=\phi_{\mathrm{SES}}$ 


$$
\begin{aligned}
& \operatorname{var}\left(\zeta_{1}\right)=\psi_{11} \\
& \operatorname{var}\left(\zeta_{2}\right)=\psi_{22} \\
& \operatorname{cov}\left(\zeta_{1}, \zeta_{2}\right)=\psi_{12}=\psi_{21}
\end{aligned}
$$

Matricialmente, temos os modelos:

- Modelo estrutural:

$$
\left(\begin{array}{c}
\text { Alienação67 } \\
\text { Alienação71 }
\end{array}\right)=\left(\begin{array}{ll}
0 & 0 \\
c_{1} & 0
\end{array}\right)\left(\begin{array}{c}
\text { Alienação67 } \\
\text { Alienação71 }
\end{array}\right)+\left(\begin{array}{c}
d_{1} \\
d_{2}
\end{array}\right)(\operatorname{SES})+\left(\begin{array}{c}
\zeta_{1} \\
\zeta_{2}
\end{array}\right)
$$

- Modelo de mensuração para as variáveis latentes dependentes:

$$
\left(\begin{array}{c}
\text { Anomia67 } \\
\text { Incapacidade67 } \\
\text { Anomia71 } \\
\text { Incapacidade71 }
\end{array}\right)=\left(\begin{array}{cc}
a_{1} & 0 \\
a_{2} & 0 \\
0 & a_{3} \\
0 & a_{4}
\end{array}\right)\left(\begin{array}{c}
\text { Alienação67 } \\
\text { Alienação71 }
\end{array}\right)+\left(\begin{array}{c}
\varepsilon_{1} \\
\varepsilon_{2} \\
\varepsilon_{3} \\
\varepsilon_{4}
\end{array}\right)
$$

- Modelo de mensuração para as variáveis latentes independentes:

$$
\begin{gathered}
\left(\begin{array}{c}
\text { Educação } \\
\text { SEI }
\end{array}\right)=\left(\begin{array}{l}
b_{1} \\
b_{2}
\end{array}\right)(S E S)+\left(\begin{array}{l}
\delta_{1} \\
\delta_{2}
\end{array}\right) \\
\Phi=\phi_{S E S}
\end{gathered}
$$

e

em que

$$
\Psi=\left(\begin{array}{ll}
\psi_{11} & \psi_{12} \\
\psi_{21} & \psi_{22}
\end{array}\right)
$$

$a_{1}, \ldots, a_{4}$ : representam o impacto das variáveis latentes dependentes (Alienação67 e Alienação71) nas variáveis observadas Anomia67, Incapacidade67, Anomia71 e Incapacidade71; 
$b_{1}, b_{2}$ : representam o impacto da variável latente independente (SES) nas variáveis observadas Educação e SEI;

$c_{1}$ : efeito direto da variável latente dependente (Alienação67) em outra variável latente dependente (Alienação71);

$d_{1}, d_{2}$ : representam o efeito direto da variável latente independente (SES) em variáveis latentes dependentes (Alienação67 e Alienação71);

$\varepsilon_{1}, \ldots, \varepsilon_{4}$ : erros de mensuração das variáveis observadas Anomia67, Incapacidade67, Anomia71

e Incapacidade71, respectivamente;

$\delta_{1}, \delta_{2}$ : erros de mensuração das variáveis observadas Educação e SEI, respectivamente;

$\zeta_{1}, \zeta_{2}$ : erros da equação estrutural;

$\Phi$ : matriz de covariância da variável latente independente SES;

$\Psi$ : matriz de covariância dos erros nas equações estruturais (ou seja, dos $\zeta$ 's).

A seguir, na Figura 2.3 apresenta-se o diagrama de caminho do Estudo de Desempenho da Função Administrativa (Exemplo 2). 
Figura 2.3. Diagrama de caminho para o Estudo do Desempenlo da Função Administrativa de Funcionários.

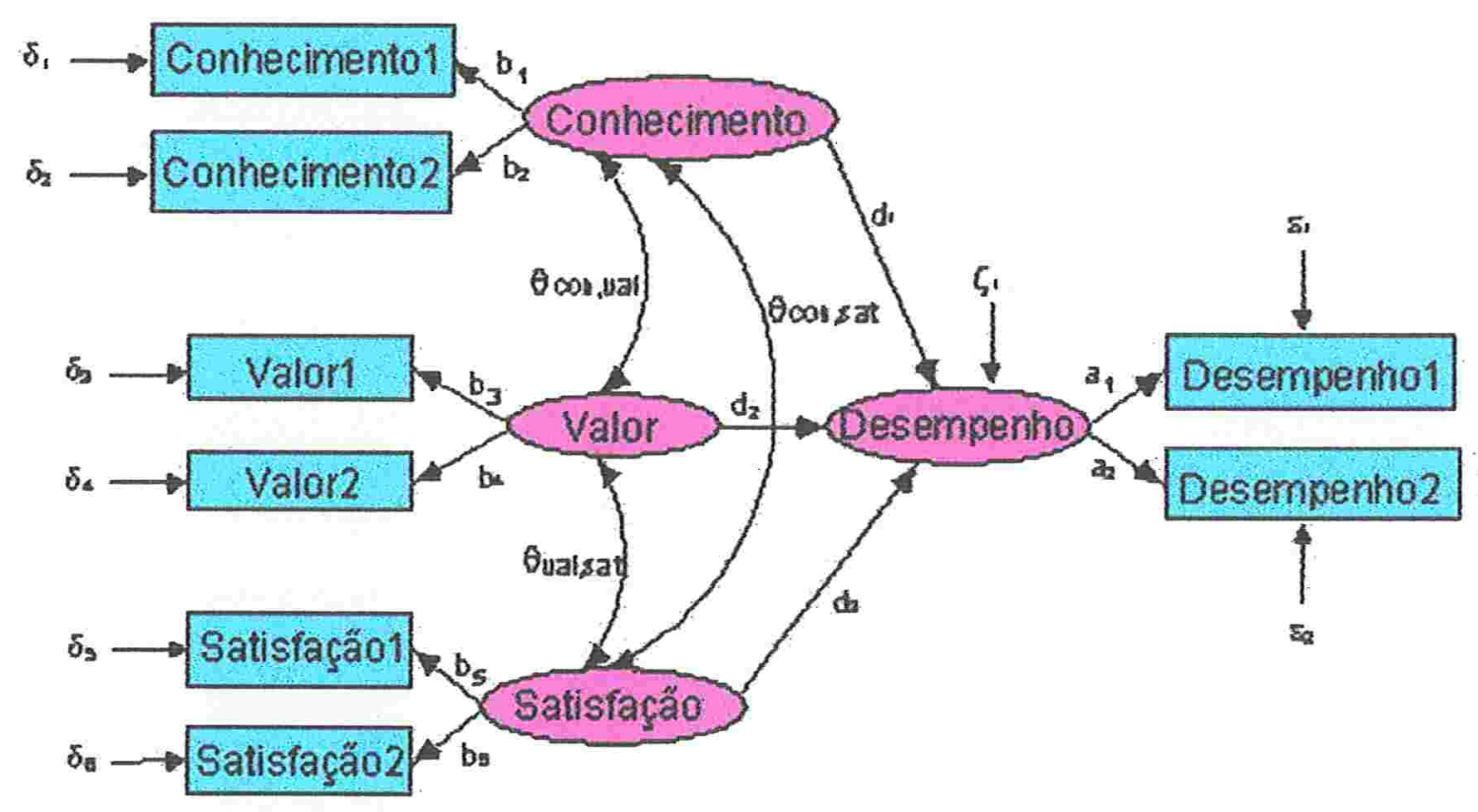

Pela Figura 2.3 temos que a variável latente Desempenho recebe influência direta das variáveis latentes Conhecimento, Valor e Satisfação; portanto, ela é uma variável latente dependente. Por sua vez, as variáveis latentes Conhecimento, Valor e Satisfação não recebem influência direta de outras variáveis latentes e, então, elas são variáveis latentes independentes.

Então, a equação estrutural para o Estudo do Desempenho da Função Administrativa é dada por:

Desempenho $=d_{1}$ Conhecimento $+d_{2}$ Valor $+d_{3}$ Satisfação $+\zeta_{1}$ 
E, as equações de mensuração são divididas em dois grupos:

- Equações para a variável latente dependente:

Desempenho1 $=a_{1}$ Desempenho $+\varepsilon_{1}$

Desempenho2 $=a_{2}$ Desempenho $+\varepsilon_{2}$

- Equações para as variáveis latentes independentes:

$$
\begin{aligned}
& \text { Conhecimento1 }=b_{1} \text { Conhecimento }+\delta_{1} \\
& \text { Conhecimento } 2=b_{2} \text { Conhecimento }+\delta_{2} \\
& \text { Valor } 1=b_{3} \text { Valor }+\delta_{3} \\
& \text { Valor } 2=b_{4} \text { Valor }+\delta_{4} \\
& \text { Satisfação1 }=b_{5} \text { Satisfação }+\delta_{5} \\
& \text { Satisfação2 }=b_{6} \text { Satisfação }+\delta_{6}
\end{aligned}
$$

Temos também que:

$$
\begin{aligned}
& \operatorname{var}(\text { Conhecimento })=\phi_{\text {con }} \\
& \operatorname{var}(\text { Valor })=\phi_{\text {val }} \\
& \operatorname{var}(\text { Satisfação })=\phi_{\text {sat }} \\
& \operatorname{cov}(\text { Conhecimento, Valor })=\phi_{\text {con,val }} \\
& \operatorname{cov}(\text { Conhecimento, Safisfação })=\phi_{\text {con,sat }} \\
& \operatorname{cov}(\text { Valor, Satisfação })=\phi_{\text {val,sat }} \\
& \operatorname{var}\left(\zeta_{1}\right)=\psi_{11} \\
& \operatorname{corr}(\text { Conhecimento, Valor })=\theta_{\text {con,val }}
\end{aligned}
$$


$\operatorname{corr}($ Conhecimento, Safisfação $)=\theta_{\text {con,sat }}$

$\operatorname{corr}($ Valor, Satisfação $)=\theta_{\text {val,sat }}$

Matricialmente, temos os modelos:

- Modelo estrutural:

$$
(\text { Desempenho })=\left(\begin{array}{lll}
d_{1} & d_{2} & d_{3}
\end{array}\right)\left(\begin{array}{c}
\text { Conhecimento } \\
\text { Valor } \\
\text { Satisfação }
\end{array}\right)+\left(\zeta_{1}\right)
$$

- Modelo de mensuração para a variável latente dependente:

$$
\left(\begin{array}{l}
\text { Desempenho1 } \\
\text { Desempenho2 }
\end{array}\right)=\left(\begin{array}{l}
a_{1} \\
a_{2}
\end{array}\right)(\text { Desempenho })+\left(\begin{array}{c}
\varepsilon_{1} \\
\varepsilon_{2}
\end{array}\right)
$$

- Modelo de mensuração para as variáveis latentes independentes:

$$
\left(\begin{array}{c}
\text { Conhecimento1 } \\
\text { Conhecimento2 } \\
\text { Valor1 } \\
\text { Valor2 } \\
\text { Satisfação1 } \\
\text { Satisfação2 }
\end{array}\right)=\left(\begin{array}{ccc}
b_{1} & 0 & 0 \\
b_{2} & 0 & 0 \\
0 & b_{3} & 0 \\
0 & b_{4} & 0 \\
0 & 0 & b_{5} \\
0 & 0 & b_{6}
\end{array}\right)\left(\begin{array}{c}
\text { Conhecimento } \\
\text { Valor } \\
\text { Satisfação }
\end{array}\right)+\left(\begin{array}{c}
\delta_{1} \\
\delta_{2} \\
\delta_{3} \\
\delta_{4} \\
\delta_{5} \\
\delta_{6}
\end{array}\right)
$$

e

$$
\begin{aligned}
& \Phi=\left(\begin{array}{ccc}
\phi_{\text {con }} & \phi_{\text {con,val }} & \phi_{\text {con,sat }} \\
& \phi_{\text {val }} & \phi_{\text {val,sat }} \\
& & \phi_{\text {sat }}
\end{array}\right)
\end{aligned}
$$

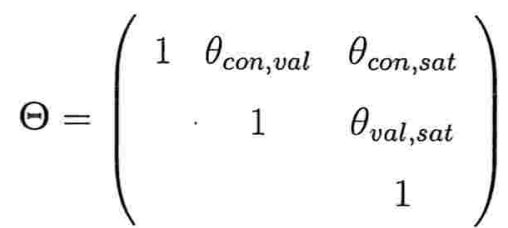




$$
\Psi=\psi_{11}
$$

em que

$a_{1}, a_{2}$ : representam o impacto da variável latente dependente (Desempenho) nas variáveis observadas Desempenho1 e Desempenho2;

$b_{1}, \ldots, b_{6}$ : representam o impacto das variáveis latentes independentes (Conhecimento, Valor e Safisfação) nas variáveis observadas Conhecimento1, Conhecimento2, Valor1, Valor2, Satisfação1 e Satisfação2;

$d_{1}, d_{2}, d_{3}$ : representam o efeito direto das variáveis latentes independentes (Conhecimento, Valor e Satisfação) na variável latente dependente Desempenho;

$\varepsilon_{1}, \varepsilon_{2}$ : erros de mensuração das variáveis observadas Desempenho1 e Desempenho2;

$\delta_{1}, \ldots, \delta_{6}$ : erros de mensuração das variáveis observadas Conhecimento1, Conhecimento2, Valor1, Valor2, Satisfação1 e Satisfação2;

$\zeta_{1}$ : erro da equação estrutural;

$\Phi$ : matriz de covariância das variáveis latentes independentes;

$\Psi$ : matriz de covariância dos erros na equação estrutural;

$\Theta$ : matriz de correlação das variáveis latentes independentes.

A seguir na Figura 2.4 apresenta-se o diagrama de caminho do Estudo sobre Nacionalismo e Identificação na Espanha (Exemplo 3). 
Figura 2.4. Diagrama de caminho para o Estudo sobre Nacionalismo e Identificação na. Espanha.

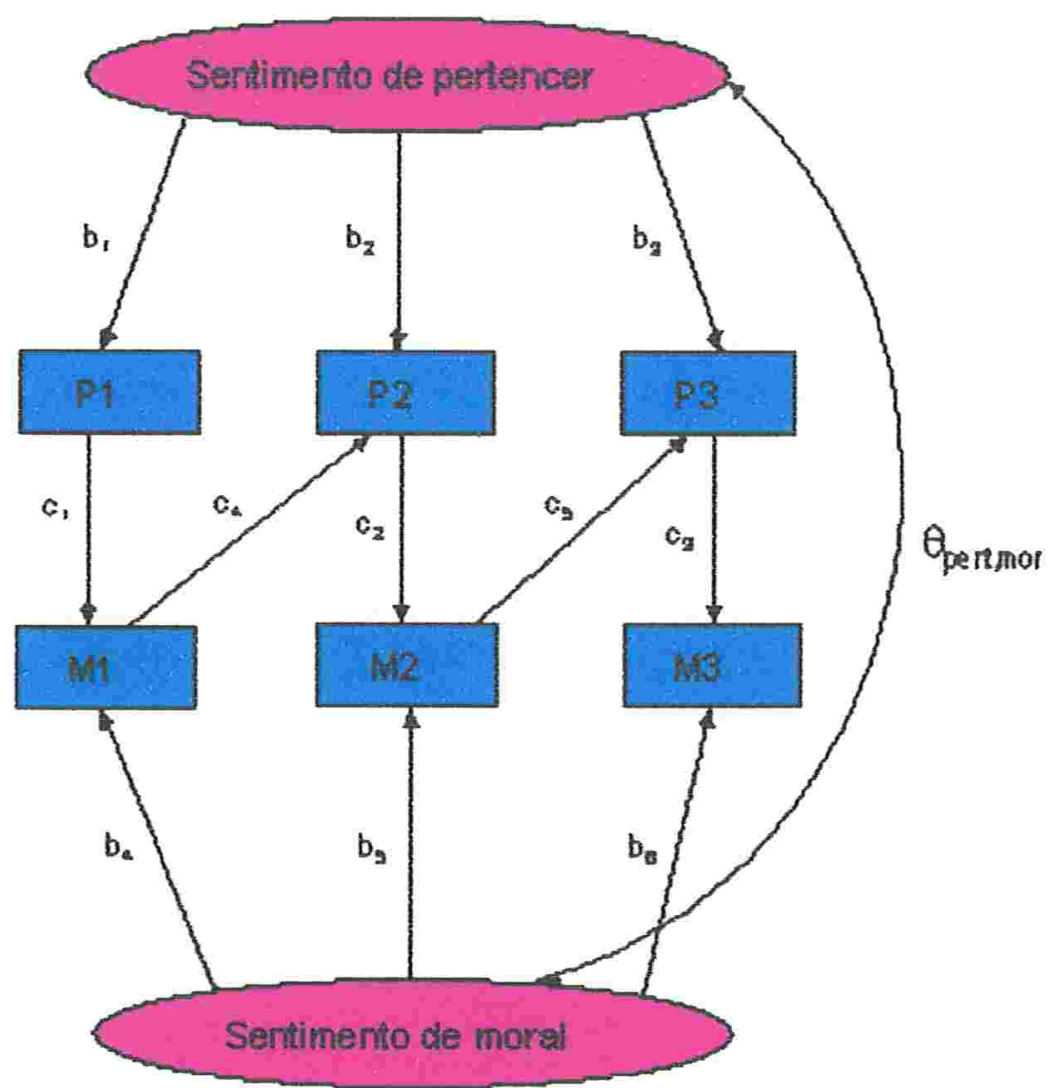

Observando a Figura 2.4 vemos que as variáveis latentes Sentimento de Pertencer e Sentimento de Moral não recebem influência direta de outras variáveis latentes, portanto, ambas são variáveis latentes exógenas (independentes). Por sua vez, analisando as variáveis observadas $P_{1}, P_{2}, P_{3}, M_{1}, M_{2}$ e $M_{3}$, notamos que $P_{2}$ e $P_{3}$ recebem influência direta de $M_{1}$ e $M_{2}$, respectivamente e, $M_{1}, M_{2}$ e $M_{3}$ recebem infuência direta de $P_{1}, P_{2}$ e $P_{3}$, respectivamente. Portanto, como as equações estruturais são utilizadas para analisar várias relações de dependência entre as variáveis que são intercorrelacionadas, temos para esse 
exemplo que:

- Equações Estruturais:

$$
\begin{aligned}
& \mathrm{M}_{1}=c_{1} \mathrm{P}_{1}+\zeta_{1} \\
& \mathrm{M}_{2}=c_{2} \mathrm{P}_{2}+\zeta_{2} \\
& \mathrm{M}_{3}=c_{3} \mathrm{P}_{3}+\zeta_{3} \\
& \mathrm{P}_{2}=c_{4} \mathrm{M}_{1}+\zeta_{4} \\
& \mathrm{P}_{3}=c_{5} \mathrm{M}_{2}+\zeta_{5}
\end{aligned}
$$

- Equações de mensuração para as variáveis latentes independentes:

$$
\begin{aligned}
& \mathrm{P}_{1}=b_{1} \text { Sentimento de Pertencer }+\delta_{1} \\
& \mathrm{P}_{2}=b_{2} \text { Sentimento de Pertencer }+\delta_{2} \\
& \mathrm{P}_{3}=b_{3} \text { Sentimento de Pertencer }+\delta_{3} \\
& \mathrm{M}_{1}=b_{4} \text { Sentimento de Moral }+\delta_{4} \\
& \mathrm{M}_{2}=b_{5} \text { Sentimento de Moral }+\delta_{5} \\
& \mathrm{M}_{3}=b_{6} \text { Sentimento de Moral }+\delta_{6}
\end{aligned}
$$

Temos também que:

$\operatorname{var}($ Sentimento de Pertencer $)=\phi_{\text {pert }}$

$\operatorname{var}($ Sentimento de Moral $)=\phi_{\text {mor }}$

$\operatorname{cov}($ Sentimento de Pertencer, Sentimento de Moral $)=\phi_{\text {pert,mor }}$

$\operatorname{var}\left(\zeta_{1}\right)=\psi_{11}$

$\operatorname{var}\left(\zeta_{2}\right)=\psi_{22}$ 


$$
\begin{aligned}
& \operatorname{var}\left(\zeta_{3}\right)=\psi_{33} \\
& \operatorname{var}\left(\zeta_{4}\right)=\psi_{44} \\
& \operatorname{var}\left(\zeta_{5}\right)=\psi_{55} \\
& \operatorname{cov}\left(\zeta_{1}, \zeta_{2}\right)=\psi_{12} \\
& \operatorname{cov}\left(\zeta_{1}, \zeta_{3}\right)=\psi_{13} \\
& \operatorname{cov}\left(\zeta_{1}, \zeta_{4}\right)=\psi_{14} \\
& \operatorname{cov}\left(\zeta_{1}, \zeta_{5}\right)=\psi_{15} \\
& \operatorname{cov}\left(\zeta_{2}, \zeta_{3}\right)=\psi_{23} \\
& \operatorname{cov}\left(\zeta_{2}, \zeta_{4}\right)=\psi_{24} \\
& \operatorname{cov}\left(\zeta_{2}, \zeta_{5}\right)=\psi_{25} \\
& \operatorname{cov}\left(\zeta_{3}, \zeta_{4}\right)=\psi_{34} \\
& \operatorname{cov}\left(\zeta_{3}, \zeta_{5}\right)=\psi_{35} \\
& \operatorname{cov}\left(\zeta_{4}, \zeta_{5}\right)=\psi_{45} \\
& \operatorname{corr}(\text { Sentimento de Pertencer, Sentimento de Moral })=\theta_{\text {pert,mor }}
\end{aligned}
$$

Matricialmente, temos os modelos:

- Modelo estrutural:

$$
\left(\begin{array}{l}
\mathrm{M}_{1} \\
\mathrm{M}_{2} \\
\mathrm{M}_{3} \\
\mathrm{P}_{2} \\
\mathrm{P}_{3}
\end{array}\right)=\left(\begin{array}{ccccc}
c_{1} & 0 & 0 & 0 & 0 \\
0 & c_{2} & 0 & 0 & 0 \\
0 & 0 & c_{3} & 0 & 0 \\
0 & 0 & 0 & c_{4} & 0 \\
0 & 0 & 0 & 0 & c_{5}
\end{array}\right)\left(\begin{array}{c}
\mathrm{P}_{1} \\
\mathrm{P}_{2} \\
\mathrm{P}_{3} \\
\mathrm{M}_{1} \\
\mathrm{M}_{2}
\end{array}\right)+\left(\begin{array}{c}
\zeta_{1} \\
\zeta_{2} \\
\zeta_{3} \\
\zeta_{4} \\
\zeta_{5}
\end{array}\right)
$$

- Modelo de mensuração: 


$$
\left(\begin{array}{l}
\mathrm{P}_{1} \\
\mathrm{P}_{2} \\
\mathrm{P}_{3} \\
\mathrm{M}_{1} \\
\mathrm{M}_{2} \\
\mathrm{M}_{3}
\end{array}\right)=\left(\begin{array}{cc}
b_{1} & 0 \\
b_{2} & 0 \\
b_{3} & 0 \\
0 & b_{4} \\
0 & b_{5} \\
0 & b_{6}
\end{array}\right)\left(\begin{array}{c}
\text { Sentimento de Pertencer } \\
\text { Sentimento de Moral }
\end{array}\right)+\left(\begin{array}{c}
\delta_{1} \\
\delta_{2} \\
\delta_{3} \\
\delta_{4} \\
\delta_{5} \\
\delta_{6}
\end{array}\right)
$$

e

$$
\begin{aligned}
& \begin{array}{c}
\Phi=\left(\begin{array}{cccc}
\phi_{\text {pert }} & \phi_{\text {pert }, \text { mor }} \\
& \phi_{\text {mor }}
\end{array}\right) \\
\Psi=\left(\begin{array}{ccccc}
\psi_{11} & \psi_{12} & \psi_{13} & \psi_{14} & \psi_{15} \\
& \psi_{22} & \psi_{23} & \psi_{24} & \psi_{25} \\
& \psi_{33} & \psi_{34} & \psi_{35} \\
& & & \psi_{44} & \psi_{45} \\
& & & & \psi_{55}
\end{array}\right)
\end{array} \\
& \begin{array}{c}
\Phi=\left(\begin{array}{cccc}
\phi_{\text {pert }} & \phi_{\text {pert }, \text { mor }} \\
& \phi_{\text {mor }}
\end{array}\right) \\
\Psi=\left(\begin{array}{ccccc}
\psi_{11} & \psi_{12} & \psi_{13} & \psi_{14} & \psi_{15} \\
& \psi_{22} & \psi_{23} & \psi_{24} & \psi_{25} \\
& \psi_{33} & \psi_{34} & \psi_{35} \\
& & & \psi_{44} & \psi_{45} \\
& & & & \psi_{55}
\end{array}\right)
\end{array} \\
& \Theta=\left(\begin{array}{cc}
1 & \theta_{\text {pert }, \text { mor }} \\
& 1
\end{array}\right)
\end{aligned}
$$

em que

$b_{1}, \ldots, b_{6}$ : representam o impacto das variáveis latentes independentes (Sentimento de Pertencer e Sentimento de Moral) nas variáveis observadas ( $P_{1}, P_{2}, P_{3}, M_{1}, M_{2}$ e $\left.M_{3}\right)$; $c_{1}, \ldots, c_{5}$ : representam o efeito direto das variáveis observadas $\left(\mathrm{P}_{1}, \mathrm{P}_{2}, \mathrm{P}_{3}, \mathrm{M}_{1}, \mathrm{M}_{2}\right)$ em outras variáveis observadas $\left(\mathrm{M}_{1}, \mathrm{M}_{2}, \mathrm{M}_{3}, \mathrm{P}_{2}, \mathrm{P}_{3}\right)$;

$\delta_{1}, \ldots, \delta_{6}$ : erros de mensuração das variáveis observadas $\left(\mathrm{P}_{1}, \mathrm{P}_{2}, \mathrm{P}_{3}, \mathrm{M}_{1}, \mathrm{M}_{2}\right.$ e $\left.\mathrm{M}_{3}\right)$; $\zeta_{1}, \ldots, \zeta_{5}$ : erros das equações estruturais;

$\Phi$ : matriz de covariância das variáveis latentes independentes;

$\Psi$ : matriz de covariância dos erros nas equações estruturais;

$\Theta$ : matriz de correlação das variáveis latentes independentes. 
Na Figura 2.5 apresenta-se o diagrama de caminho do Estudo da Relacão entre Democracia Política e Industrialização (Exemplo 4).

Figura 2.5. Diagrama de caminho para o Estudo da Relação entre Democracia Política e Industrialização.

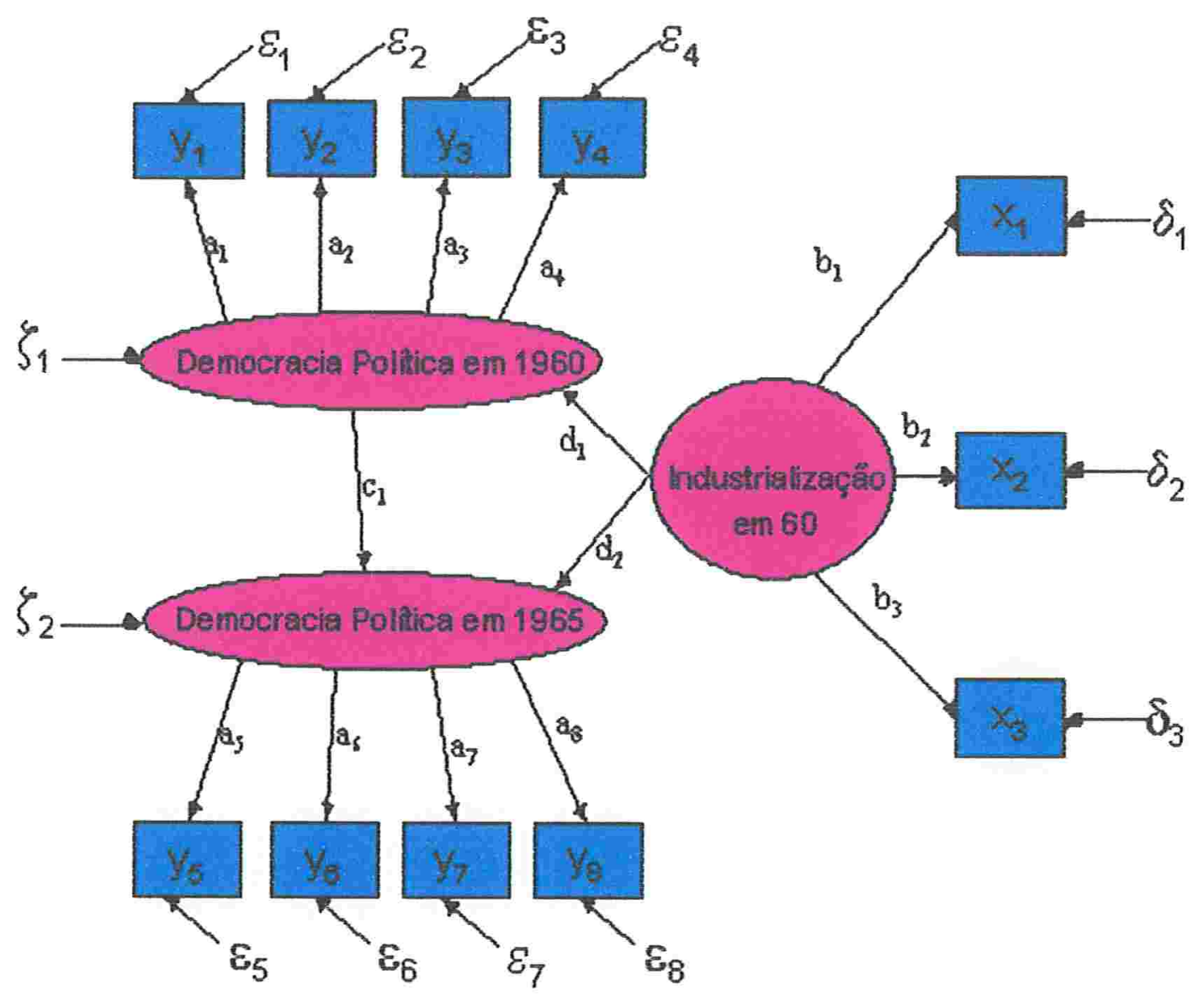

Observando a Figura 2.5 notamos que a variável latente Industrialização em 60 não recebe influência direta de outras variáveis latentes, portanto, ela ê uma variável latente 
independente. Por sua vez, a variável latente Democracia Política em 65 recebe influência direta das variáveis latentes Democracia Política em 60 e Industrialização em 60 e, assim, ela é uma variável latente dependente. A variável latente Democracia Política em 60 também recebe influência direta da variável latente Industrialização em 60 e, então, ela também é uma variável latente dependente.

Então, as equações estruturais para o Estudo da Relação entre Democracia Política e Industrialização são dadas por:

$$
\begin{aligned}
& \text { DP60 }=d_{1} \text { Ind60 }+\zeta_{1} \\
& \text { DP65 }=c_{1} \text { DP60 }+d_{2} \text { Ind60 }+\zeta_{2}
\end{aligned}
$$

em que DP60 e DP65 são a Democracia Política em 1960 e em 1965, respectivamente e, Ind60 é a Industrialização em 1960.

E, as equações de mensuração são divididas em dois grupos:

- Equações para as variáveis latentes dependentes:

$$
\begin{aligned}
& y_{1}=a_{1} \mathrm{DP} 60+\varepsilon_{1} \\
& y_{2}=a_{2} \mathrm{DP} 60+\varepsilon_{2} \\
& y_{3}=a_{3} \mathrm{DP} 60+\varepsilon_{3} \\
& y_{4}=a_{4} \mathrm{DP} 60+\varepsilon_{4} \\
& y_{5}=a_{5} \mathrm{DP} 65+\varepsilon_{5} \\
& y_{6}=a_{6} \mathrm{DP} 65+\varepsilon_{6} \\
& y_{7}=a_{7} \mathrm{DP} 65+\varepsilon_{7} \\
& y_{8}=a_{8} \mathrm{DP} 65+\varepsilon_{8}
\end{aligned}
$$


- Equações para a variável latente independente:

$$
\begin{aligned}
& x_{1}=b_{1} \text { Ind } 60+\delta_{1} \\
& x_{2}=b_{2} \text { Ind } 60+\delta_{2} \\
& x_{3}=b_{3} \text { Ind } 60+\delta_{3}
\end{aligned}
$$

Temos também que:

$$
\begin{aligned}
& \operatorname{var}(\text { Ind60 })=\phi_{\text {Ind60 }} \\
& \operatorname{var}\left(\zeta_{1}\right)=\psi_{11} \\
& \operatorname{var}\left(\zeta_{2}\right)=\psi_{22} \\
& \operatorname{cov}\left(\zeta_{1}, \zeta_{2}\right)=\psi_{12}=\psi_{21}
\end{aligned}
$$

Matricialmente, temos os modelos:

- Modelo estrutural:

$$
\left(\begin{array}{l}
\mathrm{DP} 60 \\
\mathrm{DP} 65
\end{array}\right)=\left(\begin{array}{cc}
0 & 0 \\
c_{1} & 0
\end{array}\right)\left(\begin{array}{c}
\mathrm{DP} 60 \\
\mathrm{DP} 65
\end{array}\right)+\left(\begin{array}{c}
d_{1} \\
d_{2}
\end{array}\right)(\operatorname{Ind60})+\left(\begin{array}{c}
\zeta_{1} \\
\zeta_{2}
\end{array}\right)
$$

- Modelo de mensuração para as variáveis latentes dependentes:

$$
\left(\begin{array}{l}
y_{1} \\
y_{2} \\
y_{3} \\
y_{4} \\
y_{5} \\
y_{6} \\
y_{7} \\
y_{8}
\end{array}\right)=\left(\begin{array}{ll}
a_{1} & 0 \\
a_{2} & 0 \\
a_{3} & 0 \\
a_{4} & 0 \\
0 & a_{5} \\
0 & a_{6} \\
0 & a_{7} \\
0 & a_{8}
\end{array}\right)\left(\begin{array}{l}
\mathrm{DP} 60 \\
\mathrm{DP} 65
\end{array}\right)+\left(\begin{array}{c}
\varepsilon_{1} \\
\varepsilon_{2} \\
\varepsilon_{3} \\
\varepsilon_{4} \\
\varepsilon_{5} \\
\varepsilon_{6} \\
\varepsilon_{7} \\
\varepsilon_{8}
\end{array}\right)
$$


- Modelo de mensuração para a variável latente independente:

$$
\begin{gathered}
\left(\begin{array}{c}
x_{1} \\
x_{2} \\
x_{3}
\end{array}\right)=\left(\begin{array}{l}
b_{1} \\
b_{2} \\
b_{3}
\end{array}\right)(\operatorname{Ind} 60)+\left(\begin{array}{c}
\delta_{1} \\
\delta_{2} \\
\delta_{3}
\end{array}\right) \\
\Phi=\phi_{\text {Ind } 60}
\end{gathered}
$$

e

em que

$$
\Psi=\left(\begin{array}{ll}
\psi_{11} & \psi_{12} \\
\psi_{21} & \psi_{22}
\end{array}\right)
$$

$a_{1}, \ldots, a_{8}$ : representam o impacto das variáveis latentes dependentes (DP60 e DP65) nas variáveis observadas $y_{1}, \ldots, y_{8}$;

$b_{1}, b_{2}, b_{3}$ : representam o impacto da variável latente independente (Ind60) nas variáveis observadas $x_{1}, x_{2}$ e $x_{3}$;

$c_{1}$ : efeito direto da variável latente dependente (DP60) em outra variável latente dependente (DP65);

$d_{1}, d_{2}$ : representam o efeito direto da variável latente independente (Ind60) em variáveis latentes dependentes (DP60 e DP65);

$\varepsilon_{1}, \ldots, \varepsilon_{8}$ : erros de mensuração das variáveis observadas $y_{1}, \ldots, y_{8}$, respectivamente;

$\delta_{1}, \delta_{2}, \delta_{3}$ : erros de mensuração das variáveis observadas $x_{1}, x_{2}$ e $x_{3}$, respectivamente;

$\zeta_{1}, \zeta_{2}$ : erros da equação estrutural;

$\Phi$ : matriz de covariância da variável latente independente Ind60;

$\Psi$ : matriz de covariância dos erros nas equações estruturais (ou seja, dos $\zeta$ 's).

Na Figura 2.6, apresenta-se o diagrama de caminho para o Estudo dos Agricultores Familiares (Exemplo 5). 
Figura 2.6. Diagrama de Caminho para o Estudo dos Agricultores Familiares.

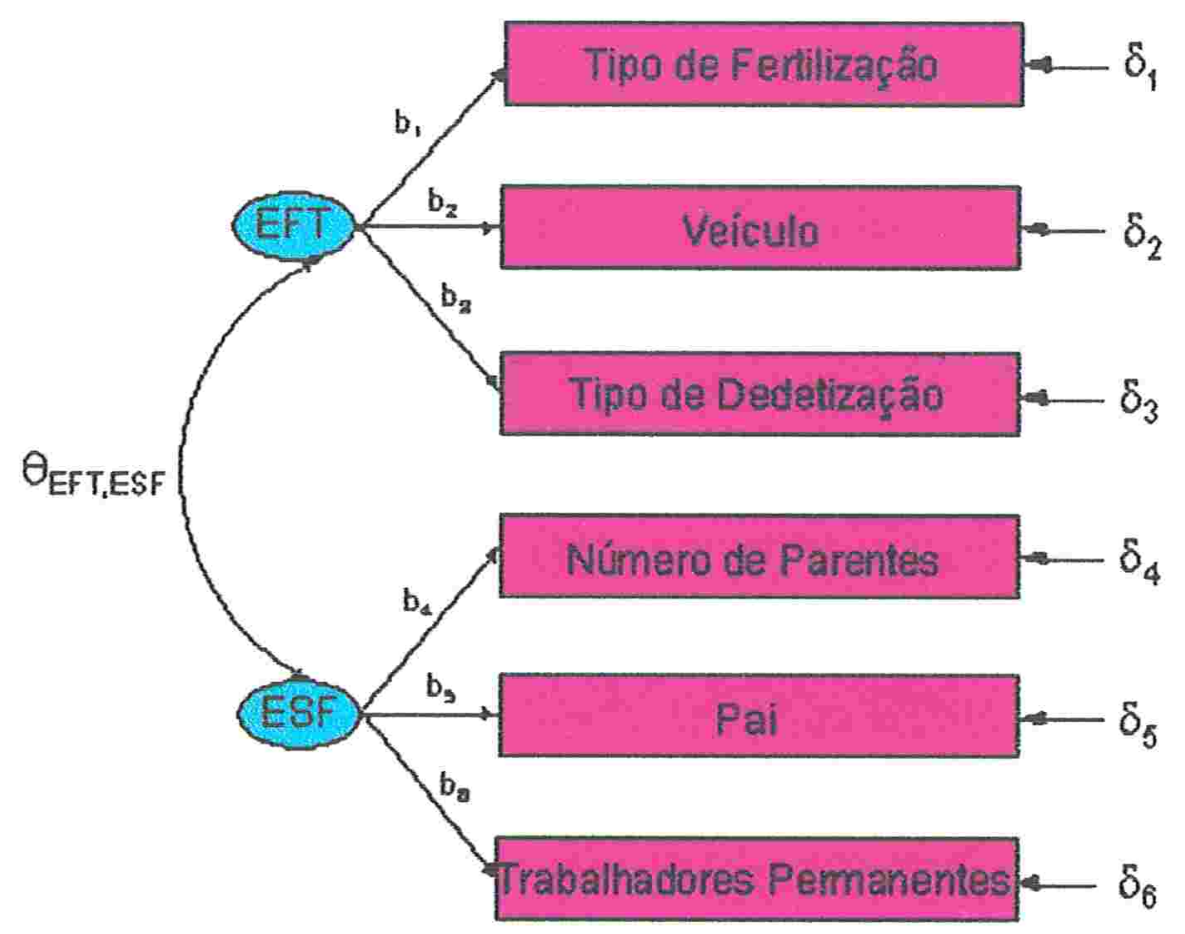

Pela Figura 2.6 temos que nenhuma variável latente recebe influência direta de outra, então, EFT e ESF são variáveis latentes independentes. E, com isso, este estudo é composto apenas de equações de mensuração:

Tipo de Fertilização $=b_{1}$ EFT $+\delta_{1}$

Veículo $=b_{2} \mathrm{EFT}+\delta_{2}$

Tipo de Dedetização $=b_{3} \mathrm{EFT}+\delta_{3}$

Número de Parentes $=b_{4} \mathrm{ESF}+\delta_{4}$

$\mathrm{Pai}=b_{5} \mathrm{ESF}+\delta_{5}$ 
Trabalhadores Permanentes $=b_{6}$ ESF $+\delta_{6}$

Temos também que:

$\operatorname{var}(\mathrm{EFT})=\phi_{\mathrm{EFT}}$

$\operatorname{var}(\mathrm{ESF})=\phi_{\mathrm{ESF}}$

$\operatorname{cov}(\mathrm{EFT}, \mathrm{ESF})=\phi_{\mathrm{EFT}, \mathrm{ESF}}$

$\operatorname{corr}(\mathrm{EFT}, \mathrm{ESF})=\theta_{\mathrm{EFT}, \mathrm{ESF}}$

Matricialmente, temos o seguinte modelo de mensuração:

$$
\begin{gathered}
\left(\begin{array}{c}
\text { Tipo de Fertilização } \\
\text { Veículo } \\
\text { Tipo de Dedetização } \\
\text { Número de Parentes } \\
\text { Pai } \\
\text { Trabalhadores Permanentes }
\end{array}\right)=\left(\begin{array}{cc}
b_{1} & 0 \\
b_{2} & 0 \\
b_{3} & 0 \\
0 & b_{4} \\
0 & b_{5} \\
0 & b_{6}
\end{array}\right)\left(\begin{array}{c}
\text { EFT } \\
\text { ESF }
\end{array}\right)+\left(\begin{array}{c}
\delta_{1} \\
\delta_{2} \\
\delta_{3} \\
\delta_{4} \\
\delta_{5} \\
\delta_{6}
\end{array}\right) \\
\Phi=\left(\begin{array}{cc}
\phi_{E F T} & \phi_{E F T, E S F} \\
\phi_{E S F}
\end{array}\right)
\end{gathered}
$$

e

$$
\Theta=\left(\begin{array}{cc}
1 & \theta_{E F T, E S F} \\
& 1
\end{array}\right)
$$

em que

$b_{1}, \ldots, b_{6}$ : representam o impacto das variáveis latentes independentes EFT e ESF nas variáveis observadas (Tipo de Fertilização, Veículo, Tipo de Dedetização, Número de Parentes, Pai e Trabalhadores Permanentes); 
$\delta_{1}, \ldots, \delta_{6}$ : erros de mensuração das variáveis observadas (Tipo de Fertilização, Veículo, Tipo de Dedetização, Número de Parentes, Pai e Trabalhadores Permanentes, respectivamente);

$\Phi:$ matriz de covariância das variáveis latentes independentes EFT e ESF;

$\Theta$ : matriz de correlação das variáveis latentes independentes EFT e ESF.

\subsection{Modelos}

A modelagem de equações estruturais engloba uma grande classe de modelos, dependendo da aplicação desejada, ou seja, há um modelo para análise fatorial confirmatória, outro para MANOVA, entre outros.

Nas Subseções 2.2.1 a 2.2.4 apresentamos alguns modelos de equações estruturais e suas suposições.

\subsubsection{Modelo Completo}

O modelo completo consiste de um sistema de equações estruturais, que tem dois subsistemas principais: o modelo de variáveis latentes (equações estruturais) e o modelo de mensuração. Ou seja, ele é formado pelas equações (2.1), (2.2) e (2.3):

$$
\begin{aligned}
\eta & =\mathrm{B} \eta+\Gamma \xi+\zeta \\
\mathrm{y} & =\Lambda_{y} \eta+\varepsilon \\
\mathrm{x} & =\Lambda_{x} \xi+\delta
\end{aligned}
$$

E, as suposições do modelo são:

- $E(\eta)=0$

- $E(\xi)=0$;

- $E(\zeta)=0$ 
- $\zeta$ e $\xi$ são não-correlacionados;

- (I - B) é não-singular;

- $E(\varepsilon)=0$;

- $E(\delta)=0$;

- $\varepsilon$ é não-correlacionado com $\eta, \xi$ e $\delta$;

- $\delta$ é não-correlacionado $\operatorname{com} \xi, \eta$ e $\varepsilon$.

Portanto, podemos verificar que:

1. $\Phi_{(n \times n)}=E\left(\xi \xi^{\prime}\right)$;

2. $\Psi_{(m \times m)}=E\left(\zeta \zeta^{\prime}\right)$;

3. $\Theta_{\varepsilon(p \times p)}=E\left(\varepsilon \varepsilon^{\prime}\right)$;

4. $\Theta_{\delta(q \times q)}=E\left(\delta \delta^{\prime}\right)$.

Assume-se também que uma variável latente endógena não tem influência direta sobre ela mesma, o que leva à diagonal principal da matriz $\mathrm{B}$ ser nula.

É possível mostrar também que a matriz de covariância de $\mathrm{z}=\left(\mathrm{y}^{\prime}, \mathrm{x}^{\prime}\right)^{\prime}$ de dimensão $(p+q) \times(p+q)$ para o modelo completo é dada por:

$$
\Sigma(\theta)=\left(\begin{array}{cc}
\Lambda_{y}(\mathrm{I}-\mathrm{B})^{-1}\left(\Gamma \Phi \Gamma^{\prime}+\Psi\right)\left(\mathrm{I}-\mathrm{B}^{\prime}\right)^{-1} \Lambda_{y}^{\prime}+\Theta_{\varepsilon} & \Lambda_{y}(\mathrm{I}-\mathrm{B})^{-1} \Gamma \Phi \Lambda_{x}^{\prime} \\
\Lambda_{x} \Phi \Gamma^{\prime}\left(\mathrm{I}-\mathrm{B}^{\prime}\right)^{-1} \Lambda_{y}^{\prime} & \Lambda_{x} \Phi \Lambda_{x}^{\prime}+\Theta_{\delta}
\end{array}\right)
$$

em que $\theta$ é um vetor de dimensão $t \times 1$ de parâmetros livres (coeficientes que acompanham as variáveis latentes nas equações estruturais e de mensuração, variâncias e covariâncias das variáveis latentes independentes, erros de mensuração e erros das equações estruturais). 


\subsubsection{Análise Fatorial}

Utilizamos Análise Fatorial quando temos algumas variáveis de interesse teórico que não podem ser diretamente observadas, ou seja, informações sobre elas podem ser obtidas indiretamente observando seus efeitos em variáveis observáveis. Em outras palavras, análise fatorial é um procedimento estatístico para revelar um pequeno número de variáveis latentes através do estudo da covariância entre um conjunto de variáveis observáveis.

\section{Análise Fatorial Exploratória (AFE) x Análise Fatorial Confirmatória (AFC)}

$\mathrm{Na}$ AFE, o pesquisador não especifica a estrutura da relação entre as variáveis no modelo, ou seja, ele deve assumir as seguintes restrições:

1. todas as variáveis latentes podem ser correlacionadas (ou, em alguns tipos de AFE, todas variáveis latentes são não-correlacionadas);

2. todas as variáveis observadas podem ser diretamente afetadas por todas as variáveis latentes;

3. os erros são não-correlacionados entre si;

4. todas as variáveis observadas são afetadas por um erro;

5. todas as variáveis latentes são não-correlacionadas com todos os erros.

$\mathrm{Na} A \mathrm{FC}$, o pesquisador impõe as restrições de acordo com seu conhecimento sobre o que se está estudando. Estas restrições determinam:

1. quais pares de variáveis latentes são correlacionadas;

2. quais variáveis observadas são afetadas por quais variáveis latentes;

3. quais variáveis observadas são afetadas por um erro;

4. quais pares de erros são correlacionados. 
Além disso, na $\mathrm{AFC}$, podem ser realizados testes estatísticos para determinar se os dados amostrais são consistentes com as restrições impostas, ou seja, se os dados confirmam o modelo gerado de acordo com o conhecimento do pesquisador na área.

Figura 2.7. Exemplo de Diagrama de Caminho para Análise Fatorial Exploratória.

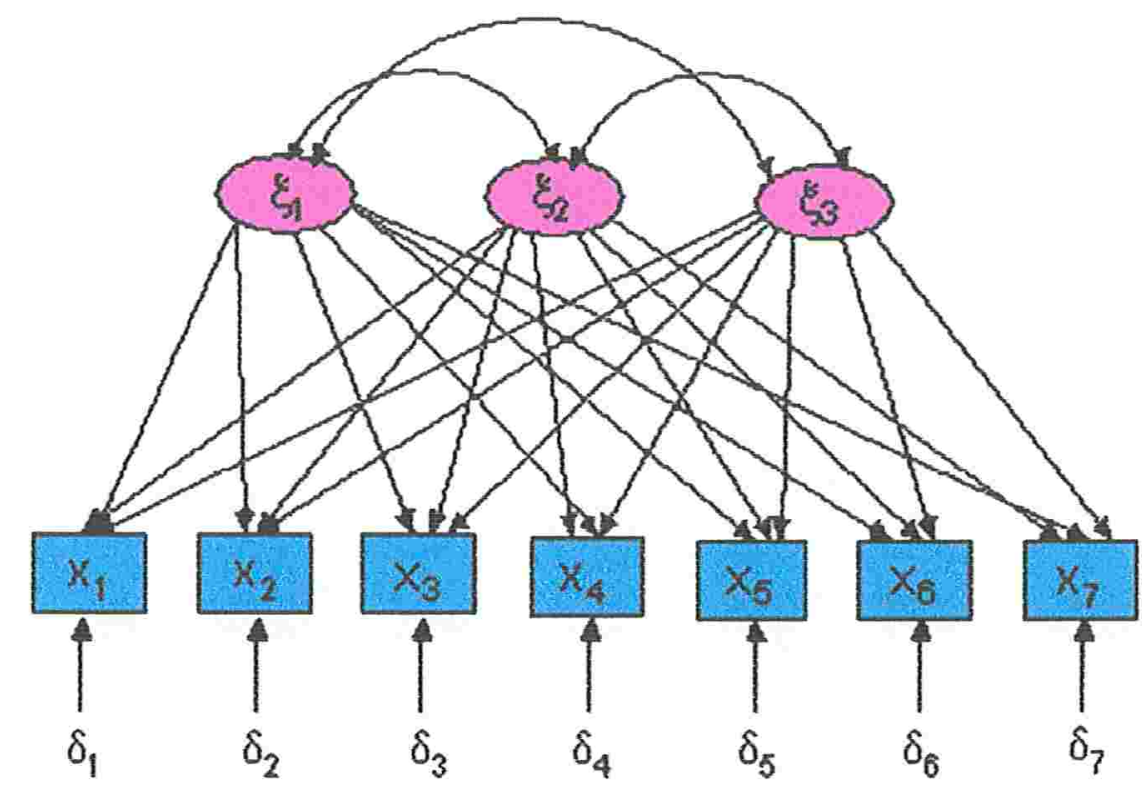


Figura 2.8. Exemplo de Diagrama de Caminho para Análise Fatorial Confirmatória.

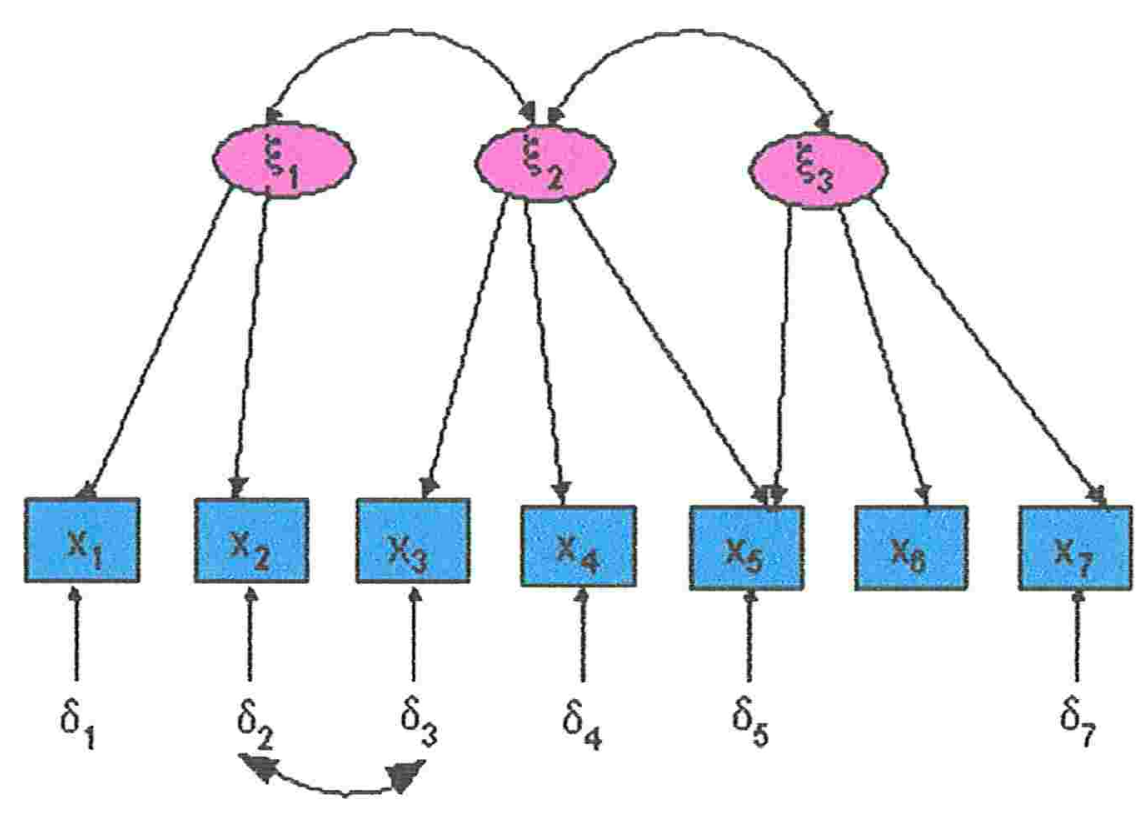

Podemos observar a diferença entre os modelos de análise fatorial exploratória e confirmatória comparando as Figuras 2.7 e 2.8. No modelo exploratório, todas as variáveis latentes podem ser correlacionadas (ou alternativamente, todas são não-correlacionadas), enquanto no modelo confirmatório as variáveis latentes $\xi_{1}$ e $\xi_{3}$ são não-correlacionadas. No modelo confirmatório pode-se impor que as variáveis observáveis não sejam afetadas por todas as variáveis latentes, ao passo que no modelo fatorial exploratório inicial todas as variáveis observáveis são afetadas por todas as variáveis latentes. Na Figura 2.8 (AFC), dois erros são correlacionados e uma das variáveis observáveis não está asssociada a nenhum crro, cnquanto na Figura 2.7 (AFE) todos os crros são não-correlacionados c um crro ć 
associado com cada variável observável.

\section{Análise Fatorial Confirmatória de $2^{\mathrm{a}}$ Ordem}

O exemplo de AFC apresentado na Figura 2.8 é também conhecido como Análise Fatorial Confirmatória de $1^{\underline{a}}$ Ordem. Nesta seção, será apresentado o modelo de Análise Fatorial de $2^{\text {a }}$ Ordem.

Este modelo é composto apenas pelas equações (2.1) e (2.2) do modelo completo, ou seja:

$$
\begin{aligned}
\eta & =\mathrm{B} \eta+\Gamma \xi+\zeta \\
\mathrm{y} & =\Lambda_{y} \eta+\varepsilon
\end{aligned}
$$

com as mesmas suposições anteriores.

É um modelo no qual fatores de segunda ordem $(\xi)$ são explicados por fatores de primeira ordem $(\eta)$ os quais são mensurados através de variáveis observadas (y).

Temos uma aplicação da análise fatorial confirmatória de segunda ordem, por exemplo, quando queremos mensurar a imagem de uma loja (fator de segunda ordem) através da Atmosfera, Preços competitivos, Variedade de produtos, Qualidade dos produtos e da Clientela (fatores de primeira ordem), os quais são mensurados através de algumas variáveis observáveis (Latif, 2000). O diagrama de caminho correspondente a essa aplicação apresenta-se na Figura 2.9. 
Figura 2.9. Diagrama de caminho para análise fatorial confirmatória de segunda ordem.

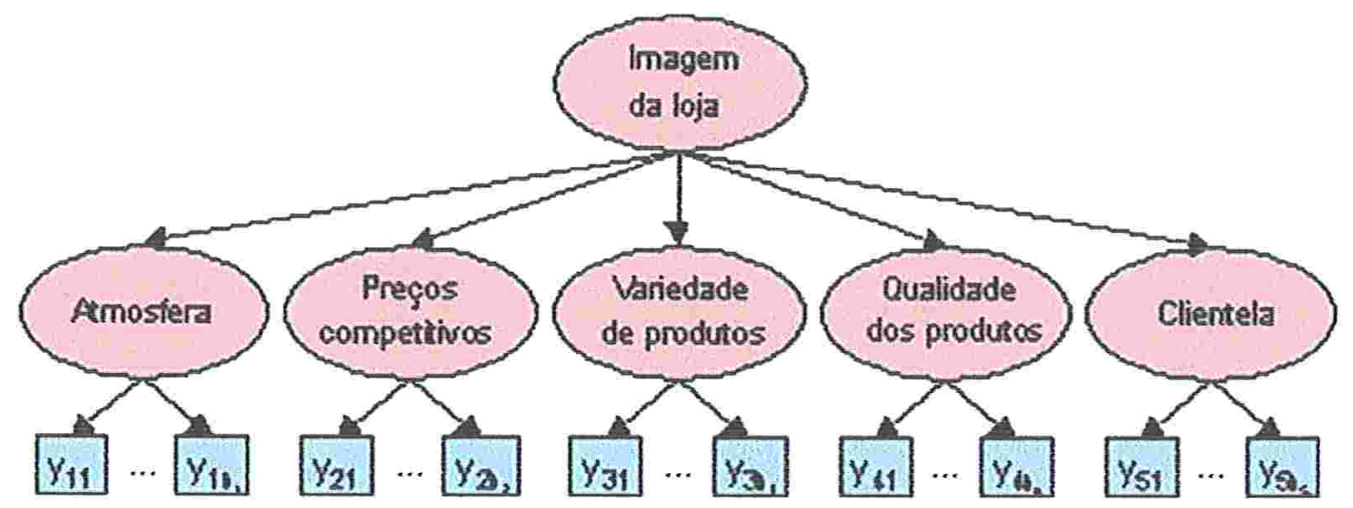

\subsubsection{Modelo para análise de várias amostras independentes}

Neste caso, utiliza-se um modelo completo para cada amostra (Bollen, 1989b). Portanto, para a $k$-ésima amostra, temos:

$$
\begin{aligned}
\eta & =\mathbf{B}^{(k)} \eta+\Gamma^{(k)} \xi+\zeta \\
\mathrm{x} & =\Lambda_{x}^{(k)} \xi+\delta \\
\mathbf{y} & =\Lambda_{y}^{(k)} \eta+\varepsilon
\end{aligned}
$$

Este modelo é utilizado quando queremos saber se os modelos de mensuração ou de equações estruturais de dois grupos apresentam os mesmos valores para os parâmetros. Por 
exemplo, podemos utilizar esse modelo para verificar se as empresas com e sem programa de treinamento têm a mesma relação positiva entre anos de trabalho e desempenho.

\subsubsection{Modelo completo com estrutura de médias}

Neste modelo, as variáveis aleatórias passam a não ter mais média zero e, mais quatro novos vetores de parâmetros são acrescidas ao modelo (Bollen, 1989b).

$$
\begin{gathered}
\eta=\alpha+\mathrm{B} \eta+\Gamma \xi+\zeta \\
\mathrm{x}=\tau_{x}+\Lambda_{x} \xi+\delta \\
\mathrm{y}=\tau_{y}+\Lambda_{y} \eta+\varepsilon
\end{gathered}
$$

onde $\alpha_{(m \times 1)}, \tau_{x(q \times 1)}$ e $\tau_{y(p \times 1)}$ são vetores de interceptos.

As suposições que se alteram são:

- $E(\xi)_{(n \times 1)}=\kappa$

- $E(\eta)_{(m \times 1)}=(\mathbf{I}-\mathrm{B})^{-1}(\alpha+\Gamma \kappa)$

$\mathrm{E}$, assim temos que os vetores de médias de $\mathrm{x}$ e $\mathrm{y}$ são:

- $E(\mathrm{x})_{(q \times 1)}=\tau_{x}+\Lambda_{x} \kappa$

- $E(\mathrm{y})_{(p \times 1)}=\tau_{y}+\Lambda_{y}(\mathrm{I}-\mathrm{B})^{-1}(\alpha+\Gamma \kappa)$

\subsection{Identificabilidade}

A identificabilidade é um tópico muito importante para todos os modelos de equações estruturais. Inicialmente, vamos definir o que são parâmetros "conhecidos" e "desconhecidos". 
Segundo Bollen (1989b), parâmetros "conhecidos" geralmente são características populacionais da distribuição das variáveis observadas, tais como suas variâncias e covariâncias que possuem estimadores consistentes e então para os quais a identificabilidade não é um problema. E, por sua vez, parâmetros "desconhecidos" são aqueles para os quais o "status" de identificabilidade não é conhecido (neste caso, o pesquisador deve estabelecer se existem valores únicos para eles).

Os parâmetros "desconhecidos" (parâmetros que vêm do modelo estrutural) são ditos identificáveis se eles forem funções apenas de parâmetros identificáveis e se essas funções levarem a soluções únicas.

Por exemplo, vamos supor que var(y) seja um parâmetro identificável, $\theta_{1}$ e $\theta_{2}$ sejam parâmetros "desconhecidos" e que a função que relaciona os parâmetros "desconhecidos" com o parâmetro identificável seja var $(\mathrm{y})=\theta_{1}+\theta_{2}$ (Bollen, 1989b). Para que $\theta_{1}$ e $\theta_{2}$ sejam identificáveis precisamos que a função apresentada leve a soluções únicas para ambos, o que claramente não ocorre já que temos dois parâmetros "desconhecidos" e apenas uma função (equação). Entretanto, se tivéssemos uma segunda equação da forma $\theta_{1}=\theta_{2}$, a identificabilidade estaria garantida $\operatorname{com} \theta_{1}=\theta_{2}=\operatorname{var}(\mathrm{y}) / 2$.

Em geral, podemos definir que parâmetros "conhecidos" são os elementos de $\Sigma$ (matriz de covariância populacional das variáveis observadas) e que parâmetros "desconhecidos" estão contidos em $\theta$ (vetor que contém t parâmetros livres de $B, \Gamma, \Phi$ e $\Psi$ (definidos anteriormente na página 18)). Assim, a equação que relaciona $\Sigma$ e $\theta$ é a seguinte hipótese sobre a estrutura de covariância: $\Sigma=\Sigma(\theta)$.

Portanto, uma definição alternativa de identificabilidade é dada considerando dois vetores $\theta_{1}$ e $\theta_{2}$ de dimensão $t \times 1$. As matrizes de covariância impostas pelo modelo são $\Sigma\left(\theta_{1}\right)$ e $\Sigma\left(\theta_{2}\right)$, respectivamente. Dizemos que o modelo é identificável se todas as soluções de $\theta_{1}$ e $\theta_{2}$ tais que $\Sigma\left(\theta_{1}\right)=\Sigma\left(\theta_{2}\right)$ implicarem $\theta_{1}=\theta_{2}$.

Note que a estrutura de covariância $\boldsymbol{\Sigma}=\boldsymbol{\Sigma}(\boldsymbol{\theta})$ implica em $\frac{1}{2}(p+q)(p+q+1)$ equações distintas da forma $\sigma_{i j}=\sigma_{i j}(\theta)(i \leq j)$, onde $\sigma_{i j}$ é o $i j$-ésimo elemento de $\Sigma$ e $\sigma_{i j}(\theta)$ é o $i j$-ésimo elemento de $\boldsymbol{\Sigma}(\boldsymbol{\theta})$. Logo, se um elemento de $\theta$ pode ser escrito com uma função de um ou mais elementos de $\sigma_{i j}$, então ele é identificável. E, se todos os elementos de $\theta$ 
satisfizerem essa condição, o modelo é identificável.

A seguir vamos apresentar algumas condições para checar a identificabilidade do modelo.

\subsubsection{Regra $t$}

Esta regra é uma condição necessária de identificabilidade, mas não é suficiente. Baseiase no fato de que temos $\frac{1}{2}(p+q)(p+q+1)$ equações distintas como conseqüência da estrutura de covariância $\Sigma=\Sigma(\theta)$. Note que se o número de parâmetros "desconhecidos" em $\theta$ for maior que o número de equações, a identificabilidade não é possível. Portanto, a regra t é dada pela seguinte condição:

$$
t<\frac{1}{2}(p+q)(p+q+1)
$$

em que, como definidos anteriormente, $t$ é o número de parâmetros livres, $p$ é o número de variáveis observadas dos $\eta$ 's (variáveis latentes dependentes) e $q$ é o número de variáveis observadas dos $\xi$ 's (variáveis latentes independentes).

\subsubsection{Regra Dois-Passos}

No primeiro passo, deve-se tratar o modelo como uma análise fatorial confirmatória, ou seja, os elementos de $\boldsymbol{\xi}$ e de $\boldsymbol{\eta}$ devem ser tratados como variáveis latentes independentes (isto é, como $\xi$ 's) e, conseqüentemente, os elementos de $\mathrm{x}$ e de $\mathrm{y}$ devem ser tratados como variáveis observadas dos $\xi$ 's (isto é, como variáveis $x$ ). Portanto, teremos a seguinte equação:

$$
\mathrm{x}=\Lambda_{x} \xi+\delta
$$

Assim, devemos verificar se esse modelo de análise fatorial confirmatória é identificável. Para que este modelo seja identificável, devemos analisar se existe solução única para os parâmetros estruturais em $\Lambda_{x}, \Phi$ e $\Theta_{\delta}$. 
Basicamente, existem 3 regras para verificar a identificabilidade de um modelo de análise fatorial confirmatória:

1. Regra t: análoga à regra já apresentada e, assim como já foi dito, é uma condição necessária mas não é suficiente;

2. Regra Três-Indicadores: as condições suficientes para que o modelo seja identificável são (a) três ou mais indicadores por variável latente, (b) cada linha de $\Lambda_{x}$ com um e somente um elemento diferente de zero, e (c) $\Theta_{\delta}$ diagonal;

3. Regra Dois-Indicadores : assim como na regra anterior, $\Theta_{\delta}$ deve ser diagonal. Além disso, um $\lambda_{i j}$ deve ser fixado como 1 para cada $\xi_{j}$. Sob estas condições, se tivermos dois indicadores (variáveis observadas) por variável latente é suficiente para a identificabilidade do modelo em (2.8) contanto que não haja elementos nulos em $\Phi$.

Se o modelo de análise fatorial confirmatória for identificável, devemos seguir para o segundo passo. No segundo passo, iremos examinar as equações estruturais (isto é, $\eta=\mathrm{B} \eta+\Gamma \xi+\zeta)$ e tratá-las como equações estruturais com variáveis observadas. Ou seja, iremos assumir que cada variável latente é uma variável obervada perfeitamente mensurável (isto é, a equação estrutural fica dada por $\mathrm{y}=\mathrm{By}+\Gamma \mathrm{x}+\zeta$ ). E, então, devemos determinar se $B, \Gamma$ e $\Phi$ são identificáveis utilizando as seguintes regras:

1. Regra t: mesma regra já apresentada e, assim como já foi dito, é uma condição necessária mas não é suficiente;

2. Regra da B Nula: se B $=0$, então as matrizes $\Phi, \Gamma$ e $\Psi$ podem ser escritas como funções das matrizes de covariância das variáveis observadas e, portanto, elas serão identificáveis; esta regra é uma condição suficiente para a identificabilidade, mas não é necessária; 
3. Regra Recursiva: se a matriz B for triangular inferior e $\Psi$ for diagonal, temos que o modelo é identificável; esta regra também é uma condição suficiente, porém não é necessária;

4. Condição de Ordem: seja $\mathbf{C}=[(\mathbf{I}-\mathbf{B}),-\boldsymbol{\Gamma}]$; se cada linha desta matriz tiver $(p-1)$ ou mais zeros, o modelo é identificável; esta regra é uma condição necessária, porém não é suficiente;

5. Condição do Posto: consideremos novamente a matriz C; para verificar a identificabilidade da $i$-ésima equação, devemos eliminar todas as colunas de $\mathbf{C}$ que não tiverem zeros na $i$-ésima linha de $\mathbf{C}$ e, com as colunas restantes formamos uma nova matriz $\mathrm{C}_{i}$; assim, uma condição necessária e suficiente para que a $i$-ésima equação seja identificável é que o posto de $\mathrm{C}_{i}$ seja igual a $(p-1)$ e, portanto, se todas as equações satisfizerem esta condição, o modelo é identificável.

Portanto, pela regra dois-passos temos que se o primeiro passo mostra que os parâmetros de mensuração são identificáveis e o segundo passo mostra que os parâmetros das equações estruturais também são identificáveis, então isto é suficiente para que o modelo seja identificável.

Agora vamos voltar ao Estudo de Wheaton (Exemplo 1) para tentarmos entender melhor as regras para verificar a identificabilidade do modelo.

Vamos utilizar a regra dois-passos. Inicialmente, devemos tratar o modelo como uma análise fatorial confirmatória (ver página 47). Ou seja, teremos: 


$$
\left(\begin{array}{c}
\text { Educação } \\
\text { SEI } \\
\text { Anomia67 } \\
\text { Incapacidade67 } \\
\text { Anomia71 } \\
\text { Incapacidade71 }
\end{array}\right)=\left(\begin{array}{ccc}
b_{1} & 0 & 0 \\
b_{2} & 0 & 0 \\
0 & a_{1} & 0 \\
0 & a_{2} & 0 \\
0 & 0 & a_{3} \\
0 & 0 & a_{4}
\end{array}\right)\left(\begin{array}{c}
\text { SES } \\
\text { Alienação67 } \\
\text { Alienação71 }
\end{array}\right)+\left(\begin{array}{c}
\delta_{1} \\
\delta_{2} \\
\delta_{3} \\
\delta_{4} \\
\delta_{5} \\
\delta_{6}
\end{array}\right)
$$

Notemos que a regra três-indicadores não está satisfeita para este caso, pois embora tenhamos apenas um elemento diferente de zero em cada linha de $\Lambda_{x}$ e $\Theta_{\delta}$ seja diagonal devido às suposições do modelo completo (ver página 38), não temos três ou mais indicadores por variável latente.

Agora, se fixarmos $b_{1}=a_{1}=a_{3}=1$, como temos que $\Theta_{\delta}$ é diagonal e também temos dois indicadores por variável latente, temos pela regra dois-passos que o modelo de análise fatorial confirmatória é identificável.

O segundo passo é tratar as equações estruturais como equações estruturais com variáveis observadas (ver página 48). Notemos que nem a regra B nula e nem a regra recursiva estão satisfeitas, pois a matriz $\mathbf{B}$ não é nula e nem triangular inferior (ver página 22).

Agora, note que:

$$
\begin{aligned}
\mathbf{C} & =[(\mathbf{I}-\mathbf{B}),-\boldsymbol{\Gamma}] \\
& =\left(\begin{array}{ccc}
1 & 0 & -d_{1} \\
-c_{1} & 1 & -d_{2}
\end{array}\right)
\end{aligned}
$$

Note que para este estudo temos que $p=2$, pois temos duas variáveis latentes dependentes (Alienação67 e Alienação71). Então, a condição de ordem não está satisfeita pois a segunda linha da matriz C não contém zeros. Mas, vimos que esta condição é apenas necessária e não é suficiente. Portanto, vamos verificar se a condição do posto está satisfeita. 
Eliminando as colunas de $\mathrm{C}$ que não têm zeros na primeira linha, formamos o seguinte vetor:

$$
\mathrm{C}_{1}=\left(\begin{array}{l}
0 \\
1
\end{array}\right)
$$

que tem posto igual a $1(=p-1)$.

Como na segunda linha não temos zeros, temos que $\mathrm{C}_{2}=\emptyset \mathrm{e}$, portanto, tem posto igual a 0. Logo, a condição do posto só está satisfeita para a primeira linha.

Então, não podemos afirmar que o modelo é identificável. Só para mostrar como se utiliza a regra t, vamos verificar se esta condição está safisfeita para o Estudo de Wheaton.

Vimos anteriormente na página 39 que $t$ é a soma do número de coeficientes que acompanham as variáveis latentes nas equações estruturais e de mensuração, do número de variâncias e covariâncias das variáveis latentes independentes e dos erros de mensuração e das equações estruturais. No modelo apresentado na página 22 pode-se observar que temos 8 variâncias dos erros de mensuração e das equações estruturais (ou seja, $\operatorname{var}\left(\varepsilon_{1}\right), \ldots, \operatorname{var}\left(\varepsilon_{4}\right)$, $\left.\operatorname{var}\left(\delta_{1}\right), \operatorname{var}\left(\delta_{2}\right), \operatorname{var}\left(\zeta_{1}\right), \operatorname{var}\left(\zeta_{2}\right)\right)$. Temos também 6 coeficientes nas equações estruturais e de mensuração (apenas $c_{1}, d_{1}, d_{2}, a_{2}, a_{4}$ e $b_{2}$, já que $a_{1}, a_{3}$ e $b_{1}$ foram fixadas como 1 para garantir a identificabilidade do modelo) e 1 variância da variável latente independente SES. Portanto, temos que $t=15$.

Temos 4 variáveis observadas das variáveis latentes dependentes e, assim $p=4$. Ainda temos 2 variáveis observadas da variável latente independente e, então, $q=2$. Portanto, a regra t está satisfeita pois $t<\frac{1}{2}(p+q)(p+q+1)=21$. 


\section{Capítulo 3}

\section{Estimação}

Em geral, as teorias supõem que as variáveis observadas devem ser quantitativas pois elas representam medidas, que são aproximadamente de escala intervalar. Se essas variáveis têm distribuição aproximada normal, utilizam-se as estimativas dos parâmetros obtidas através do método de máxima verossimilhança (MV) ou de mínimos quadrados generalizados (GLS) e seus respectivos erros padrões e medidas de qualidade de ajuste qui-quadrado.

Quando há não-normalidade moderada, os métodos de MV e de GLS ainda podem ser utilizados, mas a interpretação das estimativas deve ser feita com cautela. De um modo geral, define-se dois tipos de não-normalidade:

- Quando pelo menos uma variável não é contínua. Nesse caso, recomenda-se utilizar o método de mínimos quadrados ponderados generalizados (WLS) usando uma matriz de pesos adequada. Quando temos variáveis observadas categóricas, temos alguns problemas: 


$$
\begin{aligned}
\mathrm{y} & \neq \Lambda_{y} \eta+\varepsilon \\
\mathrm{x} & \neq \Lambda_{x} \xi+\delta \\
\Sigma & \neq \Sigma(\theta) \\
A \operatorname{Cov}\left(s_{i j}, s_{g h}\right) & \neq A \operatorname{Cov}\left(s_{i j}^{*}, s_{g h}^{*}\right)
\end{aligned}
$$

em que

y e x: vetores de variáveis observadas categóricas das variáveis latentes dependentes e independentes, respectivamente;

$\Sigma$ : matriz de covariância populacional das variáveis observadas categóricas;

$\Sigma(\theta)$ : matriz de covariância com estrutura imposta pelo modelo;

$A \operatorname{Cov}\left(s_{i j}, s_{g h}\right)$ e $A \operatorname{Cov}\left(s_{i j}^{*}, s_{g h}^{*}\right):$ covariâncias assintóticas entre $s_{i j}$ e $s_{g h}$ e, entre $s_{i j}^{*}$ e $s_{g h}^{*}$, respectivamente;

$s_{i j}$ e $s_{g h}$ : elementos da matriz de covariância amostral das variáveis observadas categóricas;

$s_{i j}^{*}$ e $s_{g h}^{*}$ : elementos da matriz de covariância amostral dos indicadores contínuos latentes.

Note que (3.1) e (3.2) se devem ao fato de que nos modelos de equações estruturais supõe-se que as variáveis latentes e observadas são contínuas (em geral, normais) e, ao utilizarmos variáveis categóricas estaremos agrupando as medidas das observações e perdendo precisão. Por exemplo, se considerarmos $y_{1}^{*}$ uma variável contínua com distribuição normal e $y_{1}$ uma variável ordinal que agrupa os valores de $y_{1}^{*}$ em 4 categorias, então teremos que $\mathrm{y} \neq \mathrm{y}^{*}$ em pelo menos uma linha dos vetores, o que leva a (3.1).

A violação da hipótese de estrutura de covariância (descrita anteriormente na página 46) ocorre porque assumimos que $\Sigma^{*}$ (matriz de covariância populacional dos indi- 
cadores contínuos latentes $\mathrm{y}^{*}$ e $\left.\mathrm{x}^{*}\right)$ segue a estrutura imposta, ou seja, que $\Sigma^{*}=\Sigma(\theta)$ e, em geral, temos que $\Sigma \neq \Sigma^{*}$.

Por fim, (3.4) ocorre porque, em geral, a distribuição das variáveis observadas categóricas difere da distribuição dos indicadores contínuos latentes.

Para tentar corrigir o mais importante dos problemas (equação (3.3)), podemos estimar $\Sigma^{*}$ através das variáveis observadas categóricas. Para isso, deve-se assumir uma distribuição para os indicadores contínuos latentes (em geral, utiliza-se a multinormal) e, então podemos estimar as correlações para cada par de indicadores em $\mathrm{y}^{*}$ e $\mathrm{x}^{*}$ (vetores de indicadores contínuos latentes das variáveis latentes dependentes e independentes, respectivamente).

Se ambas as variáveis forem contínuas, podemos utilizar a correlação de Pearson. Caso contrário, devemos utilizar correlações especias "polychoric" (Jöreskog, 2001), "tetrachoric" (Harris, 1988), "polyserial" (Drasgow, 1988) ou "biserial" (Kraemer, 1982). Para maiores detalhes dessas correlações, ver Apêndice A.

- Quando as variáveis são contínuas (escala intervalar) e não-normais. Aqui pode-se usar o método de MV, GLS ou WLS. Se tivermos a disponibilidade de uma amostra pequena, o uso de WLS pode não ser adequado, pois a matriz de covariância assintótica das variâncias e covariâncias amostrais não seria estimada de forma acurada; portanto, sendo melhor a utilização de MV ou GLS.

\subsection{Estimação do modelo completo}

Considere que o modelo completo seja adequado para uma população de indivíduos. Define-se as seguintes matrizes:

$\mathrm{Z}_{(N \times k)}$ : matriz dos dados observados; 
$\mathbf{M}=\frac{1}{N} \mathbf{Z}^{\prime} \mathbf{Z}$ : matriz de momento em torno do zero;

$\mathbf{S}=\frac{1}{N-1}\left(\mathbf{Z}^{\prime} \mathbf{Z}-N \overline{\mathbf{Z}} \overline{\mathbf{Z}}^{\prime}\right)$ : matriz de covariância amostral;

$\mathrm{R}=\mathrm{D}^{-1} \mathrm{SD}^{-1}$ : matriz de correlação para variáveis contínuas, onde

$\mathbf{D}=(\operatorname{diagS})^{1 / 2}$ (quando alguma variável não é contínua, $\mathbf{R}$ é a matriz

de correlação "polychoric", "tetrachoric", "polyserial" ou "biserial") ;

$\overline{\mathbf{Z}}=\frac{1}{N} \mathbf{Z}^{\prime} 1$ : vetor de médias.

Em que:

$N$ : tamanho da amostra;

$k=p+q$ : número total de variáveis observadas.

Através das definições acima, pode-se chegar às seguintes relações entre as matrizes:

- $\mathrm{M}=\frac{N-1}{N} \mathrm{~S}+\overline{\mathrm{Z}} \overline{\mathrm{Z}}^{\prime}$

- $\mathrm{S}=\frac{N}{N-1}\left(\mathrm{M}-\overline{\mathrm{Z}} \overline{\mathrm{Z}}^{\prime}\right)$.

Os métodos clássicos de estimação dos coeficientes do modelo são: máxima verossimilhança (MV), mínimos quadrados generalizados (GLS) e mínimos quadrados nãoponderados (ULS). Nos próximos tópicos abordaremos as funções de estimação específicas de cada um desses métodos. 


\subsubsection{Função de ajustamento para o método de máxima verossi- milhança}

A função de ajustamento para MV parte do princípio de máxima verossimilhança que, nos pacotes estatísticos, baseia-se na suposição de que as variáveis observadas têm uma distribuição normal multivariada. Sua expressão é dada por:

$$
F_{M V}=\log |\Sigma(\theta)|+\operatorname{tr}\left(\mathbf{S} \Sigma^{-1}(\theta)\right)-\log |\mathrm{S}|-(\mathrm{p}+\mathrm{q})
$$

em que:

$\Sigma(\theta)$ : matriz de covariância populacional do modelo proposto;

$|\Sigma(\theta)|$ : determinante de $\Sigma(\theta)$;

$\operatorname{tr}\left(\mathbf{S} \boldsymbol{\Sigma}^{-1}(\theta)\right)$ : soma dos elementos diagonais de $\mathbf{S} \boldsymbol{\Sigma}^{-1}(\boldsymbol{\theta})$.

Os estimadores de MV de B, $\Gamma, \Phi$ e $\Psi$ (descritos anteriormente na página 18) são os que minimizam a função $F_{M V}$.

Temos que esses estimadores têm propriedades importantes:

- embora possam ser viciados, eles são assintoticamente não viciados;

- são consistentes;

- são assintoticamente eficientes;

- têm distribuição assintoticamente normal.

Temos também que $(N-1) F_{M V}$, avaliada nas estimativas obtidas, tem distribuição assintoticamente qui-quadrado com $(1 / 2)(p+q)(p+q+1)-t$ graus de liberdade (Bollen, 1989b), onde $t$ é o número de parâmetros livres (descrito anteriormente na página 39). 


\subsubsection{Função de ajustamento para o método de mínimos quadra- dos generalizados}

A função de ajustamento para GLS é dada por:

$$
F_{G L S}=\frac{1}{2} \operatorname{tr}\left(\left\{[\mathrm{S}-\Sigma(\theta)] \mathrm{W}^{-1}\right\}^{2}\right)
$$

onde $\mathrm{W}_{(k \times k)}^{-1}$ é uma matriz de pesos para a matriz residual. Essa matriz de pesos é uma matriz aleatória que converge em probabilidade para uma matriz positiva-definida quando $N \longrightarrow \infty$, ou é uma matriz positiva-definida de constantes.

Diversas matrizes de pesos $\mathrm{W}^{-1}$ são estimadores consistentes de $\Sigma^{-1}$, porém a escolha mais usual é $\mathbf{W}^{-1}=\mathbf{S}^{-1}$. Assim, (3.6) fica da seguinte forma:

$$
F_{G L S}=\frac{1}{2} \operatorname{tr}\left[\left(\mathbf{I}-\boldsymbol{\Sigma}(\boldsymbol{\theta}) \mathbf{S}^{-1}\right)^{2}\right],
$$

em que $\left(\mathbf{I}-\Sigma(\theta) \mathbf{S}^{-1}\right)^{2}=\left(\mathbf{I}-\Sigma(\theta) \mathbf{S}^{-1}\right)\left(\mathbf{I}-\boldsymbol{\Sigma}(\theta) \mathbf{S}^{-1}\right)$.

O estimador de GLS é uma aplicação direta do princípio de mínimos quadrados generalizados. As estimativas de GLS têm propriedades assintóticas similares às estimativas de MV e, sob suposição de normalidade multivariada, ambos os estimadores são ótimos por serem mais precisos em amostras grandes.

Os estimadores de GLS de B, $\Gamma, \Phi$ e $\Psi$ (descritos anteriormente na página 18) são os que minimizam a função $F_{G L S}$.

Temos que $(N-1) F_{G L S}$, avaliada nas estimativas obtidas, tem distribuição assintoticamente qui-quadrado com $(1 / 2)(p+q)(p+q+1)-t$ graus de liberdade, quando o modelo é correto.

As funções de estimação de MV ou GLS podem ser utilizadas para o cálculo de estimativas dos parâmetros do modelo mesmo quando a distribuição das variáveis observadas desvia-se da normal, porém, os erros padrões e as medidas de qualidade de ajuste quiquadrado devem ser interpretados com cautela. Entretanto, se a fuga da normalidade for grande, é melhor utilizarmos o método geral de mínimos quadrados ponderados generalizados (WLS). 


\subsubsection{Função de ajustamento para o método de mínimos quadra- dos não-ponderados}

A função de ajustamento para ULS é:

$$
F_{U L S}=\frac{1}{2} \operatorname{tr}\left[(\mathbf{S}-\Sigma(\theta))^{2}\right]
$$

que é um caso particular de $F_{G L S}$ com $\mathrm{W}^{-1}=\mathbf{I}$.

Os estimadores de ULS de B, $\Gamma, \Phi$ e $\Psi$ (descritos anteriormente na página 18) são os que minimizam a função $F_{U L S}$.

\subsubsection{Função de ajustamento global}

As funções de ajustamento apresentadas para MV, GLS e ULS são funções dos parâmetros independentes $\theta$. Além disso, as funções de ajustamento são sempre não negativas e só serão nulas no caso de um ajuste perfeito (ou seja, quando $\Sigma(\theta)=\mathrm{S}$ ).

As funções de ajustamento de modelos de equações estruturais são casos particulares de uma função de ajustamento global (Bollen, 1989b), que pode ser escrita como:

$$
F=(\mathbf{s}-\sigma(\theta))^{\prime} \mathbf{W}^{-1}(\mathbf{s}-\sigma(\theta))=\sum_{g=1}^{k} \sum_{h=1}^{g} \sum_{i=1}^{k} \sum_{j=1}^{i} w^{g h, i j}\left(s_{g h}-\sigma_{g h}\right)\left(s_{i j}-\sigma_{i j}\right),
$$

em que:

$\mathrm{s}_{(u \times u)}^{\prime}=\left(s_{11}, s_{21}, s_{22}, s_{31}, \ldots, s_{k k}\right)$ : vetor dos elementos da metade inferior (incluindo a diagonal) da matriz de covariância $\mathbf{S}_{(k \times k)}$ usada para ajustar o modelo aos dados;

$\sigma^{\prime}(\boldsymbol{\theta})_{(u \times u)}=\left(\sigma_{11}, \sigma_{21}, \sigma_{22}, \sigma_{31}, \ldots, \sigma_{k k}\right)$ : vetor dos elementos correspondentes de $\boldsymbol{\Sigma}(\boldsymbol{\theta})$ reproduzidos a partir dos parâmetros do modelo;

$w^{g h, i j}:$ elemento típico de uma matriz positiva-definida $\mathrm{W}_{(u \times u)}^{-1}$; $u=\frac{1}{2} k(k+1)$.

Deve-se tentar escolher W de tal forma que seus elementos típicos $w_{g h, i j}$ sejam estimativas consistentes da covariância assintótica entre $s_{g h}$ e $s_{i j}$.

No caso particular em que as variáveis observadas têm uma distribuição normal multivariada, ou em que S tem uma distribuição de Wishart, as teorias clássicas assumem que, 
para a estrutura de covariância, as variâncias e covariâncias assintóticas dos elementos de $\mathrm{S}$ são da forma:

$$
A \operatorname{Cov}\left(s_{g h}, s_{i j}\right)=\frac{1}{N}\left(\sigma_{g i} \sigma_{h j}+\sigma_{g j} \sigma_{h i}\right)
$$

em que:

$\mathrm{N}$ : tamanho total da amostra;

$A \operatorname{Cov}\left(s_{g h}, s_{i j}\right)$ : covariância assintótica entre $s_{g h}$ e $s_{i j}$.

Por exemplo, no método de GLS, os elementos de $\mathrm{W}^{-1}$ são da forma:

$$
w^{g h, i j}=N\left(2-\delta_{g h}\right)\left(2-\delta_{i j}\right)\left(s^{g i} s^{h j}+s^{g j} s^{h i}\right),
$$

onde $\delta_{g h}$ e $\delta_{i j}$ são deltas de Kronecker.

Uma generalização que tem sido utilizada no caso de não normalidade ou curtose excessiva para variáveis contínuas é:

$$
w_{g h, i j}=m_{g h i j}-s_{g h}^{*} s_{i j}^{*}
$$

onde $m_{g h i j}=\frac{1}{N} \sum_{a=1}^{N}\left(z_{a g}-\bar{z}_{g}\right)\left(z_{a h}-\bar{z}_{h}\right)\left(z_{a i}-\bar{z}_{i}\right)\left(z_{a j}-\bar{z}_{j}\right)$ são os momentos centrais amostrais de quarta ordem, $s_{g h}^{*}=\frac{N-1}{N} s_{g h}$ e $s_{i j}^{*}=\frac{N-1}{N} s_{i j}$.

Quando W é definida pela expressão geral (3.10), dizemos que a função de ajustamento é para o método de mínimos quadrados ponderados generalizados (WLS).

Assim como $F_{M V}$ e $F_{G L S}$, temos que $(N-1) F_{W L S}$ avaliada nas estimativas obtidas tem distribuição assintoticamente qui-quadrado com $\frac{1}{2}(p+q)(p+q+1)-t$ graus de liberdade.

Embora o método de WLS seja um bom método, na teoria, por ser assintoticamente livre de distribuição, ele apresenta algumas dificuldades práticas:

1. a matriz $\mathrm{W}$ é de ordem $u \times u$ e tem $\frac{1}{2} u(u+1)$ elementos distintos;

2. para estimar momentos de quarta ordem com uma precisão razoável, são necessárias amostras muito grandes; 
3. quando há observações perdidas ("missings"), momentos diferentes podem ser baseados em diferentes números de casos.

Portanto, têm sido realizados trabalhos de modo que possamos obter estimativas da matriz de covariância assintótica das correlações estimadas mesmo sob suposições de não normalidade (Bollen, 1989b). Esta mesma abordagem pode ser utilizada quando algumas ou todas as variáveis são ordinais ou censuradas se os dados de entrada forem substituídos por dados normais. E, por fim, também podemos calcular as estimativas das variâncias e covariâncias assintóticas das correlações "polychoric" e "polyserial" estimadas.

Entretanto, o cálculo da matriz de covariância assintótica dos coeficientes estimados demanda muito tempo e memória de computador quando o número de variáveis é grande. Então, uma abordagem alternativa é calcular somente as variâncias assintóticas dos coeficientes estimados e utilizar uma função de ajuste da forma:

$$
F(\theta)=\sum_{g=1}^{k} \sum_{h=1}^{k} \frac{1}{w_{g h}}\left(s_{g h}-\sigma_{g h}\right)^{2},
$$

em que $w_{g h}$ é a estimativa da variância assintótica de $s_{g h}$.

Note que a função (3.11) corresponde a usar uma matriz de pesos diagonal $W^{-1}$. Então, ela é denominada função de ajustamento para o método de mínimos quadrados ponderados diagonalmente (DWLS). Este procedimento não produz estimativas assintoticamente eficientes dos parâmetros do modelo, mas suas estimativas são consideradas como um meio termo entre as estimativas de ULS e WLS.

Todas as funções de ajustamento apresentadas neste capítulo estão disponíveis no AMOS, no LISREL e no PROC CALIS do SAS , com exceção da função de ajustamento para o método de mínimos quadrados ponderados diagonalmente (DWLS) que não está disponível no AMOS. 


\section{Capítulo 4}

\section{Medidas de Ajuste}

Após o ajuste do modelo, é necessário analisar rigorosamente os coeficientes estimados e a força das associações. Ou seja, devemos verificar se:

- os sinais dos coeficientes estão de acordo com a realidade que se deseja traduzir pelo modelo, isto é, se a correlação entre as variáveis é realmente positiva, negativa ou nula;

- os parâmetros estimados são estatisticamente significantes.

Para realizar a validação do modelo, existem algumas medidas de ajuste, que serão apresentadas a seguir.

A hipótese sobre a estrutura de covariância que estamos interessados em testar é $H_{0}: \Sigma=\Sigma(\theta)$. As medidas que serão apresentadas ajudam a verificar se essa hipótese é verdadeira (ou seja, se $\Sigma-\Sigma(\theta)=0$ ), ou se for falsa, quantificar essa diferença. Mas, como estas são quantidades populacionais desconhecidas, deve-se utilizar S e $\Sigma(\widehat{\theta})$, que são a matriz de covariância amostral usual e a matriz de covariância $\Sigma(\theta)$ avaliada no ponto $\widehat{\theta}$ que minimiza a função de ajustamento utilizada, respectivamente.

A partir deste ponto, vamos nos referir a $\Sigma(\widehat{\boldsymbol{\theta}})$ apenas como $\widehat{\boldsymbol{\Sigma}}$. 


\subsection{Resíduos}

Uma possível medida de ajuste para quantificar a diferença entre as matrizes de covariância $\mathbf{S}$ e $\widehat{\Sigma}$ é a matriz de resíduos $\left(\Upsilon_{(k \times k)}\right)$. Os elementos dessa matriz são $v_{i j}=s_{i j}-\widehat{\sigma}_{i j}$, onde $s_{i j}$ é o $i j$-ésimo elemento de $\mathrm{S}$ e $\widehat{\sigma}_{i j}$ é o elemento correspondente em $\widehat{\Sigma}$. Através dos resíduos amostrais individuais $\left(v_{i j}\right)$, podemos dizer que:

- se $v_{i j}>0$, o modelo subestima a covariância entre as duas variáveis;

- se $v_{i j}<0$, o modelo superestima a covariância.

Podemos dizer que um modelo é "bom" se todos os resíduos estiverem próximos de zero.

Uma medida alternativa baseada nos resíduos amostrais $v_{i j}$ é a raiz do quadrado médio residual (RMR), que é dada por:

$$
R M R=\left[2 \sum_{i=1}^{k} \sum_{j=1}^{i} \frac{v_{i j}^{2}}{k(k+1)}\right]^{1 / 2}=\left[2 \sum_{i=1}^{k} \sum_{j=1}^{i} \frac{\left(s_{i j}-\widehat{\sigma}_{i j}\right)^{2}}{k(k+1)}\right]^{1 / 2}
$$

Ou seja, é a raiz do quadrado médio dos elementos abaixo da diagonal principal (incluindo a diagonal principal) da matriz de resíduos. Portanto, como o interesse é que todos os elementos da matriz de resíduos sejam iguais a zero, temos que um RMR próximo de zero indica um "bom" ajuste.

Mas, os resíduos amostrais são afetados por fatores como: a distância entre $\boldsymbol{\Sigma}$ e $\Sigma(\theta)$ e, escalas diferentes entre as variáveis observáveis. Então, uma medida alternativa para solucionar o problema de variáveis observáveis com diferentes escalas é o resíduo da correlação $\left(\iota_{i j}\right)$ :

$$
\iota_{i j}=r_{i j}-\widehat{r}_{i j}
$$

em que:

$r_{i j}$ : correlação amostral entre a $i$-ésima e a $j$-ésima variáveis;

$\widehat{r}_{i j}=\frac{\widehat{\sigma}_{i j}}{\left(\widehat{\sigma}_{i i} \widehat{\sigma}_{j j}\right)^{1 / 2}}$ : correlação entre a $i$-ésima e a $j$-ésima variáveis no modelo predito. 
Como $-1 \leq r_{i j}, \widehat{r}_{i j} \leq 1$, temos que $-2 \leq \iota_{i j} \leq 2$. Valores de $\iota_{i j}$ próximos de zero, indicam um bom ajuste e, valores próximos a -2 ou 2 , indicam um sério problema no ajuste.

Um outro fator que afeta os resíduos amostrais e os resíduos da correlação é o erro amostral, ou seja, em determinados modelos, quanto maior a amostra, menor é $v_{i j}$ em média, o que pode implicar em erros de conclusão quando a estrutura de covariância testada for verdadeira em pequenas amostras (Bollen, 1989b).

Então, o resíduo normalizado foi proposto por Jöreskog e Sörbom (1986) como uma correção para os efeitos do tamanho da amostra e de diferentes escalas das variáveis:

$$
e_{i j}=\frac{v_{i j}}{\left[\frac{\cdot\left(\widehat{\sigma}_{i i} \widehat{\sigma}_{j j}+\widehat{\sigma}_{i j}^{2}\right)}{N}\right]^{1 / 2}},
$$

onde o denominador é a raiz quadrada da variância assintótica estimada de $v_{i j}$.

Os valores absolutos mais altos de $e_{i j}$ indicam os elementos $s_{i j}$ que têm pior ajuste pelo modelo. Jöreskog e Sörbom (1988) indicaram que a variância assintótica estimada de (4.3) tende a ser muito grande, o que implica que os resíduos $e_{i j}$ são menores que uma variável normal padronizada.

Seria interessante termos um teste que avaliasse simultaneamente se todos os elementos da matriz $[\Sigma-\Sigma(\theta)]$ são zero, levando em conta o tamanho da amostra e os graus de liberdade e ser baseado nos resíduos amostrais. Na próxima seção apresentamos tal teste.

\subsection{Teste Qui-quadrado}

Note que $F$ (onde $F$ pode ser $F_{M V}, F_{G L S}, F_{U L S}$ ou $F_{W L S}$, descritas anteriormente nas Subseções 3.1.1 a 3.1.4) tem as seguintes propriedades: (1) o valor mínimo de $F$ é zero; (2) quando $H_{0}: \Sigma=\Sigma(\theta)$ é verdadeira e as suposições sobre a distribuição estão satisfeitas, F é inversamente proporcional a $N$ (ou seja, $F \longrightarrow 0$ quando $N \longrightarrow \infty$ ); e (3) dada uma amostra e um modelo, a adição de parâmetros livres (página 39) nunca deve aumentar o valor de $F$. 
Observe também que o valor de $F$ não é fácil de ser interpretado e, vimos nas Subseções 3.1.1, 3.1.2 e 3.1.4 que $(N-1) F_{M V},(N-1) F_{G L S}$ e $F_{W L S}$, avaliadas nas estimativas obtidas, têm distribuição assintoticamente qui-quadrado com $(1 / 2)(p+q)(p+q+1)-t$ graus de liberdade, onde $t$ é o número de parâmetros livres. Portanto, podemos utilizar estas estatísticas para testar $H_{0}: \Sigma=\Sigma(\theta)$. E, como testar $H_{0}$ é equivalente a testar se $\Sigma-\Sigma(\theta)=0$, o teste qui-quadrado é um teste que avalia simultaneamente se todos os elementos de $[\Sigma-\Sigma(\theta)]$ são zero.

Ele é o teste de ajuste mais comum, que é apresentado na saída de todos os programas computacionais. Se a hipótese nula for verdadeira, temos que o modelo está bem ajustado aos dados e, portanto, se tivermos um valor baixo da estatística qui-quadrado (ou seja, valor menor que o valor crítico obtido na tabela da distribuição qui-quadrado) temos que o modelo está bem ajustado.

No Estudo de Wheaton (Exemplo 1) temos $p=4, q=2$ e $t=15$ (ver página 51 ), de tal forma que $(1 / 2)(p+q)(p+q+1)-t=(1 / 2)(4+2)(4+2+1)-15=6$. Portanto, o número de graus de liberdade da distribuição qui-quadrado é 6 . A estatística qui-quadrado é 71,544 que corresponde a um nível descritivo menor do que 0,001. Logo, pode-se dizer que o modelo é rejeitado, ou seja, não tem um bom ajuste para os dados pois temos um nível descritivo baixo, menor que $0,1 \%$.

Deve-se ressaltar que é preciso ter cautela para utilizar este teste, pois a aproximação qui-quadrado assume que:

1. as variáveis têm curtose próximas da curtose da distribuição normal;

2. a matriz de covariância é analisada (segundo Jöreskog e Sörbom (1986) a estatística qui-quadrado não é acurada quando a matriz de correlação é analisada);

3. o tamanho da amostra é suficientemente grande (o número de observações deve ser pelo menos 10 vezes maior que o número de variáveis).

Portanto, na próxima seção vamos apresentar outras medidas de ajuste baseadas em F para testar $H_{0}$. 


\subsection{Medidas de Ajuste Alternativas}

Bentler e Bonett (1980) e Tucker e Lewis (1973) sugeriram que se ajustasse o "modelo de independência" (modelo em que se assume que as variáveis observadas são nãocorrelacionadas entre si e no qual apenas as variâncias das variáveis observadas são estimadas) ou algum outro modelo "baseline" que tenha um ajuste muito ruim para que pudéssemos compará-lo com o "seu modelo" (modelo especificado pelo pesquisador).

O pacote AMOS (utilizado para o ajuste de modelos de equações estruturais) compara medidas de ajuste do "seu modelo", do "modelo de independência" (modelo "baseline") e do "modelo saturado" (aquele sem restrições sobre os momentos populacionais - ou seja, é o modelo cujo número de parâmetros é igual ao número de momentos distintos - e, portanto, aquele que sempre se ajustará perfeitamente aos dados).

\subsubsection{Discrepância Mínima da Amostra (CMIN)}

Esta medida é calculada da seguinte forma:

$$
\widehat{C}=N \times F,
$$

em que $F$ é $F_{M V}, F_{G L S}, F_{U L S}$ ou $F_{W L S}$ avaliada nas estimativas obtidas. Como visto no Capítulo 3 deseja-se minimizar $F$.

Para o Estudo de Wheaton (Exemplo 1) temos, utilizando a função de ajustamento $F_{M V}$, que:

Tabela 4.1. Discrepância Mínima para o Estudo de Wheaton.

\begin{tabular}{ccc}
\hline Modelo & $\widehat{\mathrm{C}}$ & Graus de Liberdade \\
\hline "Seu Modelo" & 71,544 & 6 \\
"Modelo Saturado" & 0,000 & 0 \\
"Modelo de Independência" & 2131,790 & 15 \\
\hline
\end{tabular}


Assim, pela Tabela 4.1 temos que o "seu modelo" tem uma discrepância mínima muito alta em relação aos seus graus de liberdade, porém esse valor $(71,544)$ não parece ser tão ruim se comparado com a discrepância mínima do "modelo de independência" $(2131,790)$.

\subsubsection{Indice de Ajuste Normalizado (NFI)}

Este índice foi proposto por Bentler e Bonett (1980) e é dado por:

$$
\Delta_{1}=\frac{F_{b}-F_{m}}{F_{b}}=\frac{\chi_{b}^{2}-\chi_{m}^{2}}{\chi_{b}^{2}}
$$

em que $F_{b}$ é o valor da função de ajustamento do modelo "baseline" e $F_{m}$ é o valor da função de ajustamento do "seu modelo". Ele mede a redução na função de ajustamento quando passamos do modelo "baseline" para o "seu modelo".

O melhor ajuste possível é quando $F_{m}=0$, o que leva a $\Delta_{1}=1$. E, o pior ajuste ocorre quando "seu modelo" não se ajusta melhor que o modelo "baseline", ou seja, quando $F_{m}=F_{b}$ e, então $\Delta_{1}=0$. Logo, $0 \leq \Delta_{1} \leq 1$ e, quanto mais próximo de 1 , melhor o ajuste do modelo.

Voltando ao Estudo de Wheaton (Exemplo 1), onde temos 932 observações ( $\mathrm{N}=932)$, e da Tabela 4.1 temos que $F_{m}=\widehat{C}_{m} / N \simeq 0,077$ e $F_{b}=\widehat{C}_{b} / N \simeq 2,287$. Assim:

$$
\Delta_{1}=\frac{2,287-0,077}{2,287} \simeq 0,966
$$

Este índice tem algumas limitações:

1. o valor de $F_{m}$ pode ser reduzido pela adição de parâmetros, aumentando o valor de $\Delta_{1}$ (análogo ao aumento de $R^{2}$ na equação de regressão quando adicionamos variáveis explicativas);

2. o tamanho da amostra pode influenciar a média da distribuição amostral de $\Delta_{1}$ (quanto maior o tamanho da amostra, maior é a média), pois:

$$
(N-1) F_{m} \stackrel{a}{\sim} \chi_{g l_{m}}^{2} \Rightarrow F_{m} \stackrel{a}{\sim} \chi_{\frac{g l_{m}}{N-1}}^{2} \Rightarrow E\left(F_{m}\right) \approx \frac{g l_{m}}{N-1}
$$


(note que quanto maior $N$, menor $E\left(F_{m}\right)$ ).

E, o mesmo acontece com $F_{b}$, porém mais lentamente que $F_{m}$. Assim, comparando duas amostras de tamanhos diferentes podemos concluir que a amostra de tamanho maior tem um melhor ajuste mesmo se modelos idênticos forem ajustados para ambas as amostras.

Então, Bollen (1989a) propôs um indice de ajuste corrigido.

\subsection{3 Índice de Ajuste Corrigido (IFI)}

Este índice é calculado da seguinte forma:

$$
\Delta_{2}=\frac{F_{b}-F_{m}}{F_{b}-\left[g l_{m} /(N-1)\right]}=\frac{\chi_{b}^{2}-\chi_{m}^{2}}{\chi_{b}^{2}-g l_{m}},
$$

em que $F_{b}, F_{m}, \chi_{b}^{2}, \chi_{m}^{2}$ e $g l_{m}$ são os mesmos definidos anteriormente.

O IFI tem as seguintes propriedades para um modelo corretamente ajustado:

1. não varia necessariamente entre 0 e 1 ;

2. valores muito acima de 1 podem ser devidos a superajuste ${ }^{1}$;

3. quando o numerador e o denominador de $\Delta_{2}$ são positivos, $\Delta_{1}<\Delta_{2}$.

Assim, para o Estudo de Wheaton, temos que:

$$
\Delta_{2}=\frac{2,287-0,077}{2,287-[6 / 931]} \simeq 0,969
$$

Porém, note que:

\footnotetext{
${ }^{1}$ Segundo Sarle (2004), o superajuste pode ocorrer se pelo menos uma das condições for verdadeira: 1) O número de variáveis é maior que o número de observações (usualmente, espera-se que o número de observações seja pelo menos 10 vezes maior que o número de variáveis); 2) As variáveis são altamente correlacionadas (multicolinearidade).
} 
- a média da distribuição amostral de $\Delta_{2}$ deve estar menos relacionada ao tamanho da amostra do que a média da distribuição amostral de $\Delta_{1}$;

- o cálculo de $\Delta_{2}$ é influenciado pelo tamanho da amostra $\left(\Delta_{2}\right.$ é maior para amostras menores), pois quanto menor o tamanho da amostra, maior é a razão $\frac{g l_{m}}{N-1}$, fazendo com que o denominador de (4.6) seja menor e, portanto, $\Delta_{2}$ ficando maior;

- quanto maior o tamanho da amostra, os valores de $\Delta_{2}$ e $\Delta_{1}$ ficam próximos.

\subsubsection{Indice de Ajuste Relativo (RFI)}

Foi proposto por Bollen (1986) e é dado por:

$$
\rho_{1}=\frac{\left(F_{b} / g l_{b}\right)-\left(F_{m} / g l_{m}\right)}{\left(F_{b} / g l_{b}\right)}=\frac{\left(\chi_{b}^{2} / g l_{b}\right)-\left(\chi_{m}^{2} / g l_{m}\right)}{\left(\chi_{b}^{2} / g l_{b}\right)},
$$

em que $F_{b}, F_{m}, \chi_{b}^{2}, \chi_{m}^{2}$ e $g l_{m}$ são os mesmos definidos anteriormente e, $g l_{b}$ é o número de graus de liberdade da distribuição qui-quadrado que $(N-1) F_{b}$ segue.

Assim como o índice de ajuste normalizado (NFI), o RFI mede a redução na função de ajustamento ao passarmos do modelo "baseline" para o modelo proposto, porém essa redução é calculada relativamente aos graus de liberdade.

Note que:

- a adição de parâmetros diminui os graus de liberdade, logo, é possível que $\rho_{1}$ se mantenha o mesmo ou diminua;

- modelos ajustados que relativamente têm poucos parâmetros e um valor baixo da função de ajustamento possuem valores maiores de $\rho_{1}$ do que modelos com o mesmo valor da função de ajustamento e uma especificação mais complexa (modelo mais complexo);

- o menor valor possível de $F_{m}$ é zero, logo o valor máximo de $\rho_{1}$ é 1 ;

- é possível que $\chi_{m}^{2} / g l_{m}$ seja maior que $\chi_{b}^{2} / g l_{b}$ levando a $\rho_{1}<0$, mas, isto é improvável na prática. 
Portanto, considera-se que um valor de $\rho_{1}$ próximo de 1 indica um bom ajuste.

Para o Estudo de Wheaton, temos que:

$$
\rho_{1}=\frac{(2,287 / 15)-(0,077 / 6)}{(2,287 / 15)} \simeq 0,916 .
$$

Mas, assim como $\Delta_{1}$, a média da distribuição amostral de $\rho_{1}$ aumenta proporcionalmente a $N$, pois:

$$
(N-1) F_{m} \stackrel{a}{\sim} \chi_{g l_{m}}^{2} \Rightarrow(N-1) \frac{F_{m}}{g l_{m}} \stackrel{a}{\sim} \chi_{1}^{2} \Rightarrow \frac{F_{m}}{g l_{m}} \stackrel{a}{\sim} \chi_{\frac{1}{N-1}}^{2} \Rightarrow E\left(\frac{F_{m}}{g l_{m}}\right) \approx \frac{1}{N-1}
$$

(note que quanto maior $N$, menor $E\left(F_{m}\right)$ ).

Então, Tucker e Lewis (1973) propuseram uma medida semelhante a $\rho_{1}$, mas tal que a média de sua distribuição amostral tivesse uma menor dependência do valor de $N$.

\subsection{5 Índice de Tucker-Lewis (TLI)}

Este índice é calculado da seguinte forma:

$$
\rho_{2}=\frac{\left(F_{b} / g l_{b}\right)-\left(F_{m} / g l_{m}\right)}{\left(F_{b} / g l_{b}\right)-[1 /(N-1)]}=\frac{\left(\chi_{b}^{2} / g l_{b}\right)-\left(\chi_{m}^{2} / g l_{m}\right)}{\left(\chi_{b}^{2} / g l_{b}\right)-1}
$$

em que $F_{b}, F_{m}, \chi_{b}^{2}, \chi_{m}^{2}, g l_{b}$ e $g l_{m}$ são os mesmos definidos anteriormente.

Algumas propriedades de $\rho_{2}$ são:

- seu valor pode ser menor que 0 ou maior que 1 ;

- assim como $\rho_{1}, \rho_{2}=1$ indica um ajuste perfeito; então, valores de $\rho_{2}$ muito menores que 1 indicam que o modelo precisa ser reespecificado, ao passo que, valores muito maiores que 1 indicam superajuste;

- quando o numerador e o denominador de $\rho_{2}$ são positivos, temos que $\rho_{2}>\rho_{1}$;

- quanto maior o tamanho da amostra, os valores de $\rho_{2}$ e $\rho_{1}$ ficam próximos; 
- seu valor converge para 1 se o modelo é válido, independentemente do tamanho da amostra.

Portanto, considera-se que um valor de $\rho_{2}$ próximo de 1 indica um bom ajuste.

Para o Estudo de Wheaton, temos que:

$$
\rho_{2}=\frac{(2,287 / 15)-(0,077 / 6)}{(2,287 / 15)-(1 / 931)} \simeq 0,922
$$

Agora, o problema é definir um valor de corte para os índices NFI, IFI, RFI e TLI para que possamos concluir se um modelo está bem ajustado aos dados.

Bentler e Bonett (1980) sugeriram que para $\Delta_{1}$ e $\rho_{2}$ : "Em nossa experiência, modelos com índices de ajuste menores que 0,90 usualmente podem ser substancialmente melhorados". Porém, temos que os quatros índices de ajuste podem ser afetados por diversos fatores, podendo levar a outros pontos de corte. Alguns destes fatores são:

1. a escolha do modelo "baseline", isto é, quanto mais restritivo for o modelo "baseline", melhor é o ajuste do "seu modelo" em relação ao "baseline"; isto leva a valores maiores dos quatros índices de ajuste se comparados com os valores que eles teriam se fosse utilizado um modelo "baseline" menos restritivo;

Uma maneira de diminuir esta ambigüidade é comparar os índices de ajuste do "seu modelo" obtidos com o modelo "baseline" sem fatores e os índices de ajuste do "seu modelo" obtidos com qualquer outro modelo "baseline" apropriado.

2. padrões estabelecidos por trabalhos anteriores (Bollen, 1989b); isto é, se outras análises das mesmas variáveis (ou similares) com o mesmo modelo "baseline" tipicamente fornecem valores de 0,95 ou mais altos para os $\Delta$ 's e $\rho$ 's, então valores de 0,85 ou 0,90 podem ser inaceitáveis; alternativamente, se modelos em outra área de pesquisa têm índice de ajuste tipicamente menor que 0,80 , valores de 0,85 ou mais altos podem representar uma importante melhora em relação a trabalhos existentes; 
3. as diferenças entre os índices de ajuste podem levar a pontos de corte distintos; por exemplo, podemos reescrever $\rho_{1}$ como:

$$
\rho_{1}=\frac{\chi_{b}^{2}-\left(g l_{b} / g l_{m}\right) \chi_{m}^{2}}{\chi_{b}^{2}}
$$

indicando que $\rho_{1}$ é o mesmo que $\Delta_{1}$ a menos do fato que $\chi_{m}^{2}$ é multiplicado por $g l_{b} / g l_{m}$ e, como $\left(g l_{b} / g l_{m}\right)>1$, temos que $\rho_{1}<\Delta_{1}$ e, assim, o ponto de corte de $\rho_{1}$ pode ser menor que o de $\Delta_{1}$;

4. a função de ajustamento escolhida deve ser levada em conta para julgar a magnitude dos índices de ajuste; geralmente, os valores de $F_{b}$ e $F_{m}$ para o método de mínimos quadrados generalizados (GLS) não são necessariamente iguais aos do método de máxima verossimilhança (MV), mesmo para modelos e amostras idênticas (o mesmo ocorre para os demais métodos de estimação), o que significa que as magnitudes dos $\Delta$ 's e $\rho$ 's podem ser diferentes para os diferentes estimadores.

Portanto, definir pontos de corte para NFI, IFI, RFI e TLI é difícil, pois qualquer valor será controverso. Portanto, segundo Bollen (1989b), "Consciência dos fatores que afetam os $\Delta$ 's e os $\rho$ 's e um bom julgamento são os melhores guias para avaliar seus valores".

\subsection{6 Índice de Qualidade do Ajuste (GFI) e Índice de Qualidade do Ajuste Corrigido (AGFI)}

Jöreskog e Sörbom (1986) propuseram estes índices para modelos ajustados com $F_{M V}$ e com $F_{U L S}$ :

$$
\begin{gathered}
G F I_{M V}=1-\frac{\operatorname{tr}\left[\left(\widehat{\Sigma}^{-1} \mathrm{~S}-\mathrm{I}\right)^{2}\right]}{\operatorname{tr}\left[\left(\widehat{\Sigma}^{-1} \mathrm{~S}\right)^{2}\right]}, \\
A G F I_{M V}=1-\left[\frac{k(k+1)}{2 g l}\right]\left[1-G F I_{M V}\right],
\end{gathered}
$$


e

$$
\begin{gathered}
G F I_{U L S}=1-\frac{\operatorname{tr}\left[(\mathrm{S}-\widehat{\mathbf{\Sigma}})^{2}\right]}{\operatorname{tr}\left(\mathbf{S}^{2}\right)}, \\
A G F I_{U L S}=1-\left[\frac{k(k+1)}{2 g l}\right]\left[1-G F I_{U L S}\right],
\end{gathered}
$$

onde GFI mede a quantidade relativa das variâncias e covariâncias em S que é predita por $\widehat{\Sigma}$ e, $A G F I$ corrige GFI de um modelo pelos graus de liberdade relativos ao número de variáveis.

Ambos os índices, GFI e $A G F I$, alcançam seu valor máximo 1 quando $\mathrm{S}=\widehat{\Sigma} \mathrm{e}$, em geral, são maiores que zero (embora valores negativos sejam possíveis).

Tanaka e Huba (1985) propuseram estes índices para modelos ajustados com $F_{G L S}$ :

$$
\begin{gathered}
G F I_{G L S}=1-\frac{\operatorname{tr}\left[\left(\mathbf{I}-\widehat{\Sigma} \mathbf{S}^{-1}\right)^{2}\right]}{k}, \\
A G F I_{G L S}=1-\left[\frac{k(k+1)}{2 g l}\right]\left[1-G F I_{G L S}\right] .
\end{gathered}
$$

No estudo de simulação de Anderson e Gerbing (1984), eles obtiveram que:

- as médias das distribuições amostrais de $G F I_{M V}$ e $A G F I_{M V}$ aumentam com o aumento do tamanho da amostra;

- $G F I_{M V}$ e $A G F I_{M V}$ decrescem de acordo com o aumento do número de indicadores por fator ou do número de fatores (especialmente para pequenas amostras).

A obtenção de pontos de corte de $G F I$ e $A G F I$ segue o mesmo raciocínio de $N F I$, $I F I, R F I$ e $T L I$, ou seja, deve-se levar em conta os fatores que afetam seus valores e realizar um bom julgamento para avaliar seus valores.

Para o Estudo de Wheaton, com o auxílio do pacote AMOS, obtivemos:

1. $G F I_{M V}=0,975$ e $A G F I_{M V}=0,913$; 
2. $G F I_{U L S}=1,000$ e $A G F I_{U L S}=1,000$;

3. $G F I_{G L S}=0,978$ e $A G F I_{G L S}=0,922$.

\subsection{7 Índice de Qualidade do Ajuste de Parsimônia (PGFI)}

Em geral, as medidas de ajuste de parsimônia podem ser utilizadas para comparar modelos com diferentes números de parâmetros para determinar o impacto da adição de parâmetros ao modelo.

O PGFI (Mulaik et al., 1989) é o índice GFI corrigido pela razão entre os graus de liberdade do "seu modelo" e o número de parâmetros do "modelo saturado" (ou seja, $k(k+1) / 2)$. Ou seja:

$$
P G F I=G F I \frac{2 g l_{m}}{k(k+1)}
$$

Este índice varia entre 0 e 1, porém é improvável que ele assuma valores tão altos quanto os demais índices (por exemplo, 0,90). Portanto, ele é mais utilizado para comparar 2 modelos.

Com o auxílio do pacote AMOS obtivemos, para o Estudo de Wheaton, que PGFI= 0,279 (utilizando a função de ajustamento $F_{M V}$ ).

\subsection{8 Índice de Ajuste Normalizado de Parsimônia (PNFI)}

É um índice sugerido por James et al. (1982) que consiste do índice NFI corrigido pela razão entre os graus de liberdade do "seu modelo" e os graus de liberdade do modelo "baseline" (esta razão é denominada "PRATIO" no pacote AMOS). Ou seja:

$$
P N F I=N F I \frac{g l_{m}}{g l_{b}}
$$

Segundo Hatcher (1994), quanto maior o valor de PNFI, mais aceitável é o modelo e, os valores mínimos aceitáveis são entre 0,50 e 0,60. 
Novamente com o auxílio do pacote AMOS obtivemos, para o Estudo de Wheaton, que $P N F I=0,387$ (utilizando a função de ajustamento $F_{M V}$ ). Portanto, utilizando este índice, o modelo não estaria bem ajustado aos dados.

Porém, o principal uso deste índice é a comparação de modelos com diferentes graus de liberdade, sendo que diferenças entre 0,06 a 0,09 entre os valores de PNFI dos modelos podem indicar distinções substanciais entre eles (Latif, 2000).

\subsection{9 Índice de Ajuste Comparativo (CFI)}

Este índice foi proposto por Bentler (1990) e é dado por:

$$
C F I=1-\frac{\max \left(\widehat{\mathrm{C}}_{\mathrm{m}}-\mathrm{gl}_{\mathrm{m}}, 0\right)}{\max \left(\widehat{\mathrm{C}}_{\mathrm{b}}-\mathrm{gl}_{\mathrm{b}}, 0\right)}
$$

em que $\widehat{C}_{m}$ e $\widehat{C}_{b}$ são a discrepância mínima da amostra do "seu modelo" e do modelo "baseline", respectivamente e, $g l_{m}$ e $g l_{b}$ são seus respectivos graus de liberdade.

Segundo Garson (2001), CFI varia entre 0 e 1 e, quanto mais próximo de 1, mais aceitável é o modelo sendo que valores acima de 0,90 são considerados aceitáveis.

\subsubsection{Raiz do Erro Quadrático Médio de Aproximação (RMSEA)}

Inicialmente proposto por Steiger e Lind (1980) denominado por RMS e, posteriormente, denominado RMSEA por Browne e Cudeck (1993). Seu cálculo é realizado da seguinte maneira:

$$
R M S E A=\sqrt{\frac{\widehat{F}_{0}}{g l}},
$$

em que $\widehat{F}_{0}=\max \left(\frac{\widehat{\mathrm{c}}-\mathrm{gl}}{\mathrm{N}}, 0\right)$.

Segundo Huntley e Perry (2003), esta medida de ajuste tem sido reconhecida recentemente como um dos critérios mais informativos para ser utilizado na modelagem de estrutura de covariância. Esta medida leva em consideração o erro de aproximação na 
população e tenta responder à seguinte questão "Quão bem o modelo, com parâmetros desconhecidos mas eficientemente escolhidos, ajustam a matriz de covariância populacional?". Eles consideram a seguinte regra de decisão:

- valores menores que 0,05 indicam um bom ajuste;

- valores entre 0,08 e 0,10 indicam um ajuste razoável;

- valores acima de 0,10 indicam um ajuste pobre.

Voltando ao Estudo de Wheaton, pela Tabela 4.1 temos que $\widehat{C}=71,544$ e $g l=6$ para o "seu modelo", o que leva a $\widehat{F}_{0}=\max \left(\frac{71,544-6}{932}, 0\right) \simeq 0,070$. Portanto, para o modelo ajustado temos que:

$$
R M S E A=\sqrt{0,070 / 6} \simeq 0,108 .
$$

Também é possível utilizar intervalos de confiança para avaliar a precisão da estimativa de RMSEA. O pacote AMOS apresenta os limites inferior e superior do intervalo de confiança com coeficiente de confiança de $90 \%$ (LO90 e HI90, respectivamente).

Os limites são dados por:

$$
L O 90=\sqrt{\frac{\delta_{L} / N}{g l}}
$$

e

$$
H I 90=\sqrt{\frac{\delta_{U} / N}{g l}}
$$

em que $\delta_{L}$ e $\delta_{U}$ são obtidos, respectivamente, pela solução das equações

$$
\begin{aligned}
& \chi_{N C}^{2}(\widehat{C} \mid \delta, g l)=0,95 \\
& \chi_{N C}^{2}(\widehat{C} \mid \delta, g l)=0,05
\end{aligned}
$$

onde $\chi_{N C}^{2}(\widehat{C} \mid \delta, g l)$ é a função de distribuição da distribuição qui-quadrado não-central com parâmetro de não-centralidade $\delta$ e $g l$ graus de liberdade. 
Com o auxílio do AMOS, obtivemos $L O 90$ = 0,087 e HI90 = 0,132 para o Estudo de Wheaton utilizando a função de ajustamento $F_{M V}$.

O pacote AMOS ainda apresenta a probabilidade de um bom ajuste (PCLOSE), que é o "p-valor" para testar a hipótese nula de que o RMSEA populacional não é maior que 0,05. Ou seja, para testar $H_{0}: R M S E A \leq 0,05$. Logo,

$$
P C L O S E=1-\chi_{N C}^{2}\left(\widehat{C} \mid 0,05^{2} N g l, g l\right) \text { (Arbuckle, 1997) }
$$

Para o Estudo de Wheaton, temos que PCLOSE $=0,000$, o que indica que a probabilidade de um bom ajuste é nula.

\subsubsection{Qui-quadrado Relativo}

Esta medida é obtida dividindo a estatística qui-quadrado pelos seus graus de liberdade. Ou seja:

$$
\frac{\chi^{2}}{g l}
$$

O qui-quadrado relativo mede quantas vezes a estatística qui-quadrado $\left(\chi^{2}\right)$ é maior que seu valor esperado $(g l)$. Não há um consenso sobre qual valor indica um "bom" ajuste, com pontos de corte variando de 3, 2, ou menos (Carmines e McIver, 1981) ou até valores mais altos como 5 .

Para o Estudo de Wheaton, vimos que $\chi^{2}=71,544$ e $g l=6$ e, então o qui-quadrado relativo é 11,924 .

Note que, como o qui-quadrado relativo é dado por $(N-1) F_{M V} / g l,(N-1) F_{G L S} / g l$ ou $(N-1) F_{W L S} / g l$, ele tem uma relação similar à que o qui-quadrado usual tem com $N$ e, assim, não corrige problemas excessivos de poder (Bollen, 1989b). 


\subsubsection{Qui-quadrado Padronizado $\left(\chi_{P}^{2}\right)$}

Esta medida é dada por:

$$
\chi_{P}^{2}=\frac{\chi^{2}-g l}{\sqrt{2 g l}} .
$$

$\mathrm{O} \chi_{P}^{2}$ mede o desvio entre a estatística qui-quadrado e seu valor esperado em termos do desvio padrão $(\sqrt{2 g l})$ e, sua vantagem é que controla o desvio padrão da estatística $\chi^{2}$.

Ele tem as mesmas limitações que o qui-quadrado relativo, ou seja, não há um consenso sobre um valor de ponto de corte para indicar um "bom" ajuste e tem as mesmas relações com o tamanho da amostra.

\subsubsection{Critério da Informação de Akaike (AIC)}

É um índice de ajuste alternativo para comparar modelos baseado em Akaike (1974) e é dado por:

$$
A I C=\widehat{C}+2 t
$$

em que $t$ é o número de parâmetros livres e $\widehat{C}$ é a discrepância mínima da amostra para o modelo proposto. Recomenda-se escolher o modelo com menor valor de AIC (Bollen, 1989b).

Vimos, para o Estudo de Wheaton, que $\widehat{C}=71,544$ e $t=15$ e, portanto, $A I C=$ $71,544+2 \times 15=101,544$.

\subsubsection{Critério da Informação de Bayes (BIC)}

É um índice baseado na modificação do critério de Akaike de Schwarz (1978) e é dado por:

$$
B I C=\widehat{C}+t \times \ln (\mathrm{Nk})
$$


em que $\widehat{C}, t$ e $N$ são os mesmos descritos anteriormente e, $k$ é o número de variáveis observadas. Este índice designa uma penalidade maior para a complexidade do modelo e tem uma maior tendência de escolher modelos parsimoniosos (Arbuckle, 1997). Deve-se escolher o modelo com o menor valor de $B I C$.

Assim, como $N=932$ e $k=6$ para o Estudo de Wheaton, temos que $B I C=$ $71,544+15 \ln (932 \times 6)=200,980$.

\subsubsection{Critério de Browne-Cudeck (BCC)}

Este critério é dado por:

$$
B C C=\widehat{C}+2 t \frac{b \frac{k(k+3)}{N-k-2}}{k(k+3)},
$$

em que $\widehat{C}, t, k$ e $N$ são os mesmos descritos anteriormente e, $b=N-1$. Como nas medidas anteriores, também deve-se escolher o modelo com o menor valor de $B C C$.

Para o Estudo de Wheaton, temos que $t=15, N=932, g=6$ e $\widehat{C}=71,544$. Então, $b=931$ e $B C C=101,771$.

\subsubsection{Critério da Informação de Akaike Consistente (CAIC)}

Este critério foi proposto por Bozdogan (1987) e é dado por:

$$
C A I C=\widehat{C}+t(\ln (\mathrm{N})+1)
$$

em que $\widehat{C}, t$ e $N$ são os mesmos descritos anteriormente. O melhor modelo dentre os que são comparados é aquele que tem o menor valor de $C A I C$.

Para o Estudo de Wheaton, temos que $\widehat{C}=71,544, t=15$ e $N=932$. Então, $C A I C=71,544+15(\ln (932)+1)=189,104$. 
Note que os critérios das Subseções 4.3 .13 a 4.3 .16 não são utilizados para avaliar a qualidade do ajuste de um único modelo, eles são utilizados para comparar modelos. 


\section{Capítulo 5}

\section{Aplicação}

Uma nova camada social surgiu no Uruguai devido às transformações agrárias das duas últimas décadas: os agricultores familiares modernos. Eles atuam como importantes agentes em diversos itens da produção, principalmente através de culturas de tomate e pimentão, mas também produzindo batata-doce, berinjela, cenoura, morango e alho. Alguns desses produtores, que realizam suas plantações sob estufa, são o alvo deste estudo.

Um questionário foi aplicado a 36 agricultores familiares de Salto, ao norte do Uruguai (Barroso e Gabriel, 1996). Através deste, um dos interesses era avaliar a "estrutura financeiro-tecnológica" (EFT) e a "estrutura social e familiar" (ESF) dos agricultores. Porém, estes conceitos não são diretamente observáveis ou mensuráveis (variáveis nãoobserváveis) e, portanto, seria necessária a utilização de alguns indicadores (variáveis observáveis).

Então, para tentar mensurar a EFT foram observadas as variáveis: "tipo de fertilização" (manual ou mecânica), "veículo" (possui ou não veículo de carga para transporte da produção) e "tipo de dedetização" (pulverizador no trator, mochila de mão, mochila com motor ou outros). E, para tentar mensurar a ESF: "número de parentes" (número de parentes do agricultor que trabalham com ele o ano todo), "pai" (se o pai trabalhou ou não na horticultura) e "trabalhadores permanentes" (número de trabalhadores permanentes contratados pelo agricultor). 
Para uma melhor visualização das relações existentes entre as variáveis observáveis e as não-observáveis, apresenta-se na Figura 5.1 o diagrama de caminho do presente problema.

Figura 5.1. Diagrama de Caminho para o Estudo dos Agricultores Familiares.

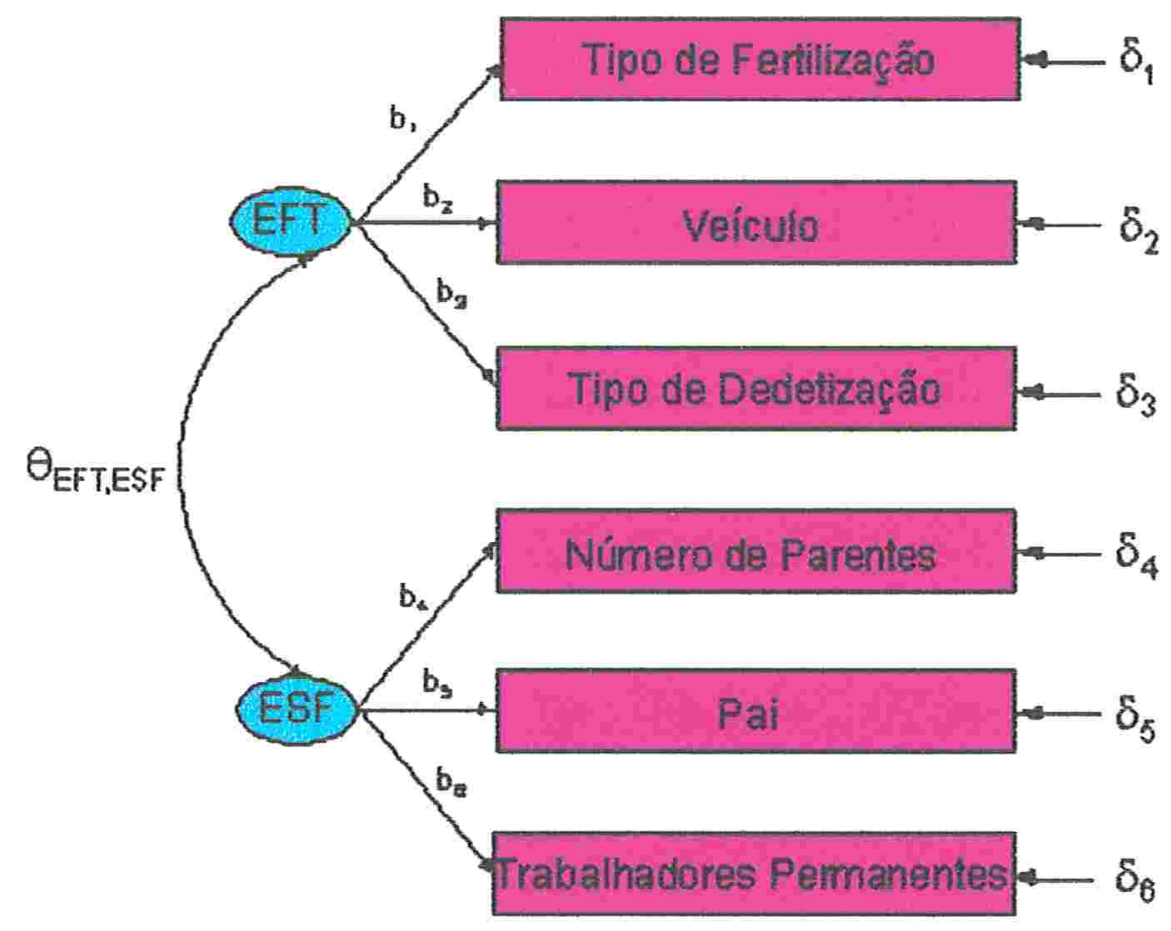

Com o auxílio da Figura 5.1, pode-se escrever as expressões do modelo de mensuração para o problema dos agricultores:

Tipo de Fertilização $=b_{1} \mathrm{EFT}+\delta_{1}$

Veículo $=b_{2} \mathrm{EFT}+\delta_{2}$

Tipo de Dedetização $=b_{3}$ EFT $+\delta_{3}$

Número de Parentes $=b_{4} \mathrm{ESF}+\delta_{4}$

$\mathrm{Pai}=b_{5} \mathrm{ESF}+\delta_{5}$

Trabalhadores Permanentes $=b_{6} \mathrm{ESF}+\delta_{6}$ 
Temos também que:

$$
\begin{aligned}
& \operatorname{var}(\mathrm{EFT})=\phi_{\mathrm{EFT}} \\
& \operatorname{var}(\mathrm{ESF})=\phi_{\mathrm{ESF}} \\
& \operatorname{cov}(\mathrm{EFT}, \mathrm{ESF})=\phi_{\mathrm{EFT}, \mathrm{ESF}} \\
& \operatorname{corr}(\mathrm{EFT}, \mathrm{ESF})=\theta_{\mathrm{EFT}, \mathrm{ESF}}
\end{aligned}
$$

E, matricialmente, temos o seguinte modelo de mensuração:

$$
\left(\begin{array}{c}
\text { Tipo de Fertilização } \\
\text { Veículo } \\
\text { Tipo de Dedetização } \\
\text { Número de Parentes } \\
\text { Pai } \\
\text { Trabalhadores Permanentes }
\end{array}\right)=\left(\begin{array}{cc}
b_{1} & 0 \\
b_{2} & 0 \\
b_{3} & 0 \\
0 & b_{4} \\
0 & b_{5} \\
0 & b_{6}
\end{array}\right)\left(\begin{array}{c}
\mathrm{EFT} \\
\mathrm{ESF}
\end{array}\right)+\left(\begin{array}{c}
\delta_{1} \\
\delta_{2} \\
\delta_{3} \\
\delta_{4} \\
\delta_{5} \\
\delta_{6}
\end{array}\right)
$$

e

$$
\begin{gathered}
\Phi=\left(\begin{array}{cc}
\phi_{E F T} & \phi_{E F T, E S F} \\
\cdot & \phi_{E S F}
\end{array}\right) \\
\Theta=\left(\begin{array}{cc}
1 & \theta_{E F T, E S F} \\
& 1
\end{array}\right)
\end{gathered}
$$

em que

$b_{1}, b_{2}, b_{3}$ : representam o impacto da variável não-observável independente EFT nas variáveis observáveis "Tipo de Fertilização", "Veículo" e "Tipo de Dedetização", respectivamente; $b_{4}, b_{5}, b_{6}$ : representam o impacto da variável não-observável independente ESF nas variáveis observáveis "Número de Parentes", "Pai" e "Trabalhadores Permanentes", respectivamente; $\delta_{1}, \ldots, \delta_{6}$ : erros de mensuração das variáveis observáveis;

$\Phi$ : matriz de covariância das variáveis latentes independentes; 
$\Theta$ : matriz de correlação das variáveis latentes independentes.

Agora precisamos verificar se o modelo proposto é identificável. Note que trata-se de um modelo de análise fatorial confirmatória e, portanto, vamos utilizar a regra doisindicadores apresentada na página 48.

Temos que $\Theta_{\delta}$ é diagonal, pois os $\delta$ 's não são correlacionados (ver Figura 5.1) e, temos também 3 indicadores por variável latente. Portanto, se fixarmos $b_{2}=b_{6}=1$, a regra dois-indicadores está satisfeita e então, o modelo é identificável.

Portanto, como o modelo é identificável, vamos estimar os parâmetros do modelo com o auxílio do pacote estatístico AMOS e assim, avaliar o impacto que cada variável observável tem sobre a respectiva variável latente.

Vimos no Capítulo 3 que quando temos alguma variável categórica no modelo é recomendável utilizar a função de ajustamento do método de mínimos quadrados ponderados generalizados (WLS). Porém, o método WLS necessita que o tamanho da amostra seja grande e, na nossa amostra temos apenas 36 indivíduos. Nesse caso, propõe-se que os parâmetros sejam estimados por GLS e WLS e os resultados sejam comparados.

Nas Figuras 5.2 e 5.3 apresentam-se os diagramas de caminho com as estimativas dos parâmetros e seus respectivos erros padrões obtidos pelos métodos WLS e GLS, respectivamente. Através dessas figuras podemos observar que os valores das estimativas não diferem muito entre os dois métodos. 
Figura 5.2. Diagrama de Caminho para o Estudo dos Agricultores Familiares com as estimativas dos parâmetros (e seus respectivos erros padróes) obtidas pelo método WLS.

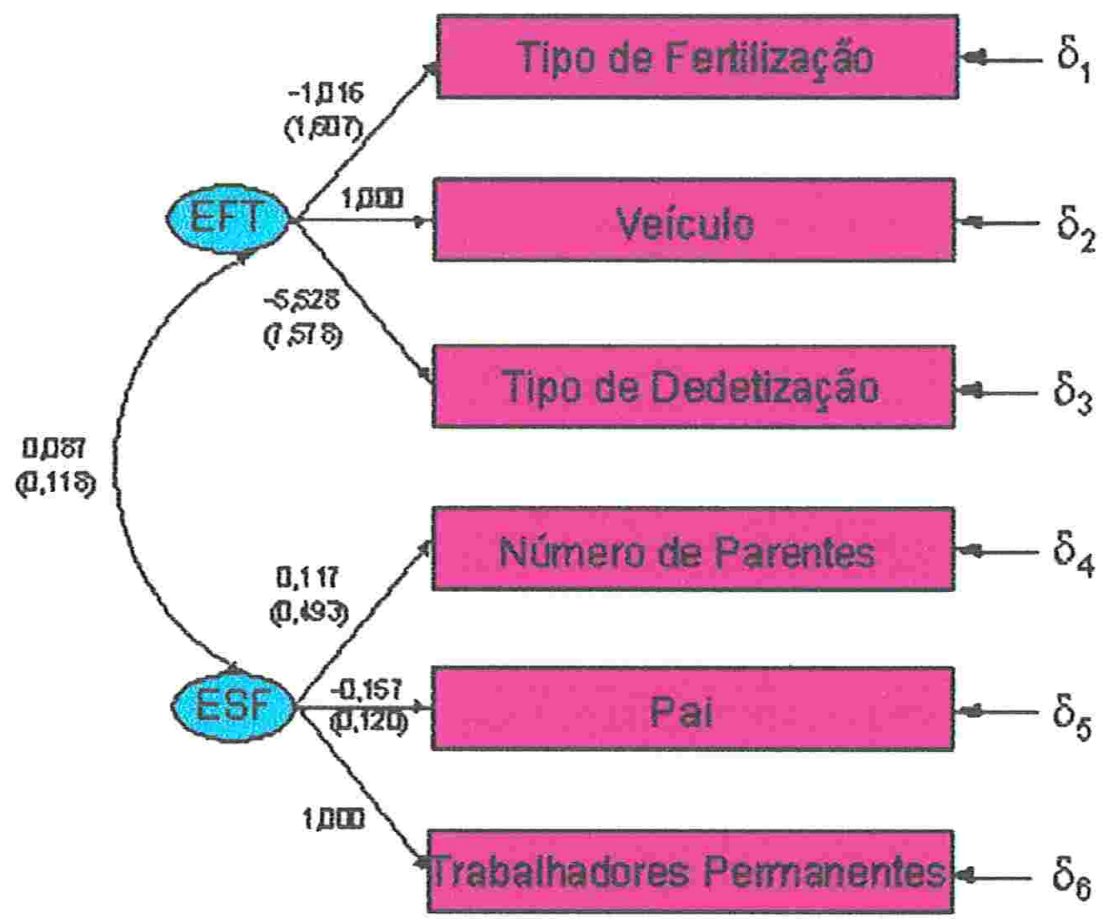


Figura 5.3. Diagrama de Caminho para o Estudo dos Agricultores Familiares com as estimativas dos parâmetros (e seus respectivos erros padrões) obtidas pelo método GLS.

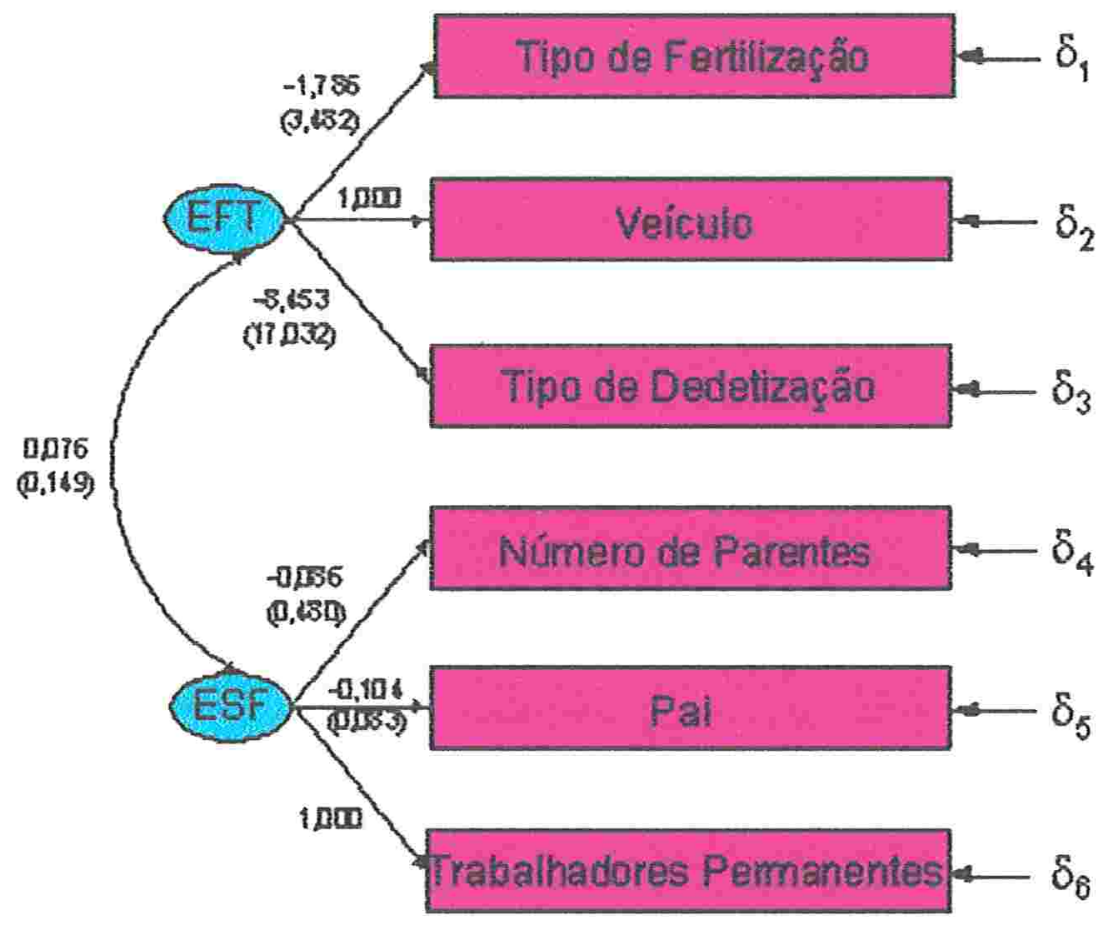

Para verificar se o modelo proposto estâ bem ajustado aos dados, vamos analisar as medidas de ajuste apresentadas pelo pacote estatístico AMOS.

Inicialmente, vamos calcular os graus de liberdade da distribuição qui-cuadrado de $(N-1) F$. Vimos anteriormente na página 56 que os graus de liberdade são dados por:

$$
(1 / 2)(p+q)(p+q+1)-t
$$

em que 
$p$ : número de variáveis observadas para mensurar a(s) variável(is) latente(s) dependente(s); $q$ : número de variáveis observadas para mensurar a(s) variável(is) latente(s) independente(s);

$t$ : número de parâmetros livres.

Neste estudo temos apenas variáveis latentes independentes (EFT e ESF), portanto, $p=0$ e $q=6$ (Tipo de Fertilização, Veículo, Tipo de Dedetização, Número de Parentes, Pai e Trabalhadores Permanentes).

Vimos também na página 39 que $t$ é dada pela soma do número de coeficientes que acompanham as variáveis latentes nas equações estruturais e de mensuração, do número de variâncias e covariâncias das variáveis latentes independentes e dos erros de mensuração e das equações estruturais. Neste estudo, temos 4 coeficientes $\left(b_{1}, b_{3}, b_{4}\right.$ e $\left.b_{5}\right), 2$ variâncias e 1 covariância das variáveis latentes independentes $\left(\phi_{E F T}, \phi_{E S F}\right.$ e $\left.\phi_{E S F, E F T}\right)$ e 6 erros de mensuração $\left(\delta_{1}, \ldots, \delta_{6}\right)$, o que nos leva a $t=13$. Assim, temos que a distribuição qui-quadrado tem 8 graus de liberdade.

Então, temos que, com o método WLS, o valor da estatística qui-quadrado é 2,864 com 8 graus de liberdade, o que nos leva a um nível descritivo (p-valor) de 0,943. E, com o método GLS, temos que $\chi^{2}=2,056$ e p-valor $=0,979$. Portanto, utilizando esta medida, pode-se dizer que o modelo está bem ajustado aos dados por ambos os métodos. Temos também que o qui-quadrado relativo é 0,358 e 0,257 respectivamente, indicando que o modelo tem um "bom" ajuste aos dados por ambos os métodos.

Na Tabela 5.1, apresenta-se a discrepância mínima da amostra para o "seu modelo", o "modelo de independência" e o "modelo saturado" obtida com o ajuste por WLS e por GLS. Através desta, nota-se que, por ambos os métodos, o modelo proposto tem uma discrepância mínima baixa em relação aos seus graus de liberdade, podendo ser um indício de que o modelo está bem ajustado. 
Tabela 5.1. Discrepância Mínima para o Estudo dos Agricultores Familiares.

\begin{tabular}{cccc}
\hline & \multicolumn{2}{c}{$\widehat{\mathrm{C}}$} & \\
\cline { 2 - 3 } Modelo & WLS & GLS & Graus de Liberdade \\
\hline "Seu Modelo" & 2,864 & 2,056 & 8 \\
"Modelo Saturado" & 0,000 & 0,000 & 0 \\
"Modelo de Independência" & 8,176 & 8,203 & 15 \\
\hline
\end{tabular}

$\mathrm{Na}$ Tabela 5.2, apresentamos os índices de ajuste normalizado, corrigido, relativo e de Tucker-Lewis (NFI, IFI, RFI e TLI, respectivamente). Pelo NFI podemos dizer que a redução na função de ajustamento ao passarmos do modelo "baseline" para o modelo proposto é de $65 \%$ com o método WLS e $74,9 \%$ com o GLS. Como não temos um consenso de ponto de corte para este índice, podemos dizer que temos um indício de bom ajuste pois seu valor está razoavelmente próximo de 1 para ambos os métodos.

Ao analisarmos o IFI, observa-se que seu valor é muito maior que 1, o que pode ser devido a superajuste. Como vimos anteriormente (página 67), o superajuste pode ser causado por tamanho de amostra pequeno em relação ao número de variáveis ou por multicolinearidade. Verificou-se que não temos problemas de multicolinearidade, porém temos uma amostra de apenas 36 indivíduos. Portanto, uma solução seria obter uma amostra maior e ajustar o modelo aos dados novamente para verificar se há uma redução no valor deste índice.

Verificando o valor de RFI, não podemos afirmar que o modelo está bem ajustado, pois seu valor não está próximo de 1 . E, por fim, analisando o TLI percebemos que seu valor é negativo, indicando que o modelo precisa ser reespecificado.

Mas, devemos lembrar que esses quatro índices utilizam o fato de que $(N-1) F$ tem distribuição assintoticamente qui-quadrado e, no nosso exemplo temos uma amostra muito pequena. Logo, essas medidas não são muito confiáveis para o nosso caso.

Portanto, vamos utilizar outras medidas de ajuste. 
Tabela 5.2. Índices de Ajuste Normalizado, Corrigido, Relativo e de Tucker-Lewis para o Estudo dos Agricultores Familiares.

\begin{tabular}{cccccc}
\hline Modelo & Método & NFI & IFI & RFI & TLI \\
\hline "Seu Modelo" & WLS & 0,650 & 30,157 & 0,343 & $-0,411$ \\
& GLS & 0,749 & 30,214 & 0,530 & $-0,640$ \\
\hline \multirow{2}{*}{ "Modelo Saturado" } & WLS & 1,000 & - & 1,000 & - \\
& GLS & & & & \\
\hline \multirow{2}{*}{ "Modelo de Independência" } & WLS & \multirow{2}{*}{0,000} & 0,000 & 0,000 & 0,000 \\
& GLS & & & & \\
\hline
\end{tabular}

Na Tabela 5.3, apresentamos a raiz do quadrado médio residual (RMR) e os índices de qualidade do ajuste (GFI), do ajuste corrigido (AGFI) e do ajuste de parsimônia (PGFI). Vimos anteriormente que um RMR próximo de zero indica um bom ajuste (página 62). Assim, pelos valores do RMR dessa tabela, podemos dizer que, por ambos os métodos, temos indícios de que o modelo está bem ajustado.

Analisando o GFI e o AGFI podemos dizer que há um indício do modelo estar bem ajustado por ambos os métodos, pois seus valores estão muito próximos de 1 .

Quanto ao PGFI, vimos que ele não assume valores tão altos quanto os demais índices e que ele é utilizado na comparação de dois modelos (ver Subseção 4.3.7). Portanto, ele não será utilizado. 
Tabela 5.3. Raiz do Quadrado Médio Residual, Índices de Qualidade do Ajuste, do Ajuste Corrigido e do Ajuste de Parsimônia para o Estudo dos Agricultores Familiares.

\begin{tabular}{cccccc}
\hline Modelo & Método & RMR & GFI & AGFI & PGFI \\
\hline \multirow{2}{*}{ "Seu Modelo" } & WLS & 0,472 & 0,999 & 0,998 & 0,381 \\
& GLS & 0,333 & 0,980 & 0,949 & 0,373 \\
\hline \multirow{2}{*}{ "Modelo Saturado" } & WLS & \multirow{2}{*}{0,000} & 1,000 & - & - \\
& GLS & & & & \\
\hline \multirow{2}{*}{ "Modelo de Independência" } & WLS & 0,448 & 0,998 & 0,997 & 0,713 \\
& GLS & 0,789 & 0,922 & 0,891 & 0,658 \\
\hline
\end{tabular}

Com o auxílio do AMOS, também obtivemos que a raiz do erro quadrático médio de aproximação (RMSEA) é 0,000 por ambos os métodos, com PCLOSE de 0,956 por WLS e de 0,984 por GLS, o que indica um bom ajuste.

Finalmente, na Tabela 5.4, apresentamos o critério da informação de Akaike (AIC), critério de Browne-Cudeck (BCC), critério da informação de Bayes (BIC) e critério da informação de Akaike consistente (CAIC). Estes índices são utilizados na comparação de modelos, porém como não foram ajustados outros modelos, vamos comparar estas medidas com as medidas do "modelo saturado" (que se ajusta perfeitamente aos dados). Note que todas as medidas do modelo proposto são menores que as do modelo saturado e, portanto, podemos dizer que o modelo está bem ajustado. 
Tabela 5.4. Critério da Informação de Akaike e suas variações.

\begin{tabular}{cccccc}
\hline Modelo & Método & AIC & BCC & BIC & CAIC \\
\hline \multirow{2}{*}{ "Seu Modelo" } & WLS & 28,864 & 35,364 & 72,742 & 62,450 \\
& GLS & 28,056 & 34,556 & 71,935 & 61,642 \\
\hline \multirow{2}{*}{ "Modelo Saturado" } & WLS & 42,000 & 52,500 & 112,881 & 96,254 \\
& GLS & & & & \\
\hline \multirow{2}{*}{ "Modelo de Independência" } & WLS & 20,176 & 23,176 & 40,428 & 35,677 \\
& GLS & 20,203 & 23,203 & 40,455 & 35,705 \\
\hline
\end{tabular}

Portanto, através das medidas de ajuste apresentadas para o modelo proposto para o problema dos agricultores familiares, podemos dizer que o modelo está bem ajustado aos dados. 


\section{Capítulo 6}

\section{Conclusão}

No Capítulo 4 apresentamos medidas de ajuste que são fornecidas nas saídas da maioria dos pacotes estatísticos utilizados na modelagem de equações estruturais (tais como AMOS, LISREL e PROC CALIS do SAS). Vimos que, em geral, estas medidas são descritivas e que não existe um consenso para estabelecer pontos de corte para indicação de bom ajuste.

Na Tabela 6.1 apresenta-se um resumo dessas medidas com seus respectivos critérios para indicação de bom ajuste. 
Tabela 6.1. Principais medidas de ajuste e sua utilização.

\begin{tabular}{|c|c|c|}
\hline Medida de Ajuste & Página & Indicação de Bom Ajuste \\
\hline Qui-Quadrado $\left(\chi^{2}\right)$ & 63 & p-valor do teste $>$ nível de significância \\
\hline CMIN $(\widehat{C})$ & 65 & $\widehat{C}<$ graus de liberdade \\
\hline $\operatorname{NFI}\left(\Delta_{1}\right)$ & 66 & \multirow{6}{*}{ Valores próximos de $1^{*}$} \\
\hline $\operatorname{IFI}\left(\Delta_{2}\right)$ & 67 & \\
\hline $\operatorname{RFI}\left(\rho_{1}\right)$ & 68 & \\
\hline TLI $\left(\rho_{2}\right)$ & 69 & \\
\hline GFI & 71 & \\
\hline AGFI & 71 & \\
\hline PGFI & 73 & \multirow{2}{*}{ Comparação de modelos ${ }^{1}$} \\
\hline PNFI & 73 & \\
\hline CFI & 74 & $\mathrm{CFI}>0,90$ \\
\hline RMSEA & 74 & RMSEA $\leq 0,05$ \\
\hline Qui-Quadrado Relativo & 76 & Valor menor que 2 (ou 3$)^{*}$ \\
\hline Qui-Quadrado Padronizado $\left(\chi_{P}^{2}\right)$ & 77 & $*$ \\
\hline $\mathrm{AIC}$ & 77 & \multirow{4}{*}{ Comparação de modelos ${ }^{2}$} \\
\hline $\mathrm{BIC}$ & 77 & \\
\hline $\mathrm{BCC}$ & 78 & \\
\hline CAIC & 78 & \\
\hline
\end{tabular}

* Não há um consenso sobre um valor de ponto de corte.

$1 \mathrm{O}$ modelo com maiores valores desses índices deve ser escolhido.

20 modelo com menores valores desses índices deve ser escolhido. 


\section{Capítulo 7}

\section{Trabalhos Futuros}

Ao longo do texto pudemos notar que a modelagem de equações estruturais não dispõe de testes estatísticos para verificar a qualidade do ajuste de um modelo proposto, sendo as medidas de ajuste disponíveis apenas descritivas.

Também foi possível notar que não existem muitos estudos aplicados a fim de esclarecer melhor o uso dos diferentes métodos de estimação e, os problemas e regras de identificabilidade do modelo.

Portanto, existe um grande espaço de pesquisa para o desenvolvimento de novas medidas de ajuste que sejam mais conclusivas (ou seja, que possam ser baseadas em testes estatísticos) e para realizar estudos aplicados com o objetivo de explicar melhor os métodos de estimação dos modelos e sua identificabilidade. 


\section{Apêndice A}

\section{Correlações}

\section{A.1 Correlação "Polychoric" (para tabelas $\mathrm{r}$ x s)}

É uma medida de associação utilizada quando ambas as variáveis são ordinais com três ou mais categorias e é estimada a partir dos pares observados nas tabelas de contigência dessas variáveis (Hair et al., 1998).

Consideremos duas variáveis contínuas $X$ e $Y$ com distribuição normal padrão, assumindo que a distribuição conjunta de $(X, Y)$ é normal padrão bivariada com correlação $\rho$. Sejam $C$ e $D$ duas variáveis categorizadas ordenadas divididas em $r$ e $s$ categorias (onde $r$ ou $s$ é maior que 2), associadas a $X$ e $Y$, respectivamente, da seguinte forma:

$$
\begin{aligned}
& C=c_{i}, \text { se } \gamma_{i-1} \leq X \leq \gamma_{i}, i=1, \ldots, r \\
& D=d_{j}, \text { se } \tau_{j-1} \leq X \leq \tau_{j}, j=1, \ldots, s
\end{aligned}
$$

Seja $\left(x_{1}, y_{1}\right),\left(x_{2}, y_{2}\right), \ldots,\left(x_{N}, y_{N}\right)$ uma amostra aleatória de uma distribuição normal bivariada. Então, a distribuição marginal de $C$ e $D$ é representada pela seguinte matriz

$$
\left(\begin{array}{cccc}
n_{11} & n_{12} & \ldots & n_{1 s} \\
n_{21} & n_{22} & \ldots & n_{2 s} \\
\vdots & \vdots & \vdots & \vdots \\
n_{r 1} & n_{r 2} & \ldots & n_{r s}
\end{array}\right)
$$


em que $n_{i j}$ é o número de observações com $C=c_{i}$ e $D=d_{j}$ numa amostra de tamanho $N=\sum_{i=1}^{r} \sum_{j=1}^{s} n_{i j}$.

A correlação "polychoric" é a correlação $\rho$ na distribuição normal padrão bivariada. Então, seja $\phi(x, y, \rho)$ a densidade da normal padrão bivariada com correlação $\rho$ :

$$
\phi(x, y, \rho)=\frac{1}{2 \pi\left(1-\rho^{2}\right)^{1 / 2}} \exp \left[\frac{-1}{2\left(1-\rho^{2}\right)} \times\left(\mathrm{x}^{2}-2 \rho \mathrm{xy}+\mathrm{y}^{2}\right)\right] .
$$

Assim, a probabilidade de uma observação $\operatorname{com} C=c_{i}$ e $D=d_{j}$ é dada por:

$$
P_{i j}(\theta)=\int_{\gamma_{i-1}}^{\gamma_{i}} \int_{\tau_{j-1}}^{\tau_{j}} \phi(x, y, \rho) d y d x
$$

onde $\theta=\left(\gamma_{1}, \ldots, \gamma_{r-1}, \tau_{1}, \ldots, \tau_{s-1}, \rho\right)$.

Logo, a função de verossimilhança amostral é dada pela função de verossimilhança da distribuição multinomial:

$L=K \sum_{i=1}^{r} \sum_{j=1}^{s} P_{i j}(\theta)^{n_{i j}}$, onde $K$ é uma constante.

Logo, o coeficiente de correlação "polychoric" $\left(\rho_{p c}\right)$ pode ser estimado maximizando-se a função $L$, ou equivalentemente, maximizando-se a log-verossimilhança $\ln (\mathrm{L})$.

Note também que maximizar $\ln (\mathrm{L})$ é equivalente a minimizar

$$
F(\theta)=\sum_{i=1}^{r} \sum_{j=1}^{s} \pi_{i j}\left[\ln \pi_{i j}-\ln P_{i j}(\theta)\right]=\sum_{i j} \pi_{i j} \ln \left[\pi_{i j} / P_{i j}(\theta)\right],
$$

onde $\pi_{i j}=n_{i j} / N$ são as proporções amostrais.

Para reduzir os cálculos, Martinson e Hamdan (1972) propuseram que fossem realizados ajustes de distribuições normais padrão univariadas para as distribuições marginais de $\mathrm{C}$ e $\mathrm{D}$ e, que depois $\ln (\mathrm{L})$ fosse maximizada somente com respeito a $\rho$. Por exemplo, se $c_{1}$ e $d_{1}$ fossem observadas 10 e 40 vezes, respectivamente, então $\widehat{\gamma}_{1}=\Phi^{-1}(0,10)=-1,282$ e $\widehat{\tau}_{1}=\Phi^{-1}(0,40)=-0,253$. Assim, o valor de $\rho$ que maximiza $\ln (\mathrm{L})$ dados esses valores fixados para $\gamma_{1}$ e $\tau_{1}$ é a estimativa de $\rho_{p c}$.

Outra estimativa de $\rho_{p c}$ foi desenvolvida por Lancaster e Hamdan (1964) e é conhecida como estimativa da série polychoric, a qual utiliza a teoria de funções ortonormais para generalizar a série "tetrachoric" de Pearson (Pearson, 1901). 
A série "tetrachoric" é obtida expandindo o lado direito de (A.1) em uma série em $\rho$.

$$
\frac{n_{22}}{N}=\int_{\widehat{\gamma}_{1}}^{\infty} \int_{\widehat{\tau}_{1}}^{\infty} \phi(x, y, \rho) d y d x
$$

em que $\widehat{\gamma}_{1}=\Phi^{-1}\left[\frac{\left(n_{11}+n_{12}\right)}{N}\right]$ e $\widehat{\tau}_{1}=\Phi^{-1}\left[\frac{\left(n_{11}+n_{21}\right)}{N}\right]$.

Então, por Kendall e Stuart (1979), temos que:

$$
\frac{n_{22}}{N}=\sum_{m=0}^{\infty} \rho^{m} g_{m}\left(\widehat{\gamma}_{1}\right) g_{m}\left(\widehat{\tau}_{1}\right)
$$

em que $g_{m}(k)=\frac{H_{m-1}(k) \phi(k)}{(m !)^{1 / 2}}, m=1,2, \ldots, H_{m-1}(k)$ é o polinômio de Chebyshev-Hermite (Kendall e Stuart, 1977) com $m-1$ graus de liberdade e $g_{0}(k)=1-\Phi(k)$.

Para ilustrar os métodos de estimação da correlação "polychoric" vamos utilizar os registros do número de nascimentos de carneirinhos de um rebanho de 227 ovelhas merino em 1952 e 1953 (Tallis, 1962). Na Tabela A.1 apresentamos esses registros.

Tabela A.1. Registro de nascimentos de carneirinhos em 1952 e 1953.

\begin{tabular}{cccccc}
\hline & & \multicolumn{3}{c}{1952} & \\
\cline { 3 - 5 } & & 0 & 1 & 2 & Total \\
\hline \multirow{3}{*}{1953} & 0 & 58 & 52 & 1 & 111 \\
& 1 & 26 & 58 & 3 & 87 \\
& 2 & 8 & 12 & 9 & 29 \\
\hline & Total & 92 & 122 & 13 & 227 \\
\hline
\end{tabular}

Consideremos $C=c_{1}$ e $D=d_{1}$ como sendo o número de ovelhas merino que não tiveram carneirinhos em 1952 e em 1953, respectivamente. E, $C=c_{2}$ e $D=d_{2}$ o número de ovelhas merino que tiveram no máximo 1 carneirinho em 1952 e em 1953, respectivamente.

Então, a estimativa de máxima verossimilhança de $\rho_{p c}$ é 0,418 com erro padrão de 0,076. E, $\widehat{\gamma}_{1}=-0,242(0,084), \widehat{\gamma}_{2}=1,594(0,134), \widehat{\tau}_{1}=-0,030(0,083)$ e $\widehat{\tau}_{2}=$ $1,133(0,106)$. 
Utilizando os cálculos propostos Martinson e Hamdan (1972), temos que:

$$
\begin{gathered}
\widehat{\gamma}_{1}=\Phi^{-1}\left(\frac{92}{227}\right) \simeq-0,240 \quad \widehat{\tau}_{1}=\Phi^{-1}\left(\frac{111}{227}\right) \simeq-0,028 \\
\widehat{\gamma}_{2}=\Phi^{-1}\left(\frac{92+122}{227}\right) \simeq 1,578 \quad \widehat{\tau}_{2}=\Phi^{-1}\left(\frac{111+87}{227}\right) \simeq 1,137
\end{gathered}
$$

e, então, $\rho_{p c}=0,420$ com erro padrão de 0,074 .

E, finalmente, a estimativa da série polychoric é $\rho_{p c}=0,556$ com $\widehat{\gamma}_{1}, \widehat{\gamma}_{2}, \widehat{\tau}_{1}$ e $\widehat{\tau}_{2}$ idênticos aos obtidos pelo método de Martinson e Hamdan (1972).

\section{A.2 Correlação "Tetrachoric" (para tabelas $2 \times 2$ )}

O contexto é o mesmo introduzido na seção anterior, onde $r=s=2$ (ou seja, as variáveis são dicotômicas). Assim, para uma amostra aleatória $\left(x_{1}, y_{1}\right),\left(x_{2}, y_{2}\right), \ldots,\left(x_{N}, y_{N}\right)$ de uma distribuição normal bivariada, a distribuição conjunta de $C$ e $D$ é representada por

$$
\left(\begin{array}{ll}
n_{11} & n_{12} \\
n_{21} & n_{22}
\end{array}\right)
$$

em que $n_{i j}$ é o número de observações com $C=c_{i}$ e $D=d_{j}$ numa amostra de tamanho $N=\sum_{i=1}^{2} \sum_{j=1}^{2} n_{i j}, c_{1}=\left\{(x, y) \mid x<x_{0}\right\}, c_{2}=c_{1}^{c}$ (ou seja, $c_{2}$ é o conjunto complementar de $c_{1}$ ), $d_{1}=\left\{(x, y) \mid y<y_{0}\right\}$ e $d_{2}=d_{1}^{c}$ (ou seja, $d_{2}$ é o conjunto complementar de $d_{1}$ ).

Ou seja, a tabela de freqüências dessa amostra é dada por:

\begin{tabular}{cccc}
\hline & $\mathbf{c}_{\mathbf{1}}$ & $\mathbf{c}_{\mathbf{2}}$ & Total \\
\hline $\mathrm{d}_{\mathbf{1}}$ & $n_{11}$ & $n_{12}$ & $n_{11}+n_{12}$ \\
$\mathrm{~d}_{\mathbf{2}}$ & $n_{21}$ & $n_{22}$ & $n_{21}+n_{22}$ \\
\hline Total & $n_{11}+n_{21}$ & $n_{12}+n_{22}$ & $N$ \\
\hline
\end{tabular}

Sejam:

$\phi(x, y, \rho)$ : densidade da normal padrão bivariada com coeficiente de correlação $\rho$; 
$\phi(x)$ : função de densidade marginal de $\mathrm{X}$;

$\phi(y)$ : função de densidade marginal de Y;

$\Phi(x, y, \rho), \Phi(x), \Phi(y)$ : funções de distribuição acumulada correspondentes.

Supondo que:

$$
\begin{aligned}
& n_{11}+n_{21} \geq n_{12}+n_{22} \\
& n_{11}+n_{12} \geq n_{21}+n_{22}
\end{aligned}
$$

e definindo:

$h=\frac{\left(x_{0}-\mu_{x}\right)}{\sigma_{x}}$

$k=\frac{\left(y_{0}-\mu_{y}\right)}{\sigma_{y}}$

h e k podem ser estimados por:

$\widehat{h}=\Phi^{-1}\left(\frac{n_{11}+n_{21}}{N}\right)$

$\widehat{k}=\Phi^{-1}\left(\frac{n_{11}+n_{12}}{N}\right)$

Logo, pode-se estimar $\rho$ resolvendo a equação abaixo:

$$
\begin{aligned}
\frac{n_{22}}{N}= & \int_{\widehat{h}}^{\infty} \int_{\widehat{k}}^{\infty} \frac{1}{2 \pi\left(1-\widehat{\rho}^{2}\right)^{1 / 2}} \exp \left[\frac{-1}{2\left(1-\widehat{\rho}^{2}\right)} \times x^{2}-2 \widehat{\rho} x y+y^{2}\right] d y d x \\
& =\widehat{\Phi}(\widehat{h}, \widehat{k}, \widehat{\rho}) .
\end{aligned}
$$

A solução da equação acima é única $(\widehat{\rho})$, usualmente é denotada por $r_{t}$ e denominada correlação "tetrachoric".

Para reduzir os cálculos, Pearson (1901) propôs algumas aproximações, sendo que uma delas é

$$
Q_{1}=\frac{n_{11} n_{22}-n_{12} n_{21}}{n_{11} n_{22}+n_{12} n_{21}}
$$

conhecida também como coeficiente de associação de Yule (Yule, 1900).

Pearson também recomendou mais três aproximaçõs razoavelmente precisas:

$$
Q_{3}=\operatorname{sen}\left(\frac{\pi}{2}\right) \frac{\sqrt{\mathrm{n}_{11} \mathrm{n}_{22}}-\sqrt{\mathrm{n}_{12} \mathrm{n}_{21}}}{\sqrt{\mathrm{n}_{11} \mathrm{n}_{22}}+\sqrt{\mathrm{n}_{12} \mathrm{n}_{21}}}
$$




$$
Q_{4}=\operatorname{sen}\left(\frac{\pi}{2}\right)\left\{1+\frac{2 \mathrm{n}_{12} \mathrm{n}_{22} \mathrm{~N}}{\left(\mathrm{n}_{11} \mathrm{n}_{22}-\mathrm{n}_{12} \mathrm{n}_{21}\right)\left(\mathrm{n}_{12}+\mathrm{n}_{21}\right)}\right\}^{-1}
$$

e

$$
Q_{5}=\operatorname{sen}\left(\frac{\pi}{2}\right)\left(1+\kappa^{2}\right)^{-1 / 2}
$$

em que $\kappa^{2}=\frac{4 n_{11} n_{12} n_{21} n_{22} N^{2}}{\left[\left(n_{11} n_{22}-n_{12} n_{21}\right)^{2}\left(n_{11}+n_{22}\right)\left(n_{12}+n_{21}\right)\right]}$.

Além do coeficiente de associação, Yule $(1900 ; 1912)$ propôs o seguinte coeficiente para aproximar a correlação "tetrachoric":

$$
Q_{2}=\frac{\sqrt{n_{11} n_{22}}-\sqrt{n_{12} n_{21}}}{\sqrt{n_{11} n_{22}}+\sqrt{n_{12} n_{21}}}
$$

Para ilustrar os métodos de estimação da correlação "tetrachoric" vamos utilizar um exemplo hipotético em que temos 100 avaliações sobre a presença ou ausência de esquizofrenia realizada por dois avaliadores (Uebersax, 2000). Na Tabela A.2 apresentamos essas avaliações.

Tabela A.2. Avaliações sobre a presença ou ausência de esquizofrenia.

\begin{tabular}{cccc}
\hline & \multicolumn{2}{c}{ Avaliador 1 } & \\
\cline { 2 - 3 } Avaliador 2 & Ausência & Presença & Total \\
\hline Ausência & 40 & 20 & 60 \\
Presença & 10 & 30 & 40 \\
\hline Total & 50 & 50 & 100 \\
\hline
\end{tabular}

Assim, temos que $\widehat{h}=\Phi^{-1}\left(\frac{40+10}{100}\right) \simeq 0,000$ e $\widehat{k}=\Phi^{-1}\left(\frac{40+20}{100}\right) \simeq 0,253$, com respectivos erros-padrões de 0,125 e 0,127 . E, por (A.3) temos que $r_{t} \simeq 0,607$ com erro-padrão de 0,115 . 
Vamos também utilizar as aproximações A.4 a A.8 para obter a correlação "tetrachoric" para o exemplo hipotético. Assim, temos que:

- $Q_{1}=\frac{40 \times 30-20 \times 10}{40 \times 30+20 \times 10} \simeq 0,714$

- $Q_{2}=\frac{\sqrt{40 \times 30}-\sqrt{20 \times 10}}{\sqrt{40 \times 30}-\sqrt{20 \times 10}} \simeq 0,420$

- $Q_{3}=\operatorname{sen}\left(\frac{\pi}{2}\right) \frac{\sqrt{40 \times 30}-\sqrt{20 \times 10}}{\sqrt{40 \times 30}-\sqrt{20 \times 10}} \simeq 0,420$

- $Q_{4}=\operatorname{sen}\left(\frac{\pi}{2}\right)\left\{1+\frac{2 \times 20 \times 30 \times 100}{(40 \times 30-20 \times 10)(20+10)}\right\}^{-1} \simeq 0,200$

- $\kappa^{2}=\frac{4 \times 40 \times 20 \times 10 \times 30 \times 100^{2}}{\left[(40 \times 30-20 \times 10)^{2}(40+30)(20+10)\right]} \simeq 4,571$

e então $Q_{5}=\operatorname{sen}\left(\frac{\pi}{2}\right)\left(1+0,471^{2}\right)^{-1 / 2} \simeq 0,214$

\section{A.3 Correlação "Polyserial" (para tabelas $\mathrm{r}$ x s)}

É uma medida de associação utilizada quando uma variável é ordinal e a outra é intervalar (Hair et al., 1998). Consideremos novamente que $C$ e $D$ são variáveis categorizadas associadas às variáveis contínuas $X$ e $Y$, respectivamente, da seguinte forma:

$$
\begin{aligned}
& C=c_{i}, \text { se } \gamma_{i-1} \leq X \leq \gamma_{i}, i=1, \ldots, r \\
& D=d_{j}, \text { se } \tau_{j-1} \leq X \leq \tau_{j}, j=1, \ldots, s
\end{aligned}
$$

Assume-se que a distribuição conjunta de $X$ e $Y$ é normal bivariada com $E(X)=\mu$, $\operatorname{Var}(X)=\sigma^{2}, E(Y)=0, \operatorname{Var}(Y)=1 \mathrm{e} \frac{\operatorname{Cov}(X, Y)}{\sigma}=\rho$.

A função de verossimilhança para uma amostra de $N$ observações de $\left(x_{k}, d_{k}\right)$ é:

$$
L=\prod_{k=1}^{N} f\left(x_{k}, d_{k}\right)=\prod_{k=1}^{N} f\left(x_{k}\right) P\left(D=d_{k} \mid x_{k}\right),
$$

onde

$$
f\left(x_{k}\right)=\frac{1}{\sqrt{2 \pi} \sigma} \exp \left[-\frac{1}{2}\left(\frac{x_{k}-\mu}{\sigma}\right)^{2}\right]
$$

$d_{k}$ : valor observado de $D$ para a k-ésima observação.

Temos que a distribuição condicional de $Y \mid X=x_{k}$ é normal com média $\rho z_{k}$ e variância $\left(1-\rho^{2}\right)$, onde $z_{k}=\left(x_{k}-\mu\right) / \sigma$. Então 


$$
P\left(D=d_{k} \mid x_{k}\right)=\Phi\left(\tau_{j}^{*}\right)-\Phi\left(\tau_{j-1}^{*}\right), \quad j=1, \ldots, s
$$

em que

$\tau_{j}^{*}=\frac{\tau_{j}-\rho z_{k}}{\left(1-\rho^{2}\right)^{1 / 2}}$

$\Phi(\tau)=\int_{-\infty}^{\tau} \phi(t) d t$

Logo, maximizando a função $L$ com respeito a $\mu, \sigma^{2}, \rho$ e $\tau_{j}$ obteremos o estimador do coeficiente de correlação "polyserial" $\left(\rho_{p s}\right)$. Ou, equivalentemente, maximizando a logverossimilhança $\ln (\mathrm{L})$.

Para reduzir os cálculos, há um estimador conhecido como estimador "dois-passos". Este estimador consiste em estimar $\mu$ e $\sigma^{2}$ através do método de máxima verossimilhança e, as estimativas dos $\tau_{j}$ 's são tomadas como sendo os valores da inversa da distribuição normal padrão avaliada nas proporções marginais de $D$. Ou seja, se por exemplo $d_{1}$ fosse observada 70 vezes numa amostra de 100 observações, então $\widehat{\tau}_{1}=\Phi^{-1}(0,70) \simeq 0,524$. Assim, o estimador "dois-passos" de $\rho_{p s}$ é obtido diferenciando $\ln (\mathrm{L})$ com respeito apenas a $\rho_{p s}$.

Outro estimador existente da correlação "polyserial" consiste em utilizar as mesmas estimativas citadas anteriormente para os $\tau_{j}$ 's, calcular a correlação "polyserial" pontual $\rho_{p p}$ (correlação usual entre $X$ e $D$ ) e a variância amostral de $D$ e, então, substituir as estimativas encontradas na expressão (A.9) (relação entre a correlação "polyserial" e a correlação "polyserial" pontual):

$$
\rho_{p p}=\frac{\rho_{p s}}{\sigma_{d}} \sum_{j=1}^{s-1} \phi\left(\tau_{j}\right)\left(d_{j+1}-d_{j}\right),
$$

em que $\sigma_{d}$ é a variância de $D$ e $\phi(\tau)=(2 \pi)^{-1 / 2} \exp \left\{-\tau^{2} / 2\right\}$ é a densidade da distribuição normal padrão.

Para ilustrar os métodos de estimação da correlação "polyserial" vamos utilizar os dados de fertilidade de um rebanho de 25 ovelhas Romney de 4 anos (Cox, 1974). A variável contínua observada $X$ é o peso (em libras) das ovelhas no acasalamento e a variável categorizada $D$ é o número de carneirinhos que as ovelhas tiveram. Na Tabela A.3 apresentamos 
essas informações.

Tabela A.3. Dados de fertilidade de um rebanho de 25 ovelhas Romney.

\begin{tabular}{cccccccccc}
\hline $\mathrm{X}$ & $\mathrm{d}$ & $\mathrm{X}$ & $\mathrm{d}$ & $\mathrm{X}$ & $\mathrm{d}$ & $\mathrm{X}$ & $\mathrm{d}$ & $\mathrm{X}$ & $\mathrm{d}$ \\
\hline 72 & 0 & 87 & 1 & 104 & 1 & 92 & 1 & 103 & 2 \\
88 & 0 & 78 & 1 & 92 & 1 & 72 & 1 & 85 & 2 \\
112 & 0 & 69 & 1 & 77 & 1 & 81 & 1 & 96 & 2 \\
93 & 1 & 101 & 1 & 80 & 1 & 88 & 1 & 96 & 2 \\
86 & 1 & 108 & 1 & 99 & 1 & 104 & 1 & 104 & 2 \\
\hline
\end{tabular}

Sabemos que, para uma amostra aleatória de uma variável aleatória $X$ com distribuição normal com média $\mu$ e variância $\sigma^{2}$, os estimadores de máxima verossimilhança da média e da variância são, respectivamente: $\widehat{\mu}=\sum_{k=1}^{N} \frac{X_{k}}{N}=\bar{X}$ e $\widehat{\sigma}^{2}=\sum_{k=1}^{N} \frac{\left(X_{k}-\bar{X}\right)^{2}}{N}$.

Portanto, o peso médio das ovelhas é 90,680 e o desvio padrão é 11,808. Ao passo que, o número médio de carneirinhos nascidos é 1,080 com desvio padrão de 0,560. Assim, a correlação "polyserial" pontual é 0,185 .

Consideremos $D=d_{1}$ como sendo o número de ovelhas Romney que não tiveram carneirinhos e $D=d_{2}$ o número de ovelhas Romney que tiveram no máximo 1 carneirinho. Então, temos que $\widehat{\tau}_{1}=\Phi^{-1}\left(\frac{3}{25}\right)=-1,175$ e $\widehat{\tau}_{2}=\Phi^{-1}\left(\frac{20}{25}\right) \simeq 0,842$. E, por fim, substituindo em (A.9) chegamos a:

$$
\begin{aligned}
\widehat{\rho}_{p s} & =(0,185) \times(0,560)\left[(2 \pi)^{-1 / 2} \exp \left\{-\frac{(-1,175)^{2}}{2}\right\}+(2 \pi)^{-1 / 2} \exp \left\{-\frac{0,842^{2}}{2}\right\}\right]^{-1} \\
& =(0,185) \times(0,560)[0,200+0,280]^{-1} \simeq 0,216
\end{aligned}
$$

É possível mostrar que a estimativa de $\rho_{p s}$ utilizando o estimador "dois-passos" é 0,211 (Drasgow, 1988). E, por fim, Cox (1974) mostrou que a estimativa de máxima verossimilhança de $\rho_{p s}$ é 0,211 com desvio-padrão de 0,224. Cox também mostrou que 
a estimativa de máxima verossimilhança de $\tau_{1}$ é $-1,169$ e de $\tau_{2}$ é 0,843 com respectivos erros-padrões de 0,423 e 0,286.

\section{A.4 Correlação "Biserial" (para tabelas $2 \times 2$ )}

É uma medida de associação utilizada quando uma variável é dicotômica e a outra é intervalar (Hair et al., 1998).

Sejam:

$X$ : variável dicotômica;

$Y$ : variável aleatória observável;

$Z$ : variável aleatória não-observável.

Se assumirmos que $(Z, Y)$ tem distribuição normal bivariada com coeficiente de correlação $\rho_{b}$, um estimador consistente de $\rho_{b}$ baseado na amostra da população $(X, Y)$ é o coeficiente de correlação "biserial" $\left(r_{b}\right)$ :

$$
r_{b}=\frac{p q\left(\bar{y}_{1}-\bar{y}_{0}\right)}{s_{y} u}
$$

onde

$u=(2 \pi)^{-1 / 2} e^{-h^{2} / 2} ;$

$s_{y}^{2}$ : variância amostral de $Y$;

$\bar{y}_{1}$ : média dos $y_{i}^{\prime} s$ correspondentes aos $x_{i}^{\prime} s$ iguais a 1 ;

$\bar{y}_{0}:$ média dos $y_{i}^{\prime} s$ correspondentes aos $x_{i}^{\prime} s$ iguais a 0 ;

$p$ : proporção de $x_{i}^{\prime} s$ na amostra com valores iguais a 1 ;

$q=1-p$

e h é definido por:

$P(Z \geq h)=p$

com Z tendo distribuição normal padrão. 
O programa PRELIS, que é distribuído juntamente com o programa LISREL, e o CALIS do SAS calculam essas correlações. 


\section{Referências Bibliográficas}

Akaike, H. (1974). A new look at the statistical model identification, IEEE Transactions on Automatic Control AC-19: 716-723.

Anderson, J. e Gerbing, D. W. (1984). The effects of sampling error on convergence, improper solutions and goodness-of-fit indices for maximum likelihood confirmatory factor analysis, Psychometrika 49: 155-173.

Arbuckle, J. L. (1997). Amos User's Guide - Version 3.6, SmallWaters Corporation, USA.

Barroso, L. P. e Gabriel, A. E. P. A. (1996). Modernização na agricultura uruguaia: O novo agricultor familiar, Technical Report RAE-CEA-9616, IME - USP, São Paulo.

Bentler, P. (1990). Comparative fit indexes in structural models, Psychological Bulletin 107: 238-246.

Bentler, P. M. e Bonett, D. G. (1980). Significance tests and goodness-of-fit in the analysis of covariance structures, Psychological Bulletin 88: 588-600.

Bollen, K. A. (1986). Sample size and Bentler and Bonett's nonnormed fit index, Psychometrika 51: 375-377.

Bollen, K. A. (1989a). A new incremental fit index for general structural equation models, Sociological Methods and Research 17: 303-316.

Bollen, K. A. (1989b). Structural Equations with Latent Variables, John Wiley, USA. 
Bollen, K. A. e Medrano, J. D. (1998). Who are the Spaniards? Nationalism and identification in Spain, Social Forces 77: 587-621.

Bozdogan, H. (1987). Model selection and Akaike's Information Criterion (AIC): The general theory and its analytical extensions, Psychometrika 52: 345-370.

Browne, M. W. e Cudeck, R. (1993). Alternative ways of assing model fit, in K. A. Bollen e L. S. Long (eds), Testing Structural Equation Models, Sage, Newbury Park, California, pp. $136-162$.

Carmines, E. G. e McIver, J. P. (1981). Analyzing models with unobserved variables: Analysis of covariance structures, in G. W. Bohrnstedt e E. F. Borgatta (eds), Social Measurement: Curren Issues, Sage, Beverly Hills, CA, pp. 65-115.

Cox, N. R. (1974). Estimation of the correlation between a continuous and a discrete variable, Biometrics 30: 171-178.

Drasgow, F. (1988). Polychoric and polyserial correlations, in L. Kotz e N. Johnson (eds), Encyclopedia of Statistical Sciences, Vol. 7, John Wiley, New York, pp. 69-74.

Garson, G. D. (2001). Structural Equation Modeling Example using WinAMOS: The Wheaton Study.

*http://www2.chass.ncsu.edu/garson/pa765/semAMOS1.htm (acessado em março de 2004)

Hair, J. F., Anderson, R. E., Tatham, R. L. e Black, W. C. (1998). Multivariate Data Analysis, Prentice-Hall, New Jersey.

Harris, B. (1988). Tetrachoric correlation coefficient, in L. Kotz e N. L. Johnson (eds), Encyclopedia of statistical Sciences, Vol. 9, John Wiley, New York, pp. 223-225.

Hatcher, L. (1994). A Step-by-step Approach to Using the SAS System for Factorial Analysis and Structural Equation Modeling, SAS Institute Inc., Cary, NC. 
Huntley, L. R. e Perry, E. (2003). Interpreting The Structural Equation Model. *http://www.oseda.missouri.edu/modot/planning/interpreting_sem.shtml (acessado em março de 2004)

James, L. R., Mulaik, S. A. e Brett, J. M. (1982). Causal Analysis: Assumptions, Models and Data, Sage, Beverly Hills.

Jöreskog, K. G. (2001). Analysis of Ordinal Variables 2: Cross-Sectional Data. *http://www.ssicentral.com/lisrel/ord2.pdf (acessado em março de 2004)

Jöreskog, K. G. e Sörbom, D. (1986). LISREL VI: Analysis of Linear Structural Relationships by Maximum Likelihood and Least Square Methods, Scientific Software, Mooresville.

Jöreskog, K. G. e Sörbom, D. (1988). LISREL \%: A Guide to the Program and Applications, SPSS, Chicago.

Kendall, M. G. e Stuart, A. (1977). Distribution Theory, Vol. 1 of The Advanced Theory of Statistics, 4 edn, Macmillan, New York.

Kendall, M. G. e Stuart, A. (1979). Inference and Relationship, Vol. 2 of The Advanced Theory of Statistics, 4 edn, Macmillan, New York.

Kraemer, H. C. (1982). Biserial correlation, in L. Kotz e N. L. Johson (eds), Encyclopedia of Statistical Sciences, Vol. 1, John Wiley, New York, pp. 276-280.

Lancaster, H. O. e Hamdan, M. A. (1964). Estimation of the correlation coefficient in contingency tables with possibly nonmetrical characters, Psychometrika 29: 383-391.

Latif, S. A. (2000). Modelagem de equações estruturais, Dissertação de mestrado, Instituto de Matemática e Estatística - USP.

Martinson, E. O. e Hamdan, M. A. (1972). Maximum likelihood and some other asymptotically efficient estimators of correlation in two-way contingency tables, Journal of Statistical Computation Simulation 1: 45-54. 
Mulaik, S. A., James, L. R., Van Alstine, J., Bennett, N., Lind, S. e Stilwell, C. D. (1989). Evaluation of goodness-of-fit indices for structural equation models, Psychological Bulletin 105: 430-445.

Pearson, K. (1901). Mathematical contributions to the theory of evolution, VII: On the correlation of characters not quantitatively measurable, Philosophical Transactions of the Royal Society of London 195A: 1-47.

Sarle, W. (2004). What is overfitting and how can I avoid it?

*http://www.faqs.org/faqs/ai-faq/neural-nets/part3/section-3.html (acessado em março de 2004)

Schwarz, G. (1978). Estimating the dimensions of a model, Annals of Statistics 6: 461-464.

Steiger, J. H. e Lind, J. M. (1980). Statistically based tests for the number of common factors, Annual Meeting of the Psychometric Society. Iowa City, Iowa.

Tallis, G. M. (1962). The maximum likelihood estimation of correlation from contingency tables, Biometrics 18: 342-353.

Tanaka, J. S. e Huba, G. J. (1985). A fit index for covariance structure models under arbitrary gls estimation, British Journal of Mathematical and Statistical Psychology 38: 197-201.

Tucker, L. R. e Lewis, C. (1973). A reliability coefficient for maximum likelihood factor analysis, Psychometrika 38: 1-10.

Uebersax, J. (2000). The Tetrachoric and Polychoric Correlation Coefficients.

*http://ourworld.compuserve.com/homepages/jsuebersax/tetra.htm (acessado em março de 2004)

Warren, R. D., White, J. K. e Fuller, W. A. (1974). An erros-in-variables analysis of managerial role performance, Journal of American Statistical Association 69: 886893. 
Wheaton, B., Muthen, D., Alwin, D. e Summers, G. (1977). Assessing reliability and stability in panel models, in D. Heise (ed.), Sociological Methodology, Jossey-Bass, San Francisco, pp. 84-136.

Yule, G. U. (1900). On the association of attributes in statistics, Philosophical Transactions of the Royal Society of London 194A: 257-319.

Yule, G. U. (1912). On the methods of measuring the association between two attributes, Journal of the Royal Statistical Society 75: 579-652. 